University of Louisville ThinkIR: The University of Louisville's Institutional Repository

Electronic Theses and Dissertations

$5-2019$

\title{
The emergent matter of archives : a rhetorical investigation of the queer formation of the Williams-Nichols archive.
}

Richard Wysocki

University of Louisville

Follow this and additional works at: https://ir.library.louisville.edu/etd

Part of the Rhetoric Commons

\section{Recommended Citation}

Wysocki, Richard, "The emergent matter of archives : a rhetorical investigation of the queer formation of the Williams-Nichols archive." (2019). Electronic Theses and Dissertations. Paper 3228.

https://doi.org/10.18297/etd/3228

This Doctoral Dissertation is brought to you for free and open access by ThinkIR: The University of Louisville's Institutional Repository. It has been accepted for inclusion in Electronic Theses and Dissertations by an authorized administrator of ThinkIR: The University of Louisville's Institutional Repository. This title appears here courtesy of the author, who has retained all other copyrights. For more information, please contact thinkir@louisville.edu. 
THE EMERGENT MATTER OF ARCHIVES: A RHETORICAL INVESTIGATION OF THE QUEER FORMATION OF THE WILLIAMS-NICHOLS ARCHIVE

\author{
By \\ Rick Wysocki \\ B.A., Chapman University, 2013 \\ M.A., University of Louisville, 2015
}

A Dissertation Submitted to the Faculty of the College of Arts and Sciences of the University of Louisville in Partial Fulfillment of the Requirements for the Degree of

Doctor of Philosophy in English/Rhetoric and Composition

Department of English University of Louisville

Louisville, Kentucky

May 2019 

THE EMERGENT MATTER OF ARCHIVES: A RHETORICAL INVESTIGATION OF THE QUEER FORMATION OF THE WILLIAMS-NICHOLS ARCHIVE

By

\author{
Rick Wysocki \\ B.A., Chapman University, 2013 \\ M.A., University of Louisville, 2015
}

A Dissertation Approved on

April 5, 2019

by the following Thesis or Dissertation Committee:

Thesis or Dissertation Director Name
Dr. Karen Kopelson

Second Committee Member Name

Dr. Mary P. Sheridan

Third Committee Member Name

Dr. Frances McDonald

Fourth Committee Member Name

Dr. Jacqueline Rhodes 


\section{DEDICATION}

This dissertation is dedicated to my parents, who have supported me in countless ways. 


\section{ACKNOWLEDGEMENTS}

I would like to thank Dr. Karen Kopelson for her guidance, feedback, and patience as she worked with me on this and other projects over the past six years. I have grown as an academic in so many ways with you as my mentor. Thank you to Dr. Mary P. Sheridan for your careful reading and for countless meetings during which we both talked entirely too fast. To Dr. Frances McDonald, thank you for keeping my theory honest. And thank you to Dr. Jacqueline Rhodes for agreeing to read on this projectyour knowledge and feedback was invaluable.

Many thanks to Patrick Danner and Chris Scheidler for reading drafts of this work. To my parents, thank you for always supporting me. To Allison, thank you for your endless love and patience. I cannot express how thankful I am for your care and support. Thank you to April, Ginsberg, and Queenie for your friendly, furry faces. Finally, my deepest thanks to David Williams. Your life's work is an inspiration and a model for the stakes of archives and knowledge-making more generally. 


\title{
ABSTRACT \\ THE EMERGENT MATTER OF ARCHIVES: A RHETORICAL INVESTIGATION OF THE QUEER FORMATION OF THE WILLIAMS-NICHOLS ARCHIVE
}

\author{
Rick Wysocki
}

April 5, 2019

Scholarly conversations across disciplines have asked researchers to consider archive as a site of power-often framed in terms of archives' potential impact on history and practices of knowledge making more generally. This dissertation contributes to such conversations as they relate to queer archives and material rhetoric, exploring the Williams-Nichols Archive, an LGBTQ archive housed at the University of Louisville. I extend interdisciplinary scholarship to argue for approaching archives as rhetorical emergences rather than as containers or locations for discovery, a perspective that foregrounds the archive and archival practices as the subject of research. Drawing on archival research and oral history interviews, I develop a materialist perspective on the rhetoric of the Williams-Nichols Archive that synthesizes insights from queer rhetoric and new materialism to consider the complex rhetoric involved in the collection, curation, and maintenance of LGBTQ archives. This research is guided by the following primary questions: How have material phenomena - such as collection, circulation, classification, and the physical matter of archival holdings - participated in the Williams-Nichols Archive's rhetorical emergence? What can this tell us about LGBTQ archives, and how might an attention to these materialities expand understandings of both queer rhetoric and 
archival theory in our field? Ultimately, I argue that attending to materiality reveals less visible forms of rhetoric and queer archival activism that can expand our understandings of queer rhetoric, material rhetoric, and archives. 


\section{TABLE OF CONTENTS}

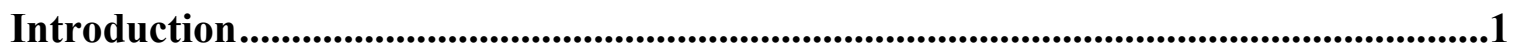

The Williams-Nichols Archive ....................................................................... 4

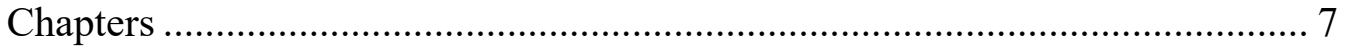

Chapter I Disclosing the Williams-Nichols Archive: Theories, Methodologies, and

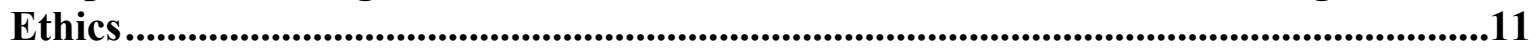

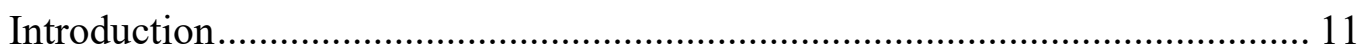

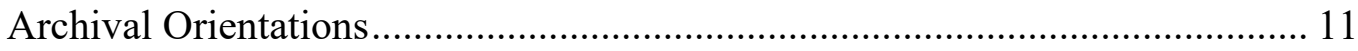

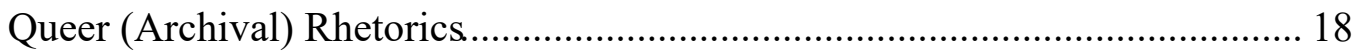

New Materialism: Dispatches from the Fourth Settlement................................ 26

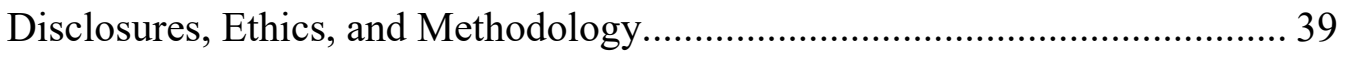

Chapter II Making the World Through Silence: Disidentifications in a Queer Archive ......................................................................................................................45

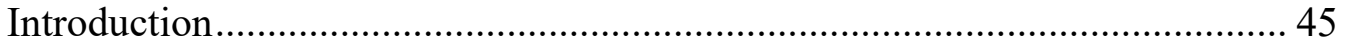

Gays and Lesbians United for Equality ......................................................... 49

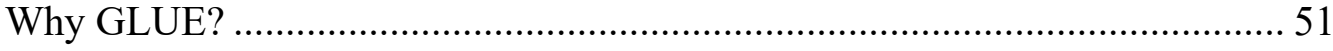

Queer Rhetoric, Silence, and Disidentification.................................................. 56

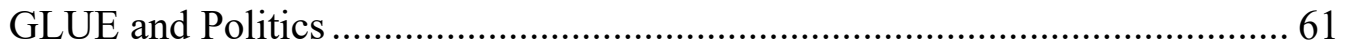

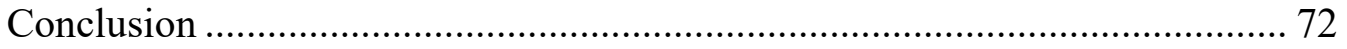

Chapter III Materializing Affect in Archival Production................................................79

Materializing Affect................................................................................. 82 
Queer Correspondence.

Archival Ethics

Conclusion

Chapter IV Queer Archives, Rhetorical Accretion, and Entanglement: Queer

Curatorial Rhetoric and the Formation of the Williams-Nichols Archive.

Introduction.

On "Material Rhetoric"

The Matter of the Williams-Nichols Archive

122

Queer Curatorial Rhetoric in Institutional Space.

Archival Records

Conclusion

Conclusion 145

References. 151

Primary Sources

Secondary Sources

Curriculum Vitae 166

Education 166

Dissertation 166

Research 166

Teaching 167

Service. 168

Awards 170 
Professional Memberships and Skills . 


\section{INTRODUCTION}

This dissertation examines the emergent, queer-rhetorical formation of the Williams-Nichols Archive (WNA) of lesbian, gay, bisexual and transgender artifacts. The archive was collected and curated by Louisville activist David Williams and is now housed in Archives and Special Collections at the University of Louisville. In this work, I locate my intervention at the intersection of archival scholarship, queer theory/rhetoric, and new materialism in order to understand the rhetorical complexities of archival formation - a critical gap in rhetoric and composition that is only beginning to be addressed. Specifically, I argue for a greater attention to the materiality of queer archival rhetoric that centers the production of the WNA as an emergent queer rhetoric. Furthermore, I explore what such a perspective might offer our disciplinary understandings of archives and archival research, a perennial concern in our field.

The import of this concern is borne out by the amount of books, journal articles, and special issues devoted to archives, and also by the fact that these scholarly productions tend to locate their arguments in a rhetoric of overturning, purporting to challenge what we or others thought we or they knew about archival research. Surveying disciplinary conversations (see Chapter 1) leaves one with the feeling that while scholars have made important moves toward enriched methods and understandings of archival research, we do not yet have accepted definitions for what constitutes an archive. Nor, 
necessarily, should we. If an archive governs and organizes possibilities for speech and action within a particular discourse, as Michel Foucault theorized in The Archaeology of Knowledge (126-131) then it behooves scholars to keep their conceptions of archives relatively fluid.

In recent years, we have seen a greater turn toward digital archives. Media theorist Wolfgang Ernst, for example, argues for an attention to digital archives due to the proliferation of non-textual media. For Ernst, "the notion of the archive in Internet communication tends to move the archive toward and economy of circulation: permanent transformations and updating" (99). Ernst's work is provocative, and it is true that shifts in media technologies transform practices of archiving. Yet, I insist that the phenomena of circulation, transformation, and updating also mark the production of physical archive. In response, this dissertation assumes that there is still work to be done in interrogating more officially "sanctioned" archives, especially when they are challenged by non- and anti-normative accessions and curatorial practices. To study the WNA, I bring together archival scholarship, conversations in queer theory/rhetoric, and cross disciplinary interventions in what has come to be called "new materialism." My synthesis of these perspectives frames the archive as a queer-rhetorical emergence constitutively, rhetorically, and critically entangled with phenomena that, upon first glance, exceed its bounds. As Karen Barad argues, entanglement refers to "a relationality between specific material (re)configurings of the world through which boundaries, properties, and meanings are differentially enacted" (Meeting 139, emphasis in original). Taking up this concept, I focus not only on the archive itself but also on its relationality to a host of material phenomena, such as inscription, circulation, affect, and material practices of 
bodies marked both as human and nonhuman. In so doing, I seek to show how a queer archive emerges from ongoing, fundamentally rhetorical entanglements with the world that exists outside its supposed boundaries.

Despite its physical location in a research university library—a location marked not only by institutional but also epistemological privilege (in that it is classified as "research material") — the WNA challenges many of the assumptions undergirding the notion of a 'traditional' archive: Williams continues to expand the collection, a practice that makes it difficult for the archive's finding aid to keep up (see Chapter 4). Furthermore, Williams collects a wide array of ephemera that challenge the typical practices of archivists. While there has been much discussion of the relationships between materiality and archives (Biesecker; Clary-Lemon; Mailloux; Morris, "Archival Turn"; Poster; Sharer), of queer archives and their unique rhetorical ontologies (Alexander and Rhodes; Bessette, "An Archive of Anecdotes"; Bessette, Retroactivism; Cvetkovich; Morris “Archival Queer”; Morris and Rawson) and—less so—of curation (Bessette, "An Archive of Anecdotes"; Kennedy) these conversations, as I demonstrate in the next chapter, have (understandably and generatively) tended toward a focus on scholarly methods and the representations made available to researchers by archives rather than on the formation of archives themselves. Responding to this dearth and extending disciplinary conversations, this dissertation seeks to advance rhetorical knowledge in three overlapping and mutually informing ways.

First, I respond to queer rhetorician Charles Morris's call to attend to "the archive itself" ("Archival Turn" 113) by considering the ways that new materialism can enrich an understanding of how archives are formed and function as rhetorical "actors" in the 
production of knowledge. In other words, rather than primarily focusing on the narratives or histories made available by the Williams-Nichols Collection, I take the formation of the archive itself as my subject, attending to the ways that the archive emerges as an apparatus entangling various human and non-human phenomena. Second, in an effort to avoid overgeneralizations that elide or efface the queerness of the WNA, I will attend to the tensions between normativity and queerness (Bessette, "Queer Rhetoric") that are engaged by dint of the entangling of Williams's “queer" curatorial practices, the LGBTQ artifacts curated, Archives and Special Collections "official" curators and archival staff, and the "sanctioned" institutional practices of a university archive. Taking these entanglements into account, I examine the rhetorical activity—intentional and incidental; human and non-human — taking place at multiple levels of archival formation. As I frequently remind readers, the WNA does not simply contain rhetoric; the archive performs it. Lastly, I demonstrate how Williams's queer curatorial practices engage with the material artifacts collected in the archive as well as with the practices of trained curators, exploring the ways that Williams's work and its entanglements perform what Krista Kennedy theorizes as a distributed curatorial rhetoric. In short, this dissertation considers its archive not a site of research but as a subject, an ongoing queer-rhetorical performance.

\section{The Williams-Nichols Archive}

The WNA is housed in the University of Louisville's Archives and Special Collections in the basement of the main campus's Ekstrom Library. According to a library finding aid regarding LGBTQ studies primary sources, the archive was "established" in 1982 by Williams and contains "over 3,500 books, 3,000 issues of 
journals and periodicals, nearly 25 linear feet of manuscripts, hundreds of video and audio tapes, and nearly 1,500 items of memorabilia and ephemera on the LGBT experience" ("Lesbian, Gay, Bisexual, Transgender [LGBT] Studies"). A 2016 interview with Williams, however, describes the collection as having " 6,300 books, 30,000 print publications, $300 \mathrm{~T}$-shirts, and loads of buttons, bumper stickers, photographs, CDs and much more" (Havens). The jump in number is not necessarily an accident—-the archive, while "established" in 1982 - is constantly re-established and transformed: typically, Williams drops off more documents and artifacts on a monthly basis. This fact highlights both the warrant for and an interesting parity between my theoretical frames, since queer theory and new materialism both call attention to phenomena not as fixed or stable but as always in processes of becoming, an insight that is clearly true of the emergent phenomenon of the WNA.

Due to Williams's prolific collection and donation as well as the fact that Archives and Special Collections have attempted to maintain Williams's methods of classification (at times finding it difficult to manage each), the archive vexes attempts at a linear history, a tendency that can be linked to the insights of queer archival scholarship. While the finding aid dates the archive's origin in 1982, Williams began collecting and storing primary source materials in the early 1980s (Williams, David. Personal interview. 21 Mar. 2018). The archive was officially incorporated in 1994, but it was only in 2001 that he donated it to be preserved by the UofL Archives and Special Collections. An Insider Louisville article detailing his receiving a "certificate of merit for notable service to and advocacy for archives in Kentucky by a private citizen" notes that Williams "donated his vast collection to U of L in 2001 in honor of his former partner Norman 
Nichols, who died of AIDS" (Ryan), but there was an additional influence: the literal, physical weight of the archive kindled fears that it would destroy the foundation of Williams's house (Williams, David. Personal interview. 21 Mar. 2018). Williams's decision to move the archive was rhetorical in a literal sense, given that it seems to have required a good deal of persuasion - the earliest suggestion I have found that the archive be moved to UofL was at a meeting for Gays and Lesbians United for Equality in 1982, ironically the year it was supposedly established. Furthermore, Archives and Special Collections is attempting to carry on Williams's own self-invented categorical system, leading to both transformative challenges and productive negotiations between Williams's queer archive and the "straight" institution of Archives and Special Collections. Within this context, I pose the following research questions:

- In what ways does Williams's archive perform queer rhetoric — entangling human and non-human phenomena and materially challenging normative forces—rather than simply exist as a collection of queer or LGBT materials? ${ }^{1}$ Since the WNA is, at an empirical level, a collection of physical materials entangled with the curatorial and storage practices of Williams, the queer phenomena that find their trace in the archival materials, and the (potentially normative) definitional practices of institutional archivists, how does the archive perform its own form of queer-rhetorical activism?

\footnotetext{
${ }^{1}$ While the rhetorical canon is not one of my guiding areas of focus, studying Williams's archive as queer rhetoric rather than as a collection has obvious implications for considering the relationships between invention and arrangement.
} 
- How might an analysis of the rhetorical activity of the WNA help to "mobilize" the physical archive, highlighting dynamic rhetoric — such as decision about what to archive, circulation of archival materials, classification, and the persuasiveness of matter itself - that takes place before researchers open their first box of materials? What might this mean methodologically for the ways we produce knowledge with archives?

- How might an attention to the rhetoric of archival formation move beyond projects of recovery (while recognizing the importance of such work) and instead help scholars discern the activist practices embedded in and inherent to the production of an archive? In what ways are these practices - in the case of the WNA - explicitly queer? How might the historical formation of the archive envision optimistic queer futures (Muñoz, Cruising Utopia)?

- What rhetorical negotiations and transformations take place in the movement of a queer archive? Similarly, how can we recognize the material complexities of institutionality while also avoiding deterministic readings that frame the "assimilation" of a queer archive into institutional space as the undoing of the archive's radical potential?

\section{$\underline{\text { Chapters }}$}

Due to the expansiveness of this project, I bound it within narrow case studies presented in individual chapters that, taken together, demonstrate complex relationships between rhetoric, queerness, and materiality exhibited by the ongoing emergence of the WNA. My first chapter, "Disclosing the Williams-Nichols Archive: Theories, Methodologies, and Ethics" reviews scholarship both in and outside of the field of 
rhetoric and composition that inform the approach I take throughout this dissertation, bringing together archival scholarship, queer theory/rhetoric, and new materialist theories. I then explore the ethics of this synthesis, and the implications on my own positionality—as a cisgender, heterosexual individual—on the project.

Chapter 2, "Making the World Through Silence: Disidentifications in a Queer Archive," takes up José Esteban Muñoz's theory of disidentification, “a strategy that tries to transform a cultural logic from within" (Disidentifications 11). Specifically, I engage archival research and semi-structured oral history interviews to argue that Gays and Lesbians United for Equality (GLUE) - a social movement organization from which what would become the WNA emerged - performed complicated strategies of silence-asdisidentification (Muñoz, Disidentifications) with largely bureaucratic genres-meetings minutes - in ways that speak to a resistance to and transformation of typical understandings of political activity. I contend that these strategies emerge in response to a complex attunement to GLUE's emergent, historically circulating archival rhetoric. Ultimately, I argue that particular silences in GLUE's archival record can paradoxically be understood as a form of queer-activist rhetoric, becoming the conditions of possibility for queer world making in Louisville.

"Materializing Affect in Archival Production," Chapter 3, explores material traces of affect within the WNA. Examining letters detailing complicated sexual orientations and feelings sent to Williams after he began to advertise his archive, I argue for considering them as personal archives that mediate queer affect against a normative public sphere. The fact that these letters often reflect multiple layers of inscription (one typewritten document was subsequently and intensely marked up and revised by hand 
before being sent, for example) points to the processuality of archiving affect forces. Crucially, however, I also consider ethical aspects of Williams's decision to archive these letters as a rhetorical emergence that calls practices of research and meaning-making into a productive discomfort. Of course, as I discuss in the chapter, these ethical considerations also extend to my decision to write about them, which highlights the stakes of archival research.

Chapter 4, "Queer Archives, Rhetorical Accretion, and Entanglement: Queer Curatorial Rhetoric and the Formation of the Williams-Nichols Archive," discusses how the history and movement of the WNA from William's home to the University of Louisville's Archives and Special Collections challenged both Williams's commitment to grassroots historiography (Bessette, Retroactivism) as well as the "official" practices of the university's trained archivists. Reading our discipline's concept of rhetorical accretion alongside Barad's conception of entanglement, I consider how the literal movement of the WNA reveals it to be entangled with phenomena marked both as human and non-human, such as activists, archivists, tables, floors, and, broadly, matter itself. This movement reveals the production of the WNA as a form of transformative rhetorical accretion. Further, I argue that considering material entanglement can help develop a robust understanding of the WNA and its demonstration of what I refer to as queer curatorial rhetoric, a complexified, reparative understanding of the incorporation of queer archives into institutional structures that is attentive to the transformative potential of a queer archive's emergence within a typically normative context. Queer curatorial rhetoric, theorized here, not only challenges normative archival practices (though 
certainly that) but that also destabilizes typical modes of thinking about subjectivity, a project of queer theory and new materialisms alike.

Finally, my concluding chapter considers the project's implications for the field of rhetoric and composition more broadly. In it, I argue that attending to the materiality of archival formation can help understand the complexities of rhetorical history, but that archival formations must necessarily be understood in their particularities - in this case, by considering the WNA as an inelectably queer archive. The materialist perspective offered by my dissertation, I claim, can contribute to disciplinary conversations by drawing greater attention to both the rhetoric of archival formation and the complex materiality of archives. 


\title{
CHAPTER I
}

\section{DISCLOSING THE WILLIAMS-NICHOLS ARCHIVE: THEORIES, METHODOLOGIES, AND ETHICS}

\begin{abstract}
$\underline{\text { Introduction }}$
As I mentioned in my Introduction, studying the formation of an archive is an expansive project and almost requires engaging in nomadic thinking. Admittedly, I weave together a wide range of conversations across disciplines throughout this scholarly production, and the connections between them may not be immediately apparent upon first glance. Given these multiple and complex theoretical orientations, the perspectives that structure my thinking deserve explicit explication. In this chapter, then, I explain my weaving together of archival scholarship in and outside of rhetoric and composition; approaches to queer theory, queer rhetoric, and queer archives that inform later chapters; and materialist perspectives that are crucial to my understanding of the WNA's queer formation. I close with a discussion of methodological and ethical considerations emerging from this synthesis, and by overtly explaining how this project contributes to understandings of rhetoric and queer theory/rhetoric.
\end{abstract}

\section{$\underline{\text { Archival Orientations }}$}

Concerns regarding the nature of archives and archival research recur throughout the disciplinary history of rhetoric and composition as well as in the related fields of 
cultural studies and critical theory. Two poststructural theorists that we have (with varying levels of persuasiveness) claimed in our discipline-Foucault and Jacques Derrida - delivered early theorizations of "the Archive" that help to lay out not only the stakes of archives for rhetoric but also conceptions of archives that have been taken up by scholars more firmly in our field. The archive to Foucault's discourse analysis, as it provides the classifications and taxonomies from which discourse emerges. Specifically, Foucault considers the archive to be "the first law of what can be said," and "that which differentiates discourses in their multiple existence and specifies them in their own duration" (129). Derrida, on the other hand, discusses the epistemology of the archive in psychoanalytic terms as an ultimately impossible desire for preservation set in motion by the Freudian death drive, a knowledge-orientation he refers to as "archive fever." I find these poststructuralist orientations compelling as a way of considering the dynamicity of archives and archives' effects on knowledge-making. However, their tendency toward discourse and textuality is often at odds with the materialist perspective I develop, which is discussed in detail below. Further, I find myself in agreement with Ann Cvetkovich's comment that "the continued turn to Derrida [is] somewhat frustrating when there are so many other places to look for archive theory" ("Queer Archival Futures").

An aspect of Derrida's treatise that is relevant to the project at hand, however, is his marking of the future-orientation of the archive. Derrida writes that the archive is "a question of the future, the question of the future itself, the question of a response, of a promise and responsibility for tomorrow. The archive: if we want to know what that will have meant, we will only know in times to come" (36). In other words, Derrida posits in this passage a future-orientation of the archive that implicates an ethics-inasmuch as the 
archive sets the ground for responsible action— but he also positions the archive as ultimately unknowable except in retrospect. Both Foucault and Derrida thus claim the stakes of archival formation as setting the ground for ethical action and also assert a need to analyze archival formation as emerging at the intersection of past, present, and future temporalities. Within more recent and mainstream disciplinary productions of rhetoric and composition, there has been a productive turn against abstract theorizing of the nature of "the archive" in favor of a more contextualized approach to particular archives. Often these discussions focus on archives of the field of rhetoric and composition and, more recently, on the pragmatics of archival research.

An apt place to begin, since it reflects these tendencies and arguably helped to set them in motion, is a 1999 special issue of College English titled "Archivists with an Attitude." In his introductory essay, John C. Brereton claims that though the archive of rhetoric and composition has been expanding, "we still aren't sure what should be in our archive, or how access can be broadened, or which tools we should bring to our task of exploring the past. In fact, we aren't sure exactly what we already have in our archive, or how in fact we even define the term" (574). Taking issue with the tendency of poststructural theory to align more traditional historical research methods with political conservatism, Linda Ferreira-Buckley suggests that skepticism toward historical accounts, and rigorous methodologies capable of accounting for the difficulties of studying history, existed long before continental philosophy. Instead of further introduction to theories of the archive, Ferreira-Buckley claims that graduate students need extensive training in historical methodologies "tailored to recovering the history of rhetorical practice and instruction" (577). Steven Mailloux, for his part, considers the 
materiality of writing from the perspective of textual studies to argue for reading students' typos as an archival form. Thomas P. Miller and Melody Bowdon, finally, provide pushback to the previous three articles, writing that as the discipline expanded what "counts" as the archive of rhetoric, "the definition of archives as depositories of the public record became problematic when we recognized the limitations imposed on 'the public"” (592). While the diversity of foci across these articles reflect rhetoric and composition's radically heterogeneous investments in archives, the bulk of their conversation focuses on histories contained in archives rather than the material formation of archives, an epistemo-methodological leaning that carries through much archival work in our field.

That is not to say that materiality has been omitted entirely, however. Literary studies scholar Carol Poster calls attention the (arguably still underemphasized) stakes of the physicality of archival material in a College English article, writing:

While we theorize, unrecovered Victorian women's writings, printed on acid paper, crumble into permanent and irretrievable oblivion.... The consequence of delay will be the permanent silencing the majority of popular female Victorian novelists by permitting physical disintegration of their works. (289)

Wendy B. Sharer similarly claims that the act of writing history "derives from previous acts of power that configure the material conditions of historical research" (120). In general, however, much archival work in our field has focused on disciplinary concerns, a tendency evinced by Susan Wells's discussion of the "three gifts" of archives: their resistance to knowledge, since there is always more to trace (60); a loosening of disciplinary resentment, since we can uncover archives that are truly "our own" rather 
than appeal to the histories of other fields; and the "possibility of reconfiguring our discipline ... [,] help[ing] us to rethink our political and institutional situation, to find ways of teaching that are neither narrowly belletristic nor baldly vocational" (61). While these are certainly productive inquiries, I worry that attending too closely to methodology and/or disciplinarity risks mistaking what researchers do in and with archives for archives themselves. Attending to methodology is important but must also include archival formation that give context and boundaries to research.

This point, in my view, is best made in a 2006 special forum on "The Politics of Archival Research" in Rhetoric \& Public Affairs. Morris notes in his introduction that, despite the primacy of the archive for doing rhetorical scholarship, "the archive itself . . . has yet to be subjected to sustained critical-rhetorical reflection by scholars in this discipline," indicating that we might (re)turn to the archive, understanding it as "a dynamic site of rhetorical power" (“Archival Turn” 113, 115). The short articles contained in the forum address this lack by framing archives as terministic screens that afford and constrain interpretations, enacting their own agency on researchers by way of deliberative, ideological classification (Finnegan 118, 119); by considering the primacy of archives as sites of "preferred memory" both in scholarship and for public history (Houck); by positioning the archive as a scene of invention rather than as an inherent, evidentiary, or ultimate historical record (Biesecker); by addressing questions of access and political control of the archival record (Stuckey); and, most relevant to this project, by "becom[ing] the deftest of archivist-rhetors, or archival queers," an act which requires both taking seriously the relationships between sexuality and rhetoric, and helping to circulate queer voices into larger spheres and discourses (Morris, "Archival 
Queer" 149). Taken together, these articles examine what Barbara A. Biesecker calls the "historicity of the archive," but only Davis Houck and Morris ("Archival Queer") focus on the role of archivists and curators. That said, the authors collected in this special forum provide among the most persuasive arguments for looking not just through the archive to produce rhetorical historiographies but also at the archive, assessing its own performances of rhetoric and politics.

And yet, in the field of rhetoric and composition, this call has arguably been elided by a greater attention to method and methodology in doing historical research in archives. In her article "An Argument for Archival Research Methods," for example, Barbara L'Eplattenier echoes Ferreira-Buckley, arguing that there is dearth of instruction and scholarship in practical archival methods, and her co-edited collection, Working in the Archives: Practical Research Methods for Rhetoric and Composition, follows up on this attention to method. In their introduction to the volume, Alexis E. Ramsey, Sharer, L'Eplattenier, and Lisa S. Mastrangelo claim that because much of archival research is self-taught, and because research guides don't account for the unique nature of rhetoric and composition scholarship, disciplinary training in archival methods would improve researchers' experiences (Ramsey et al. 1-3). They distinguish between methodologiesthe theorizing of research aims - with methods, "the practical application of methodologies - what occurs when we put the theory of methodologies into action and how that application is reflected in our work habits" (4). Whereas the "Archivists with an Attitude" was successful in calling for re-conception of archival methodology, the authors note that the call remains largely unanswered (2). 
Pointing out this tendency toward method is meant to provide context for my intervention - rather than critique - and I am also not interested in overdetermining the landscape of such conversations. Indeed, while Working in the Archives's claimed central interest lies in delivering practical methods rather than theorizing or attending to methodology (Ramsey et al. 4), its chapters contain insights into archives that extend beyond method and reflect epistemological leanings (of course, the two can't ever be fully separated). Cheryl Glenn and Jessica Enoch, for example, suggest the need for relationships with archivists and other archivist agents $(19,20)$, noting that while different theoretical orientations enable different reading practices, the aim of archival researchers is still to make truth claims about their subjects (25). Sammie L. Morris and Shirley K. Rose - an archivist and a scholar of rhetoric and composition, respectivelyargue that "because rhetorical theory addresses the creation, interpretation, and use of documents in specific contexts," relationships between archivists and rhetoricians can also benefit archival labor (53). Neal Lerner, additionally, extends his conception of the archive beyond traditionally understood boundaries (and, in that sense, addresses similar questions as this dissertation [see Introduction]) to argue that "the social forces that shape archival research are many, from a researcher's experiences and expectations, to contemporary events, to the choices made by those who have donated papers to an archive" (195). Taken together, these articulations of rhetoric and composition's "mainstream" archival scholarship call attention to the rich ways that our discipline has approached archives, but their privileging of the archive as a site for locating materials rather than a subject of research itself leaves a critical opening that I seek to explore in this dissertation. 


\section{Queer (Archival) Rhetorics}

Of course, the WNA, as a queer archive, requires specialized concepts and tools and resists many of the potentially normative conversations regarding method/ology, to the extent that the goal of such conversations is broad applicability. Insights from queer theory and queer rhetoric, in other words, are vital to understanding the archive on its own terms. Writ large, the notion of "queer" challenges normative practices and conceptions of identity, social subjectivity, institutions, and (broadly) life itself, typically on the bases of sexuality and/or gender. Even my attempt to define queer, however, calls up (at least) two related problems: (1) defining "queer," it might be argued, performs the normativizing impulse that much queer theory seeks to counteract; (2) as a straight, white, cisgender male, there are clear, inherent dangers that my attempting to leverage queer theories might minimize or exclude the voices that queer theory works to amplify. I respond to these challenges first here by reviewing scholarship dedicated to conceptions of queerness, slanting toward those related or informative to queer rhetorics and queer archives, without trying to "lock in" a singular, stable definition of the critical term. In my methodology section below, I will explicate ethical concerns regarding my own positionality in relationship to this project.

By way of a (necessarily brief) introduction, Teresa DeLauretis, Lisa Duggan, and Michael Warner all cast light on both the exigence for and the historical/conceptual complexity of queer theory. DeLauretis argues that queer theory was largely brought to bear to "transgress and transcend [distinctions of sexuality and gender identity] —or at the very least problematize them" (v). This new theoretical constellation was necessary because, as Duggan asserts, heterosexual normativity is built into many of the left 
theoretical movements that might be applied to the question of sexuality and gender ("Making It Perfectly Queer" 18). This is not to say that there is one queer theory that responds to these left-theoretical discourses, as Duggan suggests that the multiplicity of queer perspectives are "unified only by a shared dissent from the dominant organization of sex and gender," though it is important to note that "not every individual or group that adopts the name 'queer' means to invoke these altered boundaries" ("Making It Perfectly Queer" 20). In fact, Warner writes that the heterogeneity of queerness is a politically generative position, since "there remains a question whether or in what context queers have political interests, as queers, that connect them to broader demands for justice and freedom" (Warner, Fear xi). Taken together, these authors insist that queer theory cannot be reduced to single model; that queerness is not necessarily aligned with liberal rightsbased discourses (Duggan 14, 17; Warner, Fear xvi, xxvi); and that there is a tension between queer theory as an academic project versus queerness as a lived, embodied experience (DeLauretis x-xi; Duggan 26; Warner, Fear xii).

Judith Butler's Gender Trouble, however, delivered arguably the most influential discussion of what would become queer theory. Critiquing the representational feminist politics that posit an exclusionary feminist subject-i.e., a category of "woman" that excludes by dint of its definitional impulse - Butler offers a poststructuralist reading of gender, writing that "Gender is a complexity whose totality is permanently deferred, never fully what it is at any given juncture of time" (22). In other words, gender is a performative, discursive phenomenon, which problematizes a common feminist position relying on identificatory politics. As Butler explains, such feminist strategies (and strategies in general) "always have meanings that exceed the purposes for which they are 
intended" (8). This excess cuts both ways, rendering essentializing feminist politics problematic but also allowing for parodies, such as drag, where a "failed" gender performance can denaturalize viewers' gendered, ideological assumptions about the body's relationship to social subjectivity (186). Since "[g]ender is the repeated stylization of the body, a set of repeated acts within a highly rigid regulatory frame that congeal over time to produce the appearance of substance, of a natural sort of being" (198), agency exists in the reformulated subject's potential to variate these repetitions, thus disrupting naturalized identities. While, as discussed below, Butler's commitment in Gender Trouble to a poststructural, discursive account finds friction with an expanded materialism—i.e., one that extends beyond the realm of language — her commentary on the emergent nature of coalitional politics harmonizes with the perspective I develop here. Butler explains:

An open coalition, then, will affirm identities that are alternately instituted and relinquished according to the purposes at hand; it will be an open assemblage that permits of multiple convergences and divergences without obedience to a normative telos of definitional closure. (22)

As I will show throughout my analysis, the WNA can be understood as such a coalitional form, emerging from rhetorical and dynamic processes of becoming. These processes, however, implicate not only language and humans but also the materialities of physical circulation, the processual movements of affect, the physical matter of archival materials, and negotiations between curators, archivists, activists, and the materials themselves. Like Butler's conception of gender, the WNA queerly and materially resists both normative definition and closure. 
Obviously, archival approaches that, intentionally or otherwise, orient toward normativity are insufficient for studying queer archives. It is for this reason, perhaps, that whereas mainstream disciplinary discourses have largely emphasized —at least since "Archivists with an Attitude" - the pragmatics of carrying out archival research in generalizable terms, queer archival scholarship both outside of and within the discipline has generally been more interested in and receptive to theorizing the unique nature of queer archives. As Jonathan Alexander and Jacqueline Rhodes note, "For many scholars of LGBT and queer history, the archive has become an important source not only of information but also of theorizing about queer experience and possibility," contending that queer archives "suggest how a narrative of emerging — and changing — queer experience might be constructed over time." Cvetkovich's extremely influential monograph An Archive of Feelings (taken up by Alexander and Rhodes), links queer histories with those of trauma since, due to their shared suppression within the public sphere. In light of this fact, Cvetkovich notes, "gay and lesbian archives have been formed through grassroots efforts" where, "[i]n the absence of institutionalized documentation or in opposition to official histories, memory becomes a valuable historical resource, and ephemeral and personal collections of objects stand alongside the documents of the dominant culture in order to offer alternative modes of knowledge" (Archive of Feelings 8). In other words, because histories of both queer and traumatic experiences and epistemologies are underprivileged in relation to other modes of knowledge, their archives are formed through different practices of selection and materialization. 
Jean Bessette's recent monograph, Retroactivism in the Lesbian Archives, builds on Cvetkovich's insights to provide some of the best and most extended thinking about the nature of queer archives from a rhetorical perspective. Theorizing queer archives as a form of grassroots historiography enacting retroactivism - a practice through which rhetors "compose and appropriate the past toward present identifications and politics" (3) - Bessette suggests the crucial insight that queer archives are not simply collections but forms of invention (7). As Bessette argues, "Systems of classification in archives draw boundaries around materials, identifying records together in distinction from other classificatory categories" (69), a comment that points to a politics of locating queer archives, due to the diverging interests and knowledge forms of queer-identifying populations, on one hand, and professional archivists, on the other (Bessette, Retroactivism 64; Morris and Rawson 76). My work extends Bessette's attention to the productive effects of forming an archive as well as to her discussion of grassroots historiography, which the WNA clearly enacts. To avoid providing a deterministic reading of the archive that might critique its assimilation into the normative structures of a university library, however, I take up theories of queer performativity, queer utopianism, and Eve Kosofsky Sedgwick's notion of reparative reading to consider the ways that the WNA, as a queer archive, challenges and reorients normativity from within the University of Louisville Archives and Special Collections.

Jack Halberstam offers such a performative reading, defining "queer" as "nonnormative logics and organizations of community, sexual identity, embodiment, and activity in space and time." In so doing, he offers the concepts of "queer time"alternative temporalities outside heterosexual, bourgeois life markers - and "queer 
space"- the postmodern production of space through the formation of queer

counterpublics (6). Discussing the brutality inflicted on Brandon Teena, a trans man murdered in rural Nebraska, Halberstam considers the stories surrounding Brandon as performing a narrative archive, an "immaterial repository" (33), and goes on to claim that "[w]ith careful organization now, this archive may also become an important resource later for future queer historians who want to interpret the lives we have lived from the few records we have left behind" (Halberstam 46). While my project will diverge from Halberstam's acceptance of immateriality, his discussion is informative for considering the Williams-Nichols not as a repository but itself as a "queer way of life" (1) that does not contain queerness but performs it. The future-orientation proposed by Halberstam is pushed further by Muñoz, who argues for a form of utopian queer futurity. Discussing queerness as an emergent possibility, Muñoz forwards another conception of "queer time," arguing that seeing queerness as a "horizon" of futurity, rather than existing within "the spirit of political impasse that characterizes the present," allows for a reclamation of concepts like faledom and rationality from heternormative discourses (Cruising Utopia 28, 32). Taking issue with Lee Edelman's theory of the negative, ${ }^{2}$ Muñoz argues that the purchase of envisioning a utopian queer future lies in resisting "hand[ing] over futurity to normative white reproductive futurity" (95). In other words, by refusing to be content with a regulatory and limiting understanding of the queer present—which much of queer

${ }^{2}$ In No Future: Queer Theory and the Death Drive, Edelman asserts that reproductive futurity-a politics that uses the ideology of "the child" to quell the present concerns in favor of an abstract future-to-comeobstruct the potential for queer politics to challenge normativity. Instead, Edelman argues for embracing queerness as the radical negation of futurity. 
theory has sought to articulate-queer individuals should instead envision queer possibilities of the future.

Sedgwick similarly critiques dominant strands of queer theory and Theory in general. She tasks Ricouer's "hermeneutics of suspicion” as a theoretical vantage point that at times too easily aligns with a paranoid imperative toward "truth seeking" that curtails a performative orientation toward what knowledge does (125). Sedgwick explains that queer theory has, in particular, been prone to these paranoid readings, in part due to its frequent alignment with psychoanalytic thought (126). The problem with this theoretical orientation is that paranoid readings disavow reparative readings: "Reparative motives, once they become explicit, are inadmissible in paranoid theory both because they are about pleasure ('merely aesthetic') and because they are frankly ameliorative ('merely reformist')" (144). In other words, paranoid readings place the search for ideological underpinnings and hidden motives above performative knowledgemaking capable of ameliorating damaging conditions as a mode of anticipating harm. As Sedgwick explains, however: "to read from a reparative position is to surrender the knowing, anxious paranoid determination that no horror, however apparently unthinkable, shall ever come to the reader as new; to a reparatively positioned reader, it can seem realistic and necessary to experience surprise" (146). Throughout this dissertation, I take up the concept of reparative reading on two levels: first, by considering the formation of a queer archive as a reparative practice, and second, by foregrounding the ameliorative effects of queer-archival formation, a form of reparative reading that carries through my analysis. 
Bessette invokes Eve Kosofsky Sedgewick's discussion of queer theory's tendency toward anticipatory, paranoid readings of normativity to argue that queerness and normativity should be understood contextually and rhetorically. Claiming that queer theory often assumes an implicit universalizing, oppositional stance to the supposedly normative, Bessette suggests that queerness and normativity are better understood in their local particularities as "shifting, fractured valences" and that an understanding of queer rhetoric "in situ" would "not presume in advance to know the shape of the regulations and ideals of either normativity or queerness" ("Queer Rhetoric" 155). This is because rhetoric is always capable of being misdirected and also because "most practices, acts, or texts have multiple audiences, both within a given moment and if they persist across time" (157), which leads to a seemingly paradoxical recognition that a single rhetorical act might be both queer and normative, depending on the audience.

These queer theoretical articulations are vital to maintaining the ethical commitment of my work, as discussed in more detail toward the end of this chapter. While I try to avoid definitional work regarding queerness, as discussed above, I use the concept of "queer" in this dissertation to refer to resistant material practices of meaningmaking that emerge to contest, negotiate, and disidentify with normative rhetorics regarding sexuality, gender, and archival practice. This dissertation does not attempt offer a grand-theory of archival rhetoric, however, though I do at times point to the implications of my research for considering archives more broadly. Rather, my interest (and my approach to the "queerness" of the WNA) is in producing an analysis of specific, illustrative moments of the WNA's formation in its particularity as a unique LGBTQ archive. To do so, I center the archive's friction with normative forces in my tracing of its 
rhetorical formation. Taking up Warner's analysis in Publics and Counterpublics, I attend to how the archive's circulation rhetorically entangles LGBTQ (counter)publics, defined by Warner as "space[s] of discourse organized by nothing other than discourse itself" (67). I insist, however, on the irreducible materiality of these circulations. Synthesizing this insight with Bessette's discussion of normativity and queerness as well as with new materialist perspectives, my dissertation inquires into the material negotiation - among queer, straight, human, and non-human actors — inherent to the Williams Nichols Archive's ongoing emergence. With that in mind, I now turn to those approaches to materiality that will inform my work.

New Materialism: Dispatches from the Fourth Settlement

Materiality is not a new term to rhetoric and composition, but neither is the concept unified within rhetorical thought. Biesecker and John Louis Lucaites, in the introduction to their edited collection Rhetoric, Materiality, and Politics, locate the originary point of rhetorical materialism in Michael Calvin McGee’s 1982 essay “A Materialist's Conception of Rhetoric" (2) in which McGee asserts that "A material theory of rhetoric ... begins with real speeches which are demonstrably useful to an end or are failures" (19). While scholars such as Ronald Walter Greene have forwarded a Marxistmaterialist perspective, there have also been critical strands of materialism emerging from feminist (Collins; Bordelon) and decolonial (Haas; Powell) scholars within the discipline. A useful concept emerging from these conversations, often employed from a feminist perspective, is rhetorical accretion. Vicki Tolar-Collins defines rhetorical accretion as the (decidedly human) agential layering of texts that leads to mutual transformations on and with an original text (548). In other words, as rhetorical acts are 
performed, brought into relationships with other acts, and re-performed, their meanings shift, challenging assumptions about both the intentionality and the individuation of rhetorical performances. Rhetorical accretion has been taken up by Jennifer Clary-Lemon from an archival orientation to frame "location, relationships, positionalities, images, and contexts as additional layers of rhetorical accretion." These phenomena that seem to exist "outside" the archive, Clary-Lemon goes on the claim, can "be read as texts that augment our understanding of the production and distribution of particular archival documents in space and time, affect our selection and triangulation of archival texts, and hint at a need for a changing vocabulary to address archival methods and methodologies together" (387). This dissertation extends both Tolar-Collins and Clary-Lemon's perspectives on rhetorical accretion. In the former case, I take up Tolar-Collins articulation of material rhetoric as a feminist methodology, attending to how rhetorical materialisms can identify and unearth marginalized rhetoric - queer archival rhetoric, specifically. In the latter case, I welcome and extend Clary-Lemon's consideration of the non-human in theories of rhetorical accretion, which I take up explicitly in Chapter 4.

While much productive work has been engaged by various articulations of rhetorical materialism, I read these theories alongside what has been referred to, in recent years, as new materialism, a decidedly non-unified constellation of thought, largely emerging from philosophy and cultural studies, that seeks to expand our understandings of materiality beyond the binaries of matter/text and nature/culture that have continued to 
understate irreducible, material entanglement of the world. ${ }^{3}$ Rick Dolphijn and Iris van der Tuin explain that

new materialism is a cultural theory that does not privilege matter over meaning or culture over nature. It explores a monist perspective, devoid of the dualisms that have dominated the humanities (and sciences) until today, by giving special attention to matter, which has been so neglected by Cartesian thought. (86)

New materialisms' flight from dualist thought sets it against not only essentialist positivism but also poststructuralism and related branches of social constructivism, since these orientations often rely on the unmarked dualisms of nature/culture, text/reality, and matter/meaning.

Furthermore, much of new materialist thought involves a movement away from critique and toward creative, exploratory theorizing engaging a "nomadic transversing of the territories science and the humanities, performing the agential or non-innocent nature of all matter that seems to have escaped both modernist (positivist) and postmodernist humanist epistemologies" (Dolphijn and van der Tuin 101, emphasis in original). While it is true that new materialist thought is incapable of wholly avoiding our well-worn critical impulses, a commitment to nomadic thinking attempts to move beyond critique and to consider our own entanglements and responsibilities in and with the world's becoming. Barad, the theorist most influential in my own reading and uptake of new materialism, articulates the problem plainly in an interview:

\footnotetext{
${ }^{3}$ An early influence on new materialism, especially the feminist-leaning new materialist thought I engage in the dissertation, is Donna Haraway's Simians, Cyborgs, and the Reinvention of Nature.
} 
I am not interested in critique. In my opinion, critique is over-rated, overemphasized, and over utilized, to the detriment of feminism. . . Critique is all too often not a deconstructive practice, that is, a practice of reading for the constitutive exclusions of those ideas we can not do without, but a destructive practice meant to dismiss, to turn aside, to put something or someone downanother scholar, another feminist, a discipline, an approach, et cetera. ("Interview with Dolphijn, Rick and Iris van Der Tuin” 49)

In other words, critique becomes too easily wielded for its own sake, rather than as a productive, consequential, and — for many theorists—-feminist method of inquiry. This perspective harmonizes with that of Sedgwick, as each scholar positions the "critical urge" as a possible detriment to considering the performativity of knowledge.

There are a number of "new materialisms," many of which are not new, at least by commonsense definitions of the word. Furthermore, many of these theories, beyond a general consensus that matter matters, stand in stark opposition to each other. I locate my work within what Susan Hekman—extending Bruno Latour's mapping of various critical positions as "settlements"- refers to as the fourth settlement, also called the feminist settlement, that seeks to address "epistemological, ontological, political, scientific, and technical issues simultaneously" (67). Though I find Latour's work provocative and necessary —most especially his early identification of the problems inherent to critique, which resonates with Sedgwick's discussion of reparative versus paranoid reading practices (“Why Has Critique Run Out of Steam?"), I agree with Hekman's claim that "Latour's polemics sometimes stand in the way of his definition of an alternative conception. His desire to shock seems to overcome his desire to clarify" (21). A by- 
product of this desire to shock may be his consistent use of colonial, militarized metaphors: theoretical positions referred to as settlements, for example. While I find it regrettable that this metaphor has been taken up by Hekman to identify what I find as the most viable new materialist stance, I accept the metaphor of the settlement for the sake of conceptual continuity. If Latour is afflicted by a desire to shock, I promise readers that my own desire to mock will only manifest in the heading of this section above. In any case, Hekman provides a number of insights that help to qualify my uptake of new materialism and its turning away from a purely social constructivist orientation. The key point is that embracing matter and materiality does not mean a return to modernist conceptions of positivism and biological essentialism (2), a position that would be inadmissible in a dissertation purporting to address the anti-normativity of a queer archive, but rather offers new ways of considering the fundamental inseparability between matter and meaning. The concepts of disclosure and agential-realism-offered by Hekman and Barad, respectively — provide the most generative responses to the problems posed by new materialist critiques of social constructivism.

While Hekman clearly embraces a number of new materialist insights, she does identify a concern that, in working to undo the nature/culture dichotomy, much of new materialist thinking is rendered incapable of discussing anything but science. In response, Hekman writes that

We need to explore the full dimensions of the mangle that constitutes social life. We need to explore the ontology of social institutions such as politics, the economy, religion, kinship. These institutions are in a sense purely social. They have no 'natural' component; they would not exist outside our conception of 
them. Yet they are at the same time real. Their existence produces material consequences for the subjects who inhabit the societies they constitute. (89) While Hekman, in my view, underemphasizes here how "our conceptions" of institutions are dependent upon and entangled with phenomena that do exist in nature (as will be discussed in relationship to agential-realism below), her point stands: any viable materialism must be able to explain phenomena typically regarded as the "social" as well as those regarded as "natural" or "scientific." Hekman's concept of disclosure provides a way of thinking the two realms together.

Disclosure points to the ways that particular aspects of reality are manifested and presented at the intersections of human and non-human phenomena, but avoids a wholly relativist stance that forecloses on ethics and politics. While no particular disclosure can claim an objective and correct articulation of reality, "it is possible to compare the material consequences of the different disclosures of the same reality." Hekman explains:

Disclosure entails that perspectives/concepts/theories matter - that they are our means of accessing reality. But disclosure also entails that we do not constitute that reality with our concepts, but rather portray it in varying ways. An important aspect of this understanding is that the reality, like the object in a photograph or the subject of the scientist's experiment, is agentic. It pushes back, it affects the result. Another important aspect of this understanding is that there is a result. There are different material consequences to different disclosures. (92) In other words, Hekman insists that knowledge emerges from particular disclosures of the world; that these disclosures implicate both human and non-human phenomena, and that while no particular disclosure can claim to offer a totalizing, objective representation, 
insisting on the material consequences of particular disclosures (which are themselves materially constituted) can help to assess and discern the effects of particular forms of knowledge. Disclosures, then, are acts of world-making, as they have material consequences that matter and have clear bearings on how we might understand the relationships between rhetoric and materiality, as will be discussed more fully below. First, it is necessary to present Barad's theory of agential realism, an orientation that picks up on certain valences of materiality underemphasized in Hekman's account.

Barad's theory of agential realism attends to what she considers the "posthuman performativity" of the world's becoming. This conception of posthumanism is neither the rejection of the human nor an acceptance of anthropocentrism. Rather, Barad's theory recognizes historical contestations regarding who is granted the category of human and attempts to account for the "boundary-marking practices by which the 'human' and its others are differentially delineated and defined" (Meeting 136). Pushing further, Barad's agential realism considers the inseparability of matter and meaning (which Barad combines into the concept of the "material-discursive") and illuminates the role of matter in the emergence of the world: "Matter is neither fixed and given nor the mere end result of different processes. Matter is agentive, not a fixed essence or property of things" (137). Because the world's becoming is enacted through material-discursive entanglements, "a relationality between specific material (re)configurings of the world through which boundaries, properties, and meanings are differentially enacted" (139, emphasis in original), the unit of analysis is neither subjects nor objects but phenomena. Phenomena, in Barad's theory, refers to "differential patterns of mattering ('diffraction patterns') produced through complex agential intra-actions of multiple material- 
discursive practices or apparatuses of bodily production, where apparatuses are not mere observing instruments but boundary-drawing practices—specific material reconfigurings of the world - which come to matter" (140). Agency, from this view, is not a quality or capacity of humans nor things but an effect of the world's entanglement: "The universe is agential intra-activity in its becoming" (141). Throughout this dissertation, I consider the WNA both as an apparatus, in that its performatively materializes what Hekman would refer to as a particular disclosures of LGBTQ history, and as a queer rhetorical phenomenon - in Barad's sense - emerging from the entanglement of a wide array of "actors"-both human and nonhuman.

To develop this approach, I also extend new materialist thinking as it has been taken up within our discipline. An early articulation is object-oriented rhetoric, which calls into question the subject/object divide, distributes agency across human and nonhuman actors, and tries to dismantle language as the primary concern of humanistic study as a way of returning to questions of materiality. The term was proposed by Scot Barnett in a review of Graham Harman's Tool-Being, ${ }^{4}$ where Barnett argues that an attention to

\footnotetext{
${ }^{4}$ Object-Oriented Ontology/Philosophy, is one paradigm of new materialist thought that I do not take up in this dissertation and therefore gloss here for conceptual clarity and continuity. For interested readers: This perspective was first proposed by Graham Harman, who argues for a notion of object-oriented philosophy that is capable of accounting for the inhuman (49). Drawing on Harman's work, Ian Bogost coins the term object-oriented ontology, writing that "If ontology is the philosophical study of existence, then from Harman we can derive an object-oriented ontology ... contending that nothing has special status, but that everything exists equally (6). Synthesizing these two approaches, we can say that OOO generally is interested in shifting the traditional humanistic focus on people and language toward a non-human focus on the ontology of objects. OOP/OOO has been criticized as discounting humans, a response almost beckoned by Harman's claim that "we are finally in a position to oppose the long dictatorship of human beings in philosophy" (2). One mode of critique, however, has been transformative reclamation, as demonstrated in a recent edited collection entitled Object-Oriented Feminism (OOF). In her introduction to the volume, Katherine Behar writes that OOF seeks to critically leverage OOP/OOO "while twisting it toward more agential, political, embodied terrain" as a way to "provide a welcome respite from theories of subjecthood that many feminist philosophers point out are fundamentally dependent on the logic of phallocentrism." Further, as Behar goes on to suggest, the turn toward objects and materiality can help reinscribe a sense of
} 
the "missing masses"-Latour's term for the masses of non-human actors left unconsidered by humanism—can help to develop more robust theories of rhetoric and writing and to "re/consider the very nature of rhetoric itself." Nathaniel Rivers pushes this concept further, arguing that an attention to objects "demonstrates just to what extent our communities — our publics — are actively shaped by not only humans but also by a plethora of nonhumans," going on to state that "focusing on human political will, as public rhetoric analyses often do, is not enough." These perspectives are provocative and important, but I ultimately rely more heavily on feminist new-materialisms throughout this dissertation, as they more heavily foreground the intra-action between phenomena marked as human and non-human and attend to the differential emergence of bodieshuman and nonhuman — to a greater degree.

The most significant rhetorical scholarship on the relationships between new materialism and rhetoric has been presented in two monographs: Thomas Rickert's Ambient Rhetoric: The Attunements of Rhetorical Being and Laurie Gries's Still Life with Rhetoric: A New Materialist Approach for Visual Rhetorics. Rickert offers ambience as a way to consider rhetoric and materiality, re-reading Heidegger to argue that technological shifts increasingly illuminate that

Rhetoric can no longer remain centered on its theoretical commonplaces, such as rhetor/subject, audience, language, image, technique, situation, and the appeals accomplishing persuasive work, at least as they are predominantly understood and

the "real world" to feminist thought, which has been accused of becoming overly mired in the linguistic realm $(3,5)$. 
deployed. Rather it must diffuse outward to include the material environment, things (including the technological), our own embodiment, and a complex understanding of ecological relationality as participating in rhetorical practices and their theorization.... [A]mbience here refers to the active role that the material and informational environment takes in human development, dwelling, and culture, or to put this differently, it dissolves the separation between what is (privileged) human doing and what is passively material." (3)

Ambience, then, draws attention the inseparability of rhetoric and rhetorical subjects from their non-symbolic surround. From this perspective Rickert theorizes a kairotic attunement to the world's becoming, "understood not as a subjective state of mind or willed comportment but as an ambient catalysis within what is most material and concrete, a gathering that springs" (98). I welcome Rickert's call to consider materiality, especially his conception of attunement, which I draw on in later chapters. However, his Heideggerian orientation ultimately does not fit neatly with the queer-feminist-materialist perspective I extend and develop, and his near complete omission of queer and feminist materialisms in and outside our field render Ambient Rhetoric, as a whole, rather unrelated to the project I undertake here. Furthermore, Peter Simonson has noted that Rickert "indirectly continues the long early-modern tradition of conceiving invention as creation or starting point that favors the original or the new" (311). The materialistfeminist perspective I take, already discussed, does not foreground beginnings but rather consequences, entanglements, and emergences.

Gries, by contrast, has offered a new materialist approach to rhetoric that explicitly centers these phenomena. Due to rhetoric's historically defined focus on the 
intentionality of (typically singular) rhetors, as well as the discipline's underdeveloped attention to futurity (47), Gries argues for a consequentialist orientation, arguing that "The meaning of matter is constituted by the consequences that emerge with time and space via its relations with other entities.... Turning to futurity, a new materialist rhetorical approach focuses most attention on the consequences that emerge once matter is initially produced, has been perceived as relatively stable, and enters into circulation" (86). Whereas Rickert examines that which exists prior to symbolicity, Gries extends the work of Barad to (1) indicate the fundamental inseparability of meaning and matter, and (2) examine the future-oriented consequentiality of the entanglements produced by material circulation. This leads to a reconceptualized notion of rhetoric-as-emergence, where

all things have the power to become rhetorical as they crystallize, circulate, enter into relations, and generate material consequences, whether those consequences unfold in conceptual or physical realms. Rhetoric here, then, is conceived of as a virtual-actual event that unfolds with time and space as things - whether they be images, pictures, books, movies, rocks, trees, or animals — enter into material relations with humans, technologies, or other entities. (11)

As I discuss at the end of this chapter, this emergent, materialist perspective on rhetoric guides my thinking throughout this dissertation.

Apart from these two monographs, there has also been a recent edited collection titled Thinking with Bruno Latour in Rhetoric and Composition as well as a number of articles taking up a new materialist orientation. In their introduction to the former, Paul Lynch and Rivers argue that engaging Latour offers a way of returning nonhumans to the 
"social drama" described by Richard Lanham as the purview of rhetoric (3). Clay Spinuzzi, in his chapter within the collection, argues that the "symmetry" Latour proposes - that is, a symmetrical consideration of both humans and non-humans-need not be set against humanist projects but rather can be used methodologically, "let[ting] us get at different phenomena that we normally might not consider" (32). In Rhetoric Society Quarterly, Simonson attempts to redefine invention as "the generation of rhetorical materials," offering the term inventional media "to refer to the habits, artistic materials, and communicative modes through which rhetorical generation occurs" (300). This revised definition, he suggests - and I quote directly because the language he employs parallels and helps to demonstrate my thinking regarding the WNA—describes generation occurring at multiple levels: "through finding, creating, assembling, translating, recombining, channeling, or giving form to. Rhetorical materials are then the symbolic or physical elements that enter into or are gathered for the purpose of communicative address" (313). Ehren Pflugfelder, in another Rhetoric Society Quarterly article, argues that a materialist, micro-rhetorical approach to persuasions taking place between things themselves can provide a way around debates regarding big versus small rhetoric and help the field avoid casting rhetoric in purely humanistic or symbolic terms. Considering rhetoric as "closer to an ambient force that exists within material and symbolic ecologies where rhetoric is neither solely created by nor only important to humans" (449), the author claims that the concept of hyle, a term that suggests "the coordinating influences of humans and nonhumans together" (452), can help to consider both networks of materials and materiality itself, allowing rhetoricians to "stud[y] 
complex material conditions [and] identify how different materials exert influence each other [sic] within larger networks of rhetorical force" (458).

I close with a brief consideration of a final text that helps frame my approach to the relationship between curation and rhetoric: Kennedy's Textual Curation Authorship, Agency, and Technology in Wikipedia and Chambers's Cyclopaedia. The reason for the import of this text is that it, at the same time, astutely renders the notion of curation with which I approach this project but also occasionally relies on questionable assumptions about the differences between digital and print "archives"-in Kennedy's discussion, encyclopedias - that illuminate the need to consider the physical archive anew. Regarding curation, Kennedy takes a Latourian approach, arguing that "the labor of authorship is accomplished not by just the usual suspects denoted by the authorial signature and the publisher's imprint, but a broader collective of humans and nonhumans who perform the work of composing an encyclopedia" (3). In other words, curation involves a network of human and non-human actors and, as she goes on to claim, the processes that such networks engage is compositional and, thus, rhetorical (7). However, she frames digital curation as a paradigmatic shift, "mak[ing] it possible for the collaborative labor of distributed authorship to be negotiated in asynchronous environments without central oversight" (11). Without being pedantic—-there are certainly differences between digital and print technologies—The Emergent Matter of Archives will attempt to excavate the ways that distributed curatorial rhetoric operates in the formation of the WNA, the ways that "central oversight" might be challenged or negotiated by a queer archive in institutional space, and the ways that this sort of 
analysis - without minimizing the queer ontology of the WNA — might be informative to archival work in the field more broadly.

\section{Disclosures, Ethics, and Methodology}

Before embarking on the project I have promised to perform, I want to discuss how the theories and perspectives I have contoured inform my work in a methodological sense. The question of methodology is vexing, since both queer theory/rhetoric and new materialism argue for skepticism in regards to the often normative practices embedded in "rigorous" methodological analysis. Further, both orientations ask readers to adopt perspectives that radically complexify the doing of scholarship, which is always a process of transformative mediation. In Life After New Media: Mediation as a Vital Process, Sarah Kember and Joanna Zylinska offer a Baradian-inspired reorientation of media studies, a “'theory of life,' whereby mediation becomes a key trope for understanding and articulating our being in, and becoming with, the technological world, our emergence and ways of intra-acting with it, as well as the acts and processes of temporarily stabilizing the world into media, agents, relations, and networks" (xv, emphasis in original). Their commentary on temporary stabilization refers readers to a crucial question that has yet to be fully dealt with: by what methods can a new materialist analysis — so dependent upon the emergent processuality and fuzzy boundaries of the world's becoming — be enacted? The seeming obviousness that the world does not only exist in language dissipates the moment one attempts to capture that simple fact in writing.

There have been a wide array of implicit and explicit articulations of new materialist methods and methodologies responding to this challenge. Latour's Actor- 
Network Theory offers a ruthlessly descriptive practice of human and non-human actors, seeking traces of controversies and transformations that reveal processes of reassembling the world (Reassembling). Gries provides Iconographic Tracking, which "draws on traditional qualitative and quantitative research strategies to (a) follow the multiple transformations an image undergoes during circulation and (b) identify the complex consequentiality that emerges from its divergent, collective encounters" (290). Dolphijn and van der Tuin's transversal perspective on new materialism creates friction with the very question of methodology, since "Bringing new materialism (here assumed to be a pre-existing body of work) into contact with a scholarly discipline (equally assumed to be pre-existing) has distortive effects" (103).

Kember and Zylinska's own response to the problem balances these competing movements toward rigid methodology or nomadic thinking. Extending Barad's agential realism, they theorize the "cut" as a creative intervention in the world's becoming. The "cut" exists as "any ... technical practice that involves transforming matter" and is enacted as "both a technique (an ontological entity encapsulating something that is, or something that is taking place) and an ethical imperative (as expressed by the command: 'Cut!')." Most importantly, however, the cuts required to make particular disclosures - to borrow Hekman's term—intelligible always implicate ethics. As Kember and Zylinska explain, " $a$ good cut is an ethical cut, whereby an in-cision is also a de-cision. Cutting well therefore means cutting (film, tape, reality) in a way that does not lose sight of the horizon of duration or foreclose on the creative possibility of life enabled by this horizon" (82). In other words, Kember and Zylinska admit the impossibility of avoiding incisive decisions in the doing of analysi, though they explicitly state that these decisions should 
not be understood as carried out by sovereign human "agents" (82). Rather, we should attempt to engage in "cuts" that — to the best of our and their ability—do not foreclose on the ongoing transformation of the world. Or, as Barad puts it: "Meeting each moment, being alive to the possibilities of becoming, is an ethical call, an invitation that is written into the very matter of all being and becoming" (Meeting 396). This perspective casts light on at least three methodological aspects of this dissertation: my inability to "capture" the WNA in its totality, and the cuts therefore made in and by my analysis; my own methods in studying the materials entangled by and in those cuts; and an ethical responsibility to the queerness of the archive, the queer lives entangled in and with the archive, and the related question of my own positionality as a cisgender, heterosexual individual researching a queer archive.

I want to declare from the outset that this dissertation does not purport to represent the archive in its totality. In fact, it does not take such a representation to be its end goal. Rather, each chapter considers how a particular set of phenomena emerging with and from the WNA performs queer rhetoric, rather than simply represents it. This leads to a seemingly paradoxical methodological decision. Rather than focus primarily on the materials collected "in" the archive, I draw my most incisive claims from considering how the archive is constitutively and rhetorically entangled with the world that, at least based on seemingly common sense, exists "outside" it. In brief, my "cuts" resist the urge to take the WNA for granted as a collection of linguistic documents physically contained at the University of Louisville's Archives and Special Collections, asking what else might be swept up in its rhetorical becoming. 
This question beckons multiple modes of analysis. I do engage more traditional forms of archival research because, as already mentioned above, Williams presciently collected materials about the history of the archive. However, I also carried out a number of semi-structured oral history interviews with Williams, as well as with key staff of Archives and Special Collections. This decision is informed by Cvetkovich's work, who notes that because "gay and lesbian as well as activist history have ephemeral, unorthodox, and frequently suppressed archives ... oral history can be a crucial tool for the preservation of history through memory" (Archive of Feelings 166). She dissuades readers from a positivist approach, however, since oral history "is a complex tool, sometimes revealing these issues only through gaps and silences within interviews and conflicts between them" (204). Throughout this dissertation, I draw on a set of oral history interviews that — while limited in scope —are illuminating when considered in their intra-action with the archival research I engage. In approaching these interviews, I am informed by Nan Alamilia Boyd and Horacio N. Roque Ramirez's conception of queer oral history as a "leap of faith" where "the self-understood and often unspoken validation of narrators' subjective perspective does not entail taking every recorded declaration as factual truth, [but] it does require that researchers commit to listening carefully for what narrators' recollections reveal about their time and place in history" (16). With this in mind, I consider these oral histories not as positivist recountings but as particular disclosures of the archive that matter - a perspective that heightens my commitment to respecting their voices.

Finally, I must also account for the fact that this dissertation is, itself, a particular disclosure of the archive, a recognition fraught with ethical heft, not least so due to my 
own positionality in relationship to this project as a cisgender and heterosexual individual. In Linda Alcoff's terms, it is crucial to address the problem of speaking for others. Alcoff notes the dangers of speaking for others, especially from a more privileged location (7). On the other hand, to simply retreat from the other "assumes that one can retreat into one's discrete location and make claims entirely and singularly based on that location that do not range over others, that one can disentangle oneself from the implicating networks between one's discursive practices and others locations, situations, and practices" (20). LuMing Mao, in our field, responds to this problem by contouring an "art of recontextualization," which urges researchers to consider the intersections between our own knowledges and those of others; to artfully recontextualize these knowledges while at the same time avoiding either their assimilation into researchers' perspectives or an approach that reduces others to their difference; and maintaining accountability to "resisting methods and logic to silence or make invisible the same other" (48). In my own disclosure of the archive, then, I make a point to center the queerness of the archive through reparative readings that provide new perspectives on the ameliorative practices of queer archival activism, resisting at every moment the possibility of reifying narratives of passive victimization in my analysis.

Critical readers may ask how this project fits within the domain of rhetorical studies, and also why I have chosen queerness as a guiding frame in a dissertation that does not take performances of gender and/or sexuality from singular bodies as its primary subject. To the first question, I answer that my work here is deeply rhetorical, drawing on not only Gries's definition of rhetoric as an emergent, entangled becoming but also extending a multitude of concerns regarding how we understand the relationship between 
rhetoric and its surround that have existed at least since Lloyd Bitzer's theorization of the rhetorical situation. I take queer theory/rhetoric as a guiding perspective because my work is interested in how queerness challenges normativity in ways that cannot be reduced to sovereign, human bodies. While the WNA performs queer rhetoric in ways that at times may seem small or localized, to dismiss these performances would be to enact a normativizing impulse demanding that queer rhetoric be recognized upon predetermined lines of emergence. Muñoz writes that "Shouting down utopia is an easy move" (Cruising). I ask readers to resist that move for as long as possible, and to explore what the disclosure enacted by this dissertation might offer their understandings about queer rhetoric, queer archives, and the relationships between these phenomena and the world. 
CHAPTER II

\section{MAKING THE WORLD THROUGH SILENCE: \\ DISIDENTIFICATIONS IN A QUEER ARCHIVE}

"[A] disciplinarily diverse body of scholarship makes clear that queer and feminist histories have long necessitated speculative and even imaginative practices" (VanHaitsma, “Gossip” 135).

"From a new materialist perspective, things become rhetorically meaningful via the consequentiality they spark in the world" (Gries 3).

"[W]hile we may not find unmediated history in the archives, we will find rhetoric" (Bessette, Retroactivism In the Lesbian Archive: Composing Pasts and Futures 60).

\section{$\underline{\text { Introduction }}$}

When Donald Trump was inaugurated as President of the United States on January 20, 2016, a controversy emerged that gained a relatively small amount of attention as compared to the various racist, misogynist, and viscerally oppressive acts committed by Trump and his administration. Specifically, references to LGBTQ lives and identities (as well as to climate change) were omitted during the content migration from the Obama-era Whitehouse.gov page to Trump's. These elisions show the ways that archives - so often treated as static, stable, and inert - are in fact dynamic, circulating entities, a phenomenon that is as true of physical archives as it is for digital ones, albeit in 
materially and technologically different ways. As a cisgender and heterosexual individual who aims to enact queer allyship and —not least so—as a citizen, I found the idea that this information could be so easily scrubbed from an important public record to be frightening. Thinking through this and other crises of public record, I find myself returning to the 2006 forum of Rhetoric and Public Affairs, in which Morris notes that despite the primacy of the archive for doing rhetorical scholarship, "the archive itself . . . has yet to be subjected to sustained critical-rhetorical reflection by scholars in this discipline" ("Archival Turn" 113). Similarly, in the same forum, Biesecker noted the possibility of treating the archive not as a simple repository but as a "scene of invention" (124). In a precarious time for LGBTQ populations, it is absolutely critical to consider the rhetoricity and materiality of queer archives, a project carried out by scholars such as Alexander, Bessette, K. J. Rawson, Rhodes, and Morris, whose work provides the ground on which this chapter—and, more broadly, this dissertation—stands.

Of course, there has been much scholarship since the Rhetoric and Public Affairs forum that has attended to issues such as archival methods/methodologies (L'Eplattenier; Ramsey et al.; Royster and Kirsch; Clary-Lemon), activist archives (Parks), and— indeed—queer archives (Alexander and Rhodes; Morris and Rawson; Rawson, “Accessing Transgender"; Rawson, "Rhetorical Power"). This chapter builds on and extends these scholars' necessary contributions to foreground the material and rhetorical formations of queer archives. Focusing on the early days and archival practices of Gays and Lesbians United for Equality (GLUE) — an LGBTQ (or, to be more accurate to the parlance of the region at the time, lesbian and gay) organization active in Louisville from the early-1980s to the early-1990s - I weave rhetoric's "archival turn" with queer theory 
and new materialist approaches to circulation. As will become evident, the ability for an archive to circulate - and the correlated phenomenon of GLUE's public-ness, was a key factor in GLUE's rhetorical and material decisions about when, and when not, to archive its own histories. Further, GLUE's archive becomes especially poignant considering it would continue to move, grow, and would eventually circulate to the University of Louisville's Archives and Special Collections to become the WNA, one of the most valued collections held by the University. Looking at the early days of the archive, I contend, calls both the rhetoricity and the materiality of its formation into view.

Throughout this chapter, I argue three points that extend attempts to move away from understandings of archives as a location to discover rhetoric and toward a dynamic understanding of the rhetoricity of archives themselves. First, drawing on the work of Morris and Biesecker, I assert that an archive is rhetoric, not simply rhetoric's container. Archives, by way of their deep materialities, are entangled with and among humans in the emergence of knowledge and thwart a purely discursive approach to rhetorical inquiry. Second, an archive is an ongoing practice, a performance, rather than just a representation or a collection of representations of the past. This insight can be gleaned from queer scholarship, with scholars such as Sedgwick and Muñoz (Cruising) having insisted that queerness - and knowledge more generally — can be a reparative and even utopian performance. Similarly, though less optimistically, Lauren Berlant and Warner note that "Heterosexuality involves so many practices that are not sex that a world in which this hegemonic cluster would not be dominant is, at this point, unimaginable." In response, they theorize practices of queer world making to bring such "unimaginable" worlds to life (558). Reading these queer theoretical insights through Barad's new 
materialist orientation, from which Barad claims that "the world is a dynamic process of intra-activity in the ongoing reconfiguring of locally determinate causal structures with determinate boundaries, properties, meanings, and patterns of marks on bodies" ("Posthuman" 817), can help foreground the materiality of an archive against approaches that have tended to emphasize the discursivity and the a priori status of archives. Rather, an archive emerges through mutually transforming, material intra-actions of phenomena whose boundaries, themselves, are indeterminate and subject to negotiation, a concept that Gries embeds into her definition of rhetoric itself, which emphasizes rhetoric as a form of becoming able to induce change in thought, feeling, and action; organize and maintain collective formation; exert power, etc.; as it enters into relations with other things" (11). Third, archives circulate, both in their literal movement as well as in seemingly virtual but no less material activities of recomposing and circulating their meaning. In Jane Bennett's terms, then, archives are not static but exist as rhetorical vibrant matter whose boundaries and consequences are drawn and redrawn as they intraact with the world surrounding them.

In this chapter, I engage archival research and semi-structured oral history interviews to argue that GLUE performed complicated strategies of silence-asdisidentification with largely bureaucratic genres as well as with normative conceptions of politics. To do so, I invoke Muñoz's conception of disidentification as “a strategy that tries to transform a cultural logic from within" (Disidentifications 11). For Muñoz, disidentification sidesteps deadlocks between local resistance and structural change, instead framing the performance of potentially normative identities with a difference as a transformative and critical practice. I contend that these strategies emerge in response to a 
complex attunement ${ }^{5}$ to GLUE's emergent, historically circulating archival rhetoric. As I will show, decisions not only about how but when to archive GLUE's histories were by no means simple, and these decisions reflect an awareness of the uncertainties of future becomings. By largely focusing on GLUE's queer performances of the seemingly bureaucratic genre of meeting minutes, moreover, I seek to show the ways that the at times rather abstract phenomena articulated in both queer theory and new materialist philosophy are enacted at the level of such a seemingly mundane rhetorical form. In showing the ways that the meeting minutes - as not just discursive but fundamentally material artifacts - became entangled with GLUE's queer politics, I engage a "deflated" reading (Latour, "Visualisation and Cognition: Drawing Things Together"; Gitelman, Paper Knowledge) that attempts to operationalize theoretical work in the service of understanding the material rhetoric of GLUE's archive, rather than the other way around.

\section{Gays and Lesbians United for Equality}

Gays and Lesbians United for Equality (GLUE) was set in motion by a particular injustice done to Sam Dorr, a Louisville resident and manager at First National Bank. Dorr was a member of Integrity (later Dignity/Integrity), a gay advocacy group associated with the Episcopalian Church. In 1981, he was elected President of Dignity and, wishing for transparency with his employer, officially "came out" and explained his position within the advocacy organization. On November 20, 1981, Dorr was given an

\footnotetext{
${ }^{5}$ To remind readers, Rickert theorizes "attunement" as a condition that responds to the fundamental inseparability of humans and the ambient, worldly environment with which they intra-act. Rickert writes: "ambience involves more than just the whole person, as it were: ambience is inseparable from the person in the environment that gives rise to ambience. There is no person who can then be tacked onto the environment. Attunement is not additive. Rather there is a fundamental entanglement, with the individuation of particular facets being an achieved disclosure" (8).
} 
ultimatum to either remain closeted and resign from Dignity or be fired. Dorr resigned and began a lengthy law suit that eventually led to settling out of court. This, alongside the arson of Harlow's, a local gay bar, led Dorr and other lesbian and gay Louisvillians to form GLUE in 1982 (Fosl et al.).

A brochure for GLUE explains its purpose and its scope, which included, among other things, being "an umbrella organization with local social, religious, professional, and political groups ... [,] provid[ing] a forum for discussion of issues of importance to its members ... [,] striv[ing] to bring unity to the gay and lesbian community in Kentuckiana ... [,] maintain[ing] public relations liaisons with local news media ... [, and] serv[ing] as a contact source for community leaders and politicians" (GLUE, Brochure). In a sense, GLUE can be understood in terms of what sociologists John D. McCarthy and Mayer N. Zald refer to as a social movement organization, "a complex, or formal, organization which identifies its goals with the preferences of a social movement or a countermovement and attempts to implement those goals" (1218). David A. Snow and Robert D. Benford note, from a sociological perspective, what we might refer to as the rhetoricity of such organizations, claiming that social movement organizations become "actively engaged in the production and maintenance of meaning for constituents, antagonists, and bystanders or observers" (136). GLUE's practices (not least so its archive) contributed to the production of such meaningful engagements.

However, there is a sense in which GLUE thwarts the definitions of a social movement organization as defined in sociology due to its official and controversial aversion to "politics." Indeed, from its earliest meetings GLUE fashioned itself as an apolitical endeavor. A brief, illustrative example: an early copy of its meeting minutes 
states that "We read the GALANT [another lesbian and gay organization] constitution and articles of incorporation. Suggestion was made that we change 'political' to 'educational,' so we can establish a non-profit status. The wording of a constitution and articles of incorporation will be altered to fit our needs. We intend to incorporate" (GLU, ${ }^{6}$ Meeting minutes, 15 Aug. 1982). GLUE's entanglement among and across larger institutions and apparatuses, and the potential for the uncontrollable circulation of its archive (largely, at the time, comprised by its meeting minutes), led to an inability to engage in more public political activity. Some may see this as disqualifying GLUE as a social movement organization. Rather than focus on longstanding debates about what does and does not constitute a social movement or social movement organization, however, I take David Zarefsky's point that it is more useful to study the types of rhetoric emerging from and with a movement or organization than it is to contour the theoretical interventions about what does and does not constitute such a collective. Muñoz's conception of disidentification (discussed in detail below) is useful to consider how GLUE's rhetorical, material, and archival strategies reflect a transformation of, rather than a flight from, politics.

\section{Why GLUE?}

While queer theory and rhetoric have certainly been taken up in the discipline, Morris and Rawson have pointed out that the "queer turn" has been slowly enacted (74). Indeed, I have found relatively scant attention to Louisville's queer/LGBT life in

\footnotetext{
${ }^{6}$ These minutes were taken before "for Equality" was added to GLUE's title, hence the slightly different acronym.
} 
published research, and have yet to find scholarship that centers on GLUE. Historian D. Williams, for example, reads GLUE as a stepping stone to the Greater Louisville Human Rights Coalition (GLHRC), juxtaposing GLUE—which "was never meant to be a political organization"-against a lesbian-feminist desire for "political representation" (236). Similarly, historians Catherine Fosl and Lara Kelland omit GLUE entirely in their article "Bring Your Whole Self to the Work: Identity and Intersectional Politics in the Louisville LGBTQ Movement," a choice that also foregrounds the more public and visibly political work of GLHRC.

There are understandable reasons for the seeming dearth of scholarship on GLUE. GLHRC's activity of lobbying for (and eventually winning) an anti-discrimination ordinance is far more recognizable as politics, at least by more traditional definitions of the term. There were also certain aspects of GLUE that verged on what has been termed "homonormativity," a stance that Duggan defines as "a politics that does not contest dominant heteronormative assumptions and institutions, but upholds and sustains them, while promising the possibility of a demobilized gay constituency and a privatized, depoliticized gay culture anchored in domesticity and consumption" (Twilight 50). GLUE seems to have been largely white (though a member organization dedicated to the intersectionality of interracial gay relationships eventually emerged) and its ability to purchase a building in the late 1980s in order to found a center for lesbian and gay life in Louisville speaks to the class privilege of many of its members. These realities, among others, contributed to an occasional conservatism, at least in the histories described in the minutes, at the same time that GLUE was challenging heterosexism in the Louisville community through practices of queer world making. These complexities speak to 
Bessette's claim that queerness and normativity are indeterminate and dynamically rhetorical, dependent upon audience and context ("Queer Rhetoric").

Still, there are important warrants for my focus on GLUE in this chapter. First, GLUE and the archive that would eventually become the WNA share more or less the same exigence: GLUE was initiated by Sam Dorr to form a coalition of lesbian and gay rights organizations working to foster a safer and more welcoming environment for Louisville's lesbian and gay community, and what was referred to initially as "The Archives" was a project enacted by Louisville activist and DIY archivist/curator Williams to contribute to GLUE's efforts, as is evinced by The Archives's status as an official member organization of GLUE. As Williams explained to me: "I thought 'What can my contribution be personally to GLUE?' And it was natural to think of starting up an archive.... So November 19th, 1982, is when the archives were formally accepted as a member organization of GLUE" (Williams, Personal interview. 9 Feb. 2018). In a follow up interview, Williams explicated this further, discussing how activism - in his case, largely, the archive - transformed his own self-perception as a gay man in Louisville:

This was a new thing for me. Before that my entire gay life had centered around the bars, so I thought well this is good. Of course I kept up with gay national news through The Advocate. I had a subscription to The Advocate and, but you could also buy The Advocate at the dirty bookstores - adult bookstores. So I knew what was going on outside of Louisville, and [I'd] read something about San Francisco and say "Oh that's interesting," but never really thought that Louisville would be doing anything like that until the early 80s. (Williams, Personal interview. 21 
Mar. 2018)

Becoming entangled with GLUE, then, helped to transform Williams's identity from a relatively apolitical social life to a deep involvement in LGBTQ — or, more accurate to the time and region, lesbian and gay—coalition building. And, of course, Williams transformed GLUE, not only due to his involvement but also because of his role in the collection, curation, preservation, and circulation of its history.

When I went on to ask about Williams's decision to choose forming an archive as his contribution to GLUE, he explained:

Initially it started out as just an archive for Louisville back in 1982. 1982 was when there were things starting up in Louisville. That's when we were finally getting organized as a community and getting into activism and all that. A lot of flyers and meetings minutes and other things were floating around and, me being a natural packrat I thought well, you know, we need to start saving some of this because nobody else will and it's going to get lost. (Williams, Personal interview. 9 Feb. 2018)

The founding of both GLUE and the archive, then, emerged as activist responses to pressing material exigencies of not only discrimination and hate (though certainly that) but also the preservation of (counter)public memory, reflecting Steve Parks's assertion that "the slow methodological collection of testimony, texts, recordings, and visual artifacts [can] evidence[] an alternative moral universe, an alternative framework from which to shape a public and political agenda."

While Parks's work is productive and necessary, I worry that an appeal to activist archives being methodical or necessarily shaping public and political agendas may be 
used to authorize more visibly political archives and histories at the expense of more localized, fragmented, or unruly archival and historiographic undertakings, a disposition that likely has something to do with GLUE's lack of representation in scholarship. GLHRC was visibly and successfully engaged in the public work of politics, and its effect on queer life in Kentucky cannot be overstated. Still, it arguably took a relatively normative route to engaging these victories: testifying to public officials as mode of enacting legislative change. Such appeals to the State may diverge somewhat from a rigid reading of Jonathan Alexander and Jacqueline Rhodes's point that queer rhetoric carries out "a networking of . . . identifications to disrupt and re-route the flows of power." I highlight this not to critique a particular strategy, but rather to indicate differences between GLHRC and GLUE: despite certain strands of normativity woven throughout GLUE, their archive enacts alternate forms of queer world making, and these forms reveal themselves as especially salient through an examination of GLUE's rhetorical decisions of when, and when not, to archive their own histories.

Queer world making is deeply and, of course, queerly political in that it provides alternative modes of shaping and reshaping the world. As Berlant and Warner define the phrase, queer world making:

[D]iffers from community or group because it necessarily includes more people than can be identified, more spaces than can be mapped beyond a few reference points, modes of feeling that can be learned rather than experienced as a birthright. The queer world is a space of entrances, exits, unsystematized lines of acquaintance, projected horizons, typifying examples, alternate routes, blockages, incommensurate geographies. World making, as much in the mode of dirty talk as 
of print-mediated representation, is dispersed through incommensurate registers, by definition unrealizable as community or identity. (558)

The production of GLUE's archive was such a practice of queer world making, in that it historiographically registered the organization for indefinite audiences, not only speculating on but helping to create the conditions for queer futures. In its formation of the archive, furthermore, GLUE was attuned to the uncertain, future-oriented possibilities of the circulation of their archival record, and the dangers thereof.

\section{Queer Rhetoric, Silence, and Disidentification}

In taking the position that GLUE's archive is queer rhetoric (not simply rhetoric's container), I extend, with a modicum of friction, Alexander and Rhodes's highlyinfluential definition of queer rhetoric as "self-conscious and critical engagement with normative discourses of sexuality in the public sphere that exposes their naturalization and torques them to create different or counter-discourses, giving voice and agency to multiple and complex sexual experiences." While certainly engaging normativity and producing counter-discourses, GLUE's queer rhetoric can be read as neither wholly selfconscious nor-due to its circulation-fully exercised in its own spatial and temporal public. As I will discuss, the organization was aware of the phenomenon described throughout Foucault's oeuvre and later by Peggy Phelan —-[v]isibility is a trap" (6)—and GLUE was attuned to its uncertain potential for visibility.

Despite these small deviations from Alexander and Rhodes's oft-cited (and productive) definition of queer rhetoric, my analysis of the formation of GLUE's archive responds to and extends their important provocation:

how does one queer rhetorical practice to make room for alternative voices, 
alternative modalities of being, and divergent approaches to pressing debates and social issues... [R]hetorical acts, developed through interventions such as disidentification, emerge collectively over time to queer how the public sphere argues, considers issues, and/or debates the polis.

The exigencies of uncertain circulation lead GLUE to actively disidentify with normative conceptions of political activity, contesting and renegotiating what counts as political activity. And while these exigencies were entangled with normative and homophobic pressures, we can read the organization's archival record as a rhetoric of queer world making strategically composed to anticipate an emergent rhetoric where "all things have the power to become rhetorical as they crystallize, circulate, enter into relations, and generate material consequences" (Gries 11). Within this emergent rhetoric, silence paradoxically becomes a viable queer rhetorical strategy.

Erasure, a form of silence or, more accurately, being silenced, is a trope that permeates queer and feminist theory and that is especially pertinent to queer archives, due to the real, material injustices of LGBTQ histories' exclusions from normative archival records (Cvetkovich, Archive of Feelings 8; Rubin 89). In response, Halberstam has declared a need for "scavenger methodology" that "uses different methods to collect and produce information on subjects who have been deliberately or accidentally excluded from traditional studies of human behavior" (qtd. in Bessette, Retroactivism 5). And Bessette has recently extended this perspective to argue that "the archival process has wielded its power ... through omission of documents that would make queer lives and activity enunciable," leading to the emergence of lesbian grassroots historiography 
(Retroactivism 64). ${ }^{7}$ These authors are correct that queer archives—grassroots or otherwise - materially enact a necessary rejoinder to the historical oppressions of being silenced, but they leave little room for considering reparative practices of silence. As Glenn has argued, particular silences can also be a kairotic rhetorical strategy, leading her to claim that "The question is not whether speech or silence is better, more effective, more appropriate. Instead, the question is whether our use of silence is our choice (whether conscious or unconscious) or that of someone else" (18). While my commitments to both queer theory and new materialism trouble some of Glenn's underlying assumptions regarding the individuation of rhetorical subjects and the nature of "choice," her conceptualization of silence as a productive and not necessarily imposed rhetorical feature is crucial to my thinking regarding the nature of queer archival formation in this chapter and across the dissertation. Furthermore, because of the minoritized status of non-normative sexualities where particular forms of visibility can incur social harm and literal acts of violence, historiographies of queer experiences must also take into account the ways that silence functions as a positive and necessary rhetorical strategy for practices of queer archival formation. Attuning to moments of silence within GLUE’s “official” practices of documentation, I argue, reveals complex, material, and entangled performances of rhetorical (dis)identification.

GLUE's internal, heated debates about the nature of LGBTQ politics—or lack thereof-were themselves entangled with larger, dominant conceptions of political

\footnotetext{
${ }^{7}$ Bessette also notes here that "systems of classification that organized [LGBTQ] materials around categories of pathology, crime, and immorality" also contribute to the "power" of the archive (64), echoing the Foucauldian critique of the repressive hypothesis.
} 
activity. Reading gaps in GLUE's fairly comprehensive record-keeping through these entanglements - between queerness and normativity, between GLUE's counterpublic space and larger dominant institutions - indicates the ways that silences, gaps, and erasures, so frequently exerted upon queer histories by normative institutional and archival practices, can also act as intentional and future-oriented queer-rhetorical strategies. These strategies reflect an attunement to the uncertainty of rhetoric. If rhetoric can be understood as "a distributed event that unfolds with time in and across networks of complex, dynamic relations. ...-a virtual-actual process of becoming in which rhetoric unfolds in unpredictable, divergent, and inconsistent ways" (Gries 32), then GLUE's practices of record keeping demonstrate an awareness of the uncertain becomings of archival rhetoric. In this context, particular archival silences function not as a lack but as a productive material performance contributing to the emergent rhetoric of GLUE's archive and, indeed, the WNA that exists today.

The performance of silence can act as a form of what Muñoz refers to as disidentification. He writes that disidentification describes "survival strategies" that disrupt "the phantasm of normative citizenship" (Disidentifications 4). Specifically, disidentification:

scrambles and reconstructs the encoded message of a cultural text in a fashion that both exposes the encoded message's universalizing and exclusionary machinations and recruits its workings to account for, include, and empower minority identities and identifications. Thus, disidentification is a step further than cracking open the code of the majority; it proceeds to use this code as raw material for representing a disempowered politics or positionality that has been 
rendered unthinkable by the dominant culture. (31)

Furthermore, Muñoz's critique of queer theory's so-called "antirelational turn" 8 highlights utopian and future-oriented contours of queer performance. Muñoz speaks of queerness as a possibility, a becoming, writing that it "is not yet here. Queerness is an ideality. ... Queerness is also a performative because it is not simply a being but a doing for and toward the future. Queerness is essentially about the rejection of a here and now and an insistence on potentiality or concrete possibility for another world" (Cruising 1). This conception of futurity rests neither on the anti-relational focus on queerness's negativity and potential for destroying normativity—which Muñoz acknowledges as a necessary contribution to queer theory but ultimately finds lacking — nor a retreat into an assimilated queer future. Instead, queerness — and I would also add both queer rhetoric and queer archives - is an emergent transformation of social life rather than either its rejection or uncritical acceptance, a "virtual-actual process of becoming in which rhetoric unfolds in unpredictable, divergent, and inconsistent ways" (Gries 289). It is within this paradigm, I contend, that GLUE is located as an imperfect queer organization anticipating uncertain futures.

\footnotetext{
${ }^{8}$ Leo Bersani and Lee Edelman have largely formed the locus of what has been termed the "antirelational turn" in queer thinking. Bersani avers that queer subjects have "learned to desire from within the heterosexual norms and gendered structures that we can no longer think of as natural, or as exhausting all the options for self-identification" (6), a notion that is put another way by Michael Warner's conception of homonormativity through which a de-radicalized lesbian and gay politics "threatens to become an instrument for the normalization of queer life" (80). Edelman, for his part, reads Bersani through Lacan to argue that notions of procreation and futurity thwart a presentist queer politics avant la lettre. In response, he provides a scathing critique of what he terms "reproductive futurism," which "impose[s] an ideological limit on political discourse as such, preserving in the process the absolute privilege of heteronormativity by rendering unthinkable, by casting outside the political domain, the possibility of a queer resistance to this organizing principle of communal relations" (2). These so-called antirelational theories highlight the dangers of queer politics becoming assimilated into normative heterosexist modes of thinking.
} 
From this stance, we can consider GLUE's archive as a form of retroactivism, a term employed by Bessette in the context of lesbian archives. Bessette uses the term to refer to how "rhetors have composed the past together in order to identify as women and as lesbians, often by positioning themselves against other definitions of women and lesbians" (Retroactivism 18). In other words, Bessette tracks the ways that the formation of an archive manifests particular practices of identification and, in Valerie Rohy's words, constructs the archival past as an inventional resource for queerness. GLUE, to be sure, was aware of the inventional potential of their archive, but knew that the rhetoric invented in and with their archive was not under their sovereign or autonomous control. In response, their archival rhetoric is marked by gaps, fissures, and silences. Again, these practices are worthy of consideration as rhetoric, not as rhetoric's absence.

\section{$\underline{\text { GLUE and Politics }}$}

The need to reckon with the material consequences of GLUE's inability to determine its own circulation was made manifest early in the organization's existence. In a letter dated June 21, 1983, the Department of Consumer Protection warned the president of GLUE, Jack Kersey, that

Jefferson County Ordinance No. 32, Series 1982, requires that every person engaged in the act of soliciting funds or money within the limits of Jefferson County for charitable purposes, to first obtain a permit from the Jefferson County Consumer Protection Department. ... Information received by this department indicates that you may be soliciting charitable contributions in violation of the above mentioned ordinance (Aker). 
The letter went on to state that charitable contributions must be immediately stopped until GLUE secured a Charitable Fund Raising Permit, for which the organization had five days to apply. While it is difficult and potentially impossible to track the exact ways that the Department of Consumer Protection was made aware of GLUE's activity, as well as whether the department was motivated by homophobic attitudes toward the organization, this letter likely served as a reminder that GLUE was materially situated within apparatuses not fully under its control, and that the potential for GLUE's rhetoric to circulate could also undercut its aspirations to transform queer life in Louisville through the development of coalitional connections.

However, because there is no authoritative voice for GLUE and because its history is mediated through the motivated recording of entangled practices, I am wary about broaching the question of intentionality, or assessing to what extent their disidentification with politics was an intentional rhetorical strategy rather than an actual wish to keep political opinions out of the space of GLUE. Reading GLUE's archive as enacting a performative, reparative rhetoric (see Chapter 1) that intra-acted with its context can help us to consider the organization as reworking and contesting the boundaries surrounding what counts as political activity rather than existing as a passive victim to normative forces. Furthermore, it is only though an understanding of GLUE's complex relationship to politics — whether or not they identified with the word — that one can understand its rhetoric of queer silence.

In general, GLUE's conception of political activity was largely framed within normative definitions of electoral politics. Put another way, GLUE consistently rejected the influences of electoral affiliations in order to claim an apolitical stance, a necessity 
that arose both from GLUE's desire to attain a non-profit status as well as the fact that non-profit organizations were already official members of GLUE, such as Louisville's Metropolitan Community Church (MCC). Concerns and conflicts regarding GLUE's relationship to political activity echo through their archival record in multitudinous ways, from gentle entries in meeting minutes ("It was agreed that the picnic [during the 1983 Gay Pride Week) should not be a political time, but a time for fun and fellowship" [GLUE, "Minutes," 20 Feb. 1983]) to the more outright disagreements about what constitutes efficacious organizing and social activity for the lesbian and gay populations in Louisville.

What is so striking about GLUE and its member organizations, however, is how overtly activist and indeed political they were while simultaneously declaring, both publicly and also in more "private" organizational correspondence and documentation, an apolitical stance. During its existence, GLUE and its members established an archive of lesbian and gay materials (what would later become the WNA); organized the first Gay and Lesbian Hotline in Kentucky; established a media watch committee and organized letters of protest upon learning of homophobic discourse in the media and even in schools; scripted, organized, directed, and produced a television show focused on lesbian and gay issues (titled "All Together Now"); bought a building and founded a community center for lesbian and gay life in Louisville (the "Comm-10 Center"); and corresponded with political officials regarding lesbian and gay issues.

Williams's archival activity was welcomed by the organization. Indeed, Williams maintains that there was little or no concern from the organization about leaving a record: “they weren't secret in that way. They weren't concerned that somebody would find out 
about this and destroy the group from outside, like some religious right nut or something" (Williams, Personal interview. 21 Mar. 2018). But the record itself does reveal anxieties regarding the preservation and especially the circulation of materials. As I've already suggested, these anxieties were most heightened in regards to the nature of GLUE as an organization and its commitment (or lack thereof) to political activity. For example, it took over a year to pass GLUE's Constitution and By-Laws due to conflicting identifications of the organization's purpose. Part of this was due to an uneasy balance between GLUE's goal to become a recognized non-profit and its desire to serve as an organization guided by and serving the interests of Louisville's lesbian and gay community. Disagreements along these lines led to an apparent disunity among the member organizations, for which a special meeting was called on August 9, 1983.

During this meeting, Dorr noted that GLUE could not live within the guidelines of the proposed documents, which "would be the set-up of another 'elitist' group." Elizabeth Stith, the representative of Women's Amalgamation (a member organization), agreed that the documents were too strictured (GLUE, "Minutes," 9 Aug 1983). A similar controversy was caused by Deney Priddy, who served as a particularly contentious president of GLUE, when he accidentally misrepresented the officers of GLUE as the "executive board" during a meeting: "This presented problems with many of the member representatives. Elise suggested that 'executive board' be defined. Elizabeth assured everyone that the officers were not an executive committee or board, but merely officers" (GLUE, "Minutes," 20 Oct. 1983). These brief anecdotes reflect an uneasy tension between the bureaucratic aspirations of the organization and its queerness, pointing to Doug McAdams's articulation of three difficulties faced by a social movement 
organization: oligarchization, cooptation, and the loss of support from key, internal constituents and stakeholders in a social movement (54). ${ }^{9}$ Not only were these challenges present throughout GLUE's history, but they also often provided exigence for decisions to silence or omit information from the archival record.

Though it is only occasionally mentioned directly, political activity was among the most significant points of friction between the members and organizations that comprised GLUE, for reasons discussed above. These tensions found their first breaking point in a decision to completely omit discussions of politics from GLUE's archival record (though this dictum was not followed religiously). In one set of meeting minutes, a conversation regarding homophobic comments by Kentucky Senator and former baseball player Jim Bunning was recorded (GLUE, "Minutes," 3 Oct. 1983), and there was talk about organizing a formal letter of protest. In the following meeting, however, there was concern about the fact that views regarding an elected politician had been recorded in the minutes and, "After much discussion, it was decided that the meetings will be temporarily closed during any political discussion and that these discussions would not be included in the minutes. All were in agreement."

It is worth pausing briefly to consider the complexity and deep rhetoricity of this seemingly simple decision. It reflects a fundamental awareness of the circulatory potential of GLUE's archive, pre-emptively demonstrating, in a sense, Jim Ridolfo and Dànielle Nicole DeVoss's conception of rhetorical velocity, a strategy where

\footnotetext{
${ }^{9}$ McAdams refers to the constituents and stakeholders as "indigenous support," a phrase I avoid here due to its multiple meanings and connotations.
} 
"rhetoricians ... balance the future possibilities in terms of possible positive, negative, and neutral outcomes for recomposing, remixing, and appropriation." If the members of GLUE did not have the foresight to understand the indeterminate future of their records, the inclusion or exclusion of particular material from the archive would be moot: records would only circulate among members. Rather, GLUE reflected an awareness that it was creating a counterpublic archive with the potential for a diverse and possibly hostile readership in its ability to circulate among a future archival public, though they certainly could not predict the potential reach of such circulation. As Warner explains, "the notion of a public enables a reflexivity in the circulation of texts among strangers who become, by virtue of their reflexively circulating discourse, a social entity" (Publics and Counterpublics 11-12). On the other hand, counterpublics are "defined by their tension with a larger public," forming and transforming members' identities through participation (57). Crucially, such practices reorienting the dynamics between public and private (62). GLUE's material considerations led to its addressing an at-that-time imagined public invented through the intra-acting entanglements between GLUE's material conditions, the apparatuses of federal agencies capable of granting and revoking organizational status, individual attitudes and political views, and (perhaps most so) the anxiety that GLUE's counterpublic discourse might be leaked into larger spheres of public circulation and be used against GLUE itself. From these exigencies, silence can be understood as a viable, material, and rhetorical act.

And yet, the weight of GLUE's disidentification with, and corresponding silence regarding, politics proved taxing to some GLUE members; and despite the decision to not record political opinions, politics still managed to find its way into the meeting minutes, 
typically written in such a manner as to indicate "concern" from the member organizations and to perform a disidentification between GLUE itself and whatever political matters were being discussed. For example:

There was some concern about GLUE being involved with PAC (Political Action Committee). Although GLUE as an organization will never be political, there is room for a committee or an organization which is represented in GLUE which is politically active. (GLUE, "Minutes," 17 Nov 1983; emphasis added). Terrel P. asked about the acceptance of a political organization in GLUE. Deney indicated that he did not think there would be any problem accepting this type of group. Jack suggested that we ask John about the definition of voting membership. (GLUE, “Minutes,” 15 Dec. 1983; emphasis added). There have been many questions raised concerning whether or not those organizations represented in GLUE will lose their tax-exempt status due to the increased interest in political goings-on (i.e., passage of bills, policies of candidates, polling, voter registration, etc.). Stuart explained that you cannot lose your status unless you become political. 'Educational Purposes' is not a factor which would cause loss of tax-exempt status. 'Lobbying' may cause endangerment of loss of this status, but lobbying for a bill would be different from lobbying for a candidate. You can lose your tax-exempt status by raising money or actively campaigning for a particular candidate in the name of your organization. (GLUE, “Minutes,” 19 Jan. 1984; emphasis added).

Reading these quotations together and within the context of GLUE's history reveals a number of things: that GLUE's earlier decision to omit political conversations was not 
applied to situations where it was voiced that GLUE not be political; that GLUE as an umbrella organization uneasily attempted to contain other political organizations while simultaneously disidentifying itself as political; and that non-profit status was the primary cause of its aversion to "political" activity, which (as has already been discussed) altered GLUE's archival practices.

On April 17, 1984, a special meeting was called that proved highly contentious and led to fracturing among the organization. The meeting addressed a number of concerns, but what seems to be chief among them was a belief that Priddy was intentionally leading GLUE toward engaging in electoral politics, jeopardizing GLUE's aspirations to become a non-profit and the non-profit status of certain member organizations. This belief found further evidence when Priddy invited representatives of the Gay and Lesbian Democrats of Kentucky and the National Association of Gay Democratic Clubs to a GLUE meeting and, at the end of the meeting, officially (and temporarily) stepped down from his role as president to introduce the two representatives. In a letter later sent to Priddy, members' concerns were added to the agenda of the requested special meeting using the following language: "The non-political vs. political stance of GLUE — why political speakers were part of the agendaed [sic] GLUE meeting; the source of the obvious pull to political issues." The five signatories also leveraged the bureaucratic power of GLUE's documentation in this "request," writing: "Please be advised that, according to the By-Laws adopted by GLUE, Art. 3, Sec. 3: 'Special meetings may be called ... [a]t the request of any two member organizations' representatives upon ten days' written notice mailed or delivered to all member organizations' representatives"' (Kersey et al.). When the meeting came, it was fraught 
with argument that seem to be fairly well-documented in the minutes. The minutes state that "Several representatives were upset that the meeting was not ended before the speakers were presented, that there was not an equal chance for the other parties to be represented, and that the meeting was too long to give the speakers adequate attention." Members argued that "elected politics has no place in GLUE meeting"; that "we are a discussion group"; that a letter delivered by the Gay and Lesbian Democrats of Kentucky “insinuates that MCC [Metropolitan Community Church], as a member of GLUE, joined in this political effort," jeopardizing their own non-profit status; and that "Deney [Priddy] has no right to be represented as GLUE president when attending political functions, and he will lose the support of the organization if he continues in this vein." Williams spoke, arguing that "if Deney or any president (or officer) go anywhere as president of GLUE, then he or she must let the organizations know ahead of time, as he or she would be representing the organizations." The treasurer of the organization argued that " "partisan' meant supportive of specific party politics, and that all political dealings which were not of this nature were allowable under the GLUE By-Laws." Finally, the minutes document Priddy's frustration:

Deney indicated that GLUE is a 'paper tiger' and that he can no longer represent its members as President. He said that, effective May 30th, or if we should elect a successor before then, he will be resigning his post as President of GLUE. He cannot operate in this capacity if he has to get the members' permission each time he is called to a meeting. (GLUE, "Minutes," 17 Apr 1984)

This debate was certainly agonistic, and had deep effects on the organization. Williams refers to it as "the blow up" in one semi-structured oral history interview: 
Williams: Deney Priddy had been made president. . . Oh I guess the previous year. And he was very dynamic. And I thought well "He's putting new energy into GLUE." Not that it didn't have some energy already but. . . It was that year that he decided to run for alderman, and so he wanted GLUE's backing for that and he wanted more people to get involved in the political aspect of the gay and lesbian movement. And the people just basically blew up, you know.... [I]f they found out that MCC was part of a group like GLUE that was helping elect somebody to office, Dee said that they would have to withdraw as a member of GLUE, and there was a couple other groups like that also. There was a short-lived group called, it was a Hispanic-lesbian group, Hermanas, something, and they raised the same objection, I remember, very vociferously, and so at the very end of the meeting Deney proferred his resignation, he said he was gonna resign that night, and that's when Elizabeth became chair Wysocki: Yeah.

Williams: and it was a pretty rambunctious meeting. (Williams, Personal interview. 21 Mar. 2018.)

Despite GLUE's efforts to craft a nonpolitical ethos, to frame the issue along a binary between a non-political stance (measured according to the apparatus of the state and other normative institutions) and a seemingly willful assimilation into normative politics would be to misrecognize queer-rhetorical strategies as the uncritical acceptance of power structures. It would also completely omit the ways that, in its (dis)identifications with normative political activity, GLUE transformed queer life in Louisville—a queer world 
making and, paradoxically, political act. Further, it would not provide the space to understand the effects of silences in GLUE's archival record.

Which is not to say that all archival silences are capable of being understood. Just before the "blow up," Williams conducted an unpublished interview with Priddy as part of his own attempt to document GLUE. Williams pressed Priddy on his seeming attempts to politicize the organization, and Priddy responded:

a lot of member organizations see us as not being political, and I certainly do not think that GLUE is political.... We are opening up avenues to the Governor's office and to the Mayor and to the County Judge's office, but those are avenues that are non-political. They're avenues that they're opening up to educate them, and there is a difference between education and politics. We are trying our best to walk that fine line, and sometimes it does get very fine. I would like to say that if we could get everything we want without talking to the Governor's office and the mayor's office, but I'm realistic in that avenue, and in that avenue you just don't get it done. (Priddy and Kretman 7)

In the interview transcript, Williams and Priddy begin to argue, continuously cutting each other off, about the nature of GLUE's relationship to politics. Priddy eventually responds that "We're looking at a couple of options David. Some of those things we can't talk about." At the climax of this agonistic debate, a single, frustrating insertion: "[tape momentarily stopped]" (8). This gap speaks to Barbara L'Epplatenier's caution about the ways that archival research can be too hasty, too universalizing, and how archives are fraught with "cracks, fissures, and gaps" (74), as well as to repeated calls from L'Epplatenier and others for more robust considerations of how archival research 
methods attend to such difficulties (see Ramsey, Sharer, L'Eplattenier, and Mastrangelo's edited collection, Working in the Archives). The gap also clearly reflects Derrida's famous assertion, reading the concept of "the Archive" alongside Freudian psychoanalytic theory, that the gaps in not just the archive but in memory itself render them as ultimately incapable of being analyzed (20). But most importantly, we can speculatively read such silences as a feature of GLUE's archival record rather than a lack, in that these silences were entangled with and contributed larger exigencies that entered into intra-active relationships with GLUE's grassroots historiography.

\section{Conclusion}

Rather than treat the silences throughout this chapter as a kind of black box, I have attempted to approach them as generative, as contributing to the emergence of the archive's rhetoric, and as an effect of GLUE's attunement to the uncertain futures of the circulation of their archive. What this leaves us with, as argued by Biesecker, is "an invitation to write rhetorical histories of archives, which is to say, critical histories of the situated and strategic uses to which archives have been put" (130). From such a perspective, GLUE's archive can be seen as queer performances of "the generation of rhetorical materials," defined by Simonson as "the symbolic or physical elements that enter into or are gathered for the purpose of communicative address" $(300,313)$. In other words, GLUE's archive does not only contain rhetoric but is rhetoric's emergence, and particular omissions from the archival record became the conditions of possibility for queer world making in Louisville: were GLUE to be seen as political by homophobic publics, there likely would have been no GLUE.

The organization continued after the "blow-up" and Williams continues to collect 
and to archive. Eventually, GLUE was overtaken by the Fairness Campaign, a more explicitly political organization emerging from the victories of the GLHRC, and by the AIDS crisis, which was just becoming horrifically salient to GLUE during the period discussed here. As Williams explained during one of our interviews:

Williams: But eventually, yeah, the political aspect overtook GLUE, when Fairness especially came out in 1991.

Wysocki: What do you mean by that?

Williams: I mean it gained ground publicly, you know, became more open and GLUE was still kind of trudging along as being this separate organization that did its own thing.

Wysocki: Mhmm.

Williams: But it didn't get involved in the politics, which of course in the 90 s it was all politics.

Wysocki: So, you think that GLUE's—not—inability but desire to not be political, kind of just made it obsolete in a way onceWilliams: Eventually yeah. 97 I think was the last meeting. (Williams, Personal interview. 21 Mar. 2018)

Williams, to be sure, is extremely congratulatory about the successes of the more visibly political successes of GLHRC and the Fairness Campaign. But in a short document he wrote included at the front of the earliest GLUE folder in the archive, he mourns a loss, writing:

That's what happened, in my opinion, to GLUE. It was an early casualty of the Fairness Campaign and the AIDS crisis. ... It would be good to get another 
GLUE going so that we once again start acting like one cohesive community rather than several small cliques unaware of what each other is doing. Once GLUE died, a lot of other groups folded as well. Of the $20+$ groups in existence in Louisville in 1983, only a handful of organizations exist today. It would be great if we could get back the kind of energy we had in the early 1980s. There really is too much apathy in Louisville. We have always had to battle apathy within the GLBT community here in Louisville, but for a brief time in the 1980s and 90s, that apathy was shunted to the side. GLUE had a large part to play in that. (Williams, "Brief History”)

The silences I have discussed in this chapter were kind - they (seemingly) left traces of themselves, allowing me as a researcher insight into them that would not be afforded in many other cases of rhetorical silence. Furthermore, I was granted the ability to carry out oral history interviews with Williams, another privilege. I wish to mark one additional silence in this archive that shows both the stakes and the difficulties of becoming attuned to silences within (queer) archival records. I found myself somewhat surprised in the archive, reading GLUE's meeting minutes, at a particular discovery that had been erstwhile absent from the organization's archival record. A debate had been in the background of several sets of minutes about a particular event scheduled for the Gay Pride Week of 1984: a women-only night at a local theater. In a letter distributed to the member representatives of GLUE, Pam Frisk - a proponent and co-organizer of the women-only night — explained her reasoning:

I as a person working with this committee felt an honest attempt would be made to the public media and to the women and men in our community who felt a need 
for 'womenspace' and 'menspace.' I also indicated that 'even the Separatists might come to this one,' whereupon we had a very long conversation about whether or not they would come. ... I offered to call a separatist woman that I knew and ask her opinion to get the facts, as we could only speculate since we were not separatists. Her reactions were an initial shock that we would even think of including them, and positive feelings about attending, even though there were men participating in the plays as actors, stage crew, and ushers. She felt that the honesty with which it was presented to her-i.e, we stated that there would be men in the production company and that the audience would be 'women only'was a relevant factor in this decision. Since that time, I have had numerous notes and phone calls from women in the community who are pleased by this outreach effort and are supportive and willing to attend the function. Several of them have also offered to work on the Gay Pride Week theatre committee. (Frisk)

The debate that ranged before, during, and in response to this letter indicates the ways that GLUE's activism, while necessary, was imperfect and occasionally veered toward homonormative arguments, as evinced in particular responses to Frisk's letter at the same meeting in which Deney resigned. Here are three arguments that model positions that seem to be representative of the various sentiments during the meeting: (1) "we cannot be unified if we hold separate events for men and for women"; (2) "We need to accept the people in our culture (and its sub-cultures) for the persons they are and for the beliefs they present, and offer something for everyone without making them change their ways or conform to the ideas of others with different beliefs"; (3) "If we have a special night for men and for women, then we should have a special night for Blacks, a special night 
for Mexicans, etc.” (GLUE, “Minutes,” 17 Apr. 1984).

Clearly, the debate is enacted along the axes of gender and even race, with a large fear being the presumed fragmentation of GLUE's identity due to social separation, again reflecting the arguments regarding homonormativity discussed throughout this chapter, as well as Bessette's conception of the rhetoricity and contingency of queerness. To the extent that GLUE's purpose was to imagine a more just social future, it did not adequately account for the intersectionality of race as it cuts across gender and sexuality, a failure that was likely tied to its largely white status. As interesting as this debate was, however, it did not surprise me. What was surprising was Frisk's note about the lesbian separatists - until coming across this debate, I had found no indication of there being lesbian separatists in Louisville at this time. Not only was there such a group, I learned, but members of GLUE seem to have been occasionally in contact with them, enough so at least for Frisk to find little difficulty in calling one. In an interview, I asked Williams about this strange absence, and he responded:

D: Oh yeah, for a time there was the [Louisville] Lesbian Herstory Archives, and uh, you know they decided to start their own collection. And there was a reluctance on the part of some, a couple of people who I will not name, who did not want to associate with our archives. I thought, "Well okay, but it's in danger of being lost." I was looking at the big picture. But eventually when the Lesbian Herstory Archives folded we did get all their books, which was a godsend. But we didn't get any folders or any print materials. It was all just magazines and books. R: Do you think that they did that on purpose?

D: Well, I don't know. As a matter of fact, I don't know if there were any folders. 


\section{R: Fair enough, yeah.}

D: I can't say. I never heard of it. I would think that there would be. So, yeah from time to time it was a little hurtful not being able to get stuff from certain lesbians which I thought would be very valuable for the whole archives. I think we've probably got $99 \%$. But yeah there was a little divide there, yeah. Some lesbian separatists just didn't want to have anything to do with men period. As little as possible. (Williams, Personal interview. 21 Mar. 2018.)

Though he seemed frustrated, there was also a tinge of sadness in Williams's voice as he recounted this story. He did not seem angry with the separatists for their decision, but rather worried about the preservation of LGBTQ history.

However, the crucial point is this: archives don't simply sit there. They are not mere repositories, and they are not inert. Rather, they emerge from the entanglements between a variety of human and non-human phenomena: archival materials, curators and collectors, trained archivists, decisions made in the past about what and what not to record, political ideologies, social and economic contexts, and published research. As Pamela VanHaitsma argues, "scholars of queer rhetoric may treat speculation about the past, much like more traditional archival materials, as grounds on which to develop narratives about non-normative sexual, romantic, and or erotic practices—while simultaneously underscoring the impossibilities and uncertainties inherent in attempts to know the "truth" of sexuality, identity, and history" ("Gossip" 139). As I have attempted to show, VanHaitsma is correct but underemphasizes the reach of her insight. Archives are not representations of the past, they are the past's performance and, therefore, require speculation, especially (as VanHaitsma reminds) in the case of queer archives and their 
silences. Archives do not represent reality so much as perform reality through entangled processes of becoming; intervening in the world's becoming is never carried out with perfect knowledge.

My point has been that particular silences in GLUE's archive can expand our understanding of archival rhetoric and also call attention to the necessary speculative nature of archival work. This does not grant scholars the ability to claim a de-politicized, non-ethical approach to archival work: "We (but not only 'we humans') are always already responsible for the others with whom or which we are entangled, not through conscious intent but through the various ontological entanglements that materiality entails" (Barad, Meeting 393). Of course, not all silences are laudatory, such as the enforced and marginalizing silencing of LGBTQ information by the Trump administration discussed in the opening anecdote to this chapter. Some silences can be tracked, others can only be speculated upon. But as researchers enter the archive, they become swept up in the transformational entanglements of what came before. In producing meaning with and in archives, researchers become part of its becoming. This is an ethical, not just a political, realization, calling attention to the deep stakes of how we approach and engage the past. Archives are vital, in both senses of the term. 


\section{CHAPTER III}

\section{MATERIALIZING AFFECT IN ARCHIVAL PRODUCTION}

In the late-1980s, Williams renamed his organization. What was once referred to simply as "The Archives" in GLUE's meeting minutes was renamed the "Kentucky Gay and Lesbian Educational Center" (KGLEC). The mission of the archives stayed the same — to collect and preserve materials related to LGBTQ life in Louisville—but Williams seems to have intensified his personal activism, which consisted of submitting opinion pieces regarding lesbian and gay life to both "mainstream" and lesbian/gay periodicals, compiling bibliographies of (and archiving) references to lesbian and gay activity in published media, and publishing advertisements for the KGLEC and its archive. One newspaper clipping simply read: "Homosexuality: What are the facts?" (“Kentucky Gay and Lesbian Educational Center"). A more humorous listing detailed further:

What is the Kentucky Gay \& Lesbian Educational Center? A school for hard-to-educate homosexuals? Does it offer degrees in cruising?

The Educational Center is an archives and library dedicated to the collection and dissemination of information of interest to the Kentucky and southern Indiana gay and lesbian community and its friends. KGLEC accepts donations of all gay/lesbian-oriented materials and is actively engaged in the 
education of the general public on the positive aspects of homosexuality and gay/lesbian lifestyles. (Newspaper clipping)

Whereas these listings differed in content and tone, they each directed interested readers to send letters to a P.O. box, a communication technology of particular import to lesbian and gay correspondence at the time. Noting the dangers of circulating one's home address across homophobic publics, Williams humorously remarked to one letter-writer that "gays and lesbians must be the main source of income for most of the post office boxes in the country" (The Newspaper Project).

Williams archived much, if not all, of the correspondence he received and sent in relationship to these advertisements, which exists in a folder titled "The Newspaper Project" in the WNA. Not all of this correspondence was particularly significant or positive. There were many brief requests for information and some of these, furthermore, took sarcastic or condescending tones regarding supposed "facts" in relation to homosexuality. Additionally, it is difficult to tell the intentions of these writers, given that at least one of Williams's advertisements was, itself, ambiguous as to its own perspective on homosexuality. Writers may have wondered whether an unnamed listing purporting to represent the "facts" of homosexuality held positive or homophobic attitudes toward LGBTQ individuals, and it is similarly difficult to know the intentions of some of the more brief requests for information. Williams did archive one explicitly hostile response he received, which was simply a notecard listing homophobic Biblical verses. In short, many of these letters are opaque, homophobic, or both. Among them, however, are a number of moving, at times troubling accounts and narratives from writers-mainly men, though some women as well—reflecting their feelings regarding shifting sexual 
identifications. Williams responded to nearly all of these letters with packets that included pamphlets of positive information about lesbian and gay life, organizations, and resources. Additionally, he often responded with personal letters offering advice or words of comfort.

This chapter considers these letters as an archival-rhetorical materialization of affect, demonstrating what Cvetkovich refers to-in her case specifically discussing lesbian archives - as the "affective power of a useful archive, especially an archive of sexuality and gay and lesbian life, which must preserve and produce not just knowledge but feeling" (Archive of Feelings 241). From this perspective, I consider the letters sent in response to Williams's advertisements as two-pronged rhetorical phenomena that both preserve and produce feeling. I begin by discussing the approach to affect I take up in this chapter and its complementarity to the materialist perspective I extend throughout this dissertation. Then, I analyze letters sent to the KGLEC in response to Williams's newspaper advertisements, arguing that they demonstrate the materializations of emergent, queer affective forces. Given that there is little indication that these writers were aware their correspondence would be archived, I conclude by discussing the ethics and the unpredictability of the rhetorical formation of queer archives, and specifically my decision to omit personally identifying information in my discussion of their intimate and often traumatic disclosures. For this reason, I have only provided only a citation for the folder in which the letters are held, a decision — as I discuss at the end of the chapterthat resists ethical closure. 


\section{Materializing Affect}

VanHaitsma has argued for examining adaptations of romantic letter writing as a way of excavating queer rhetorical interventions. Considering the ways that two AfricanAmerican women-Addie Brown and Rebecca Primus — challenged the heteronormativity of romantic letter writing instruction, VanHaitsma claims that "these women adapted the conventions through queer practices: by negotiating forms of address that crossed categories of gender and relationship, by timing letters with urgency rather than the recommended restraint, and by repurposing the romantic letter to erotic and even political ends" (“Queering” 9). Her analysis concludes by persuasively framing the heteronormativity of the romantic letter genre as "flexible and subject to queer challenge and repurposing" (20). Whereas the letters discussed in this chapter differ greatly-both in content and context—from VanHaitsma's source material, they similarly defy normativity both through their resistant transmission of "bad feelings" and through their articulation of non-normative identifications. In this sense, these letters can be considered as materializations — and, crucially, mediations_ - of queer affect, as archives of feeling.

As a critical term across disciplines, affect has taken multivariate definitions and connotations that loosely coalesce - in ways similar to the new materialist perspective I outline in Chapter 1 -around the difficulty of discussing the material, non-linguistic nature of feeling. If, as Muñoz argues, queer archives' promise exists in their ability to provide "alternate modes of textuality and narrativity like memory and performance" ("Ephemera" 10), then traces of affect within archives can similarly serve as a rhetorical form existing beyond textuality. Cvetkovich writes that studying "archives of feelings" can be a productive method for excavating the affective histories of both queer/lesbian 
and trauma publics. Specifically, such a strategy focuses on "cultural texts as repositories of feelings and emotions, which are encoded not only into the content of the texts themselves but in the practices that surround their production and reception" (An Archive of Feelings: Trauma, Sexuality, and Lesbian Public Cultures 7).

In this chapter, I extend Cvetkovich's implicit appeal to the materiality of affective archives to frame affect as a materialization that entangles both bodies marked as both human and nonhuman. Gregory J. Seigworth and Melissa Gregg, in fact, center the body in their account, arguing that affect refers to "a body's capacity to affect and be affected." For Seigworth and Gregg, however, "bodies" are "defined not by an outer skin-envelope or other surface boundary but by their potential to reciprocate or co-participate in the passages of affect" (2). So, whereas Barad understands the body as a boundary-marking enacted upon (and with) an ultimately indissoluble entanglement of material phenomena, Seigworth and Gregg understand the body as that which has the capacity to affect. Synthesizing these perspectives, affect can be understood as the forces or intensities that move across a body's constitutive entanglements as well as the movement enacted through a body's entanglement with others. And, returning to Cvetkovich, affect is materialized not just in humans but in their entanglement with objects, a perspective that points consideration to how feelings become materialized in the formation of queer archives.

While the role of emotion - a term related to but not synonymous with affecthas been undervalued in rhetorical scholarship (Micciche 164-69), affect has been central to a number of conversations regarding rhetorical theory in ways that speak to the rhetoricity of queer archival formation. Perhaps the most influential articulation of the 
relationship between rhetoric and affect has been offered by Diane Davis, who claims that rhetoricity—an "originary (or preoriginary)" capacity for rhetorical movement and practice —emerges from "an affectability or persuadability — that is the condition for symbolic action" (qtd. in Rickert 160, emphasis in original). Rickert builds on this definition in his theorization of an "ambient rhetoric," framing affect as "a modality of the entanglement of world and body" (14). From his new materialist-inflected orientation, Rickert argues:

[P]ersuadability does not appear as simple immanence, as something that emerges from our given social interactions of individuals and aggregates. ... Human beings are in multifold fashion hardwired and 'softwired' into each other, making individuation an achievement never fully realized, since the affectability already implicit in human beings is never lost, shed, or abandoned. (161)

From this perspective, affect exists as an originary phenomenon entangling humans with each other and with their material surround. This entanglement, for Rickert, provides the ground for a (greatly expanded definition of) rhetorical practice. Taking up this view frames archives as rhetorical to the extent that they demonstrate or contribute to capacities for affectability and persuadability.

While Davis and Rickert suggest affectability as the ground of rhetoricity, Gries considers affect as an entangled participant in the emergence of rhetorical phenomena. Since rhetoric — in Gries's discussion, visual rhetoric — enlists myriad forces that include persuasive, identificatory, argumentative, and affective phenomena, it "becomes difficult to account for how any single thing specifically induces change" (69). Affect, Gries explains, refers to the "energy transfer and sense appeals that are material, autonomous, 
and dynamic and that register in bodily experience before cognition takes place." She goes on to write that "Affect is always transmitted in that it spreads, contaminates, and is absorbed by various bodies; as such, affect is contagious" (125). Reading Gries's discussion alongside Muñoz's, one of the more promising potentials of the queer archive emerges in its ability to materialize and circulate non-linguistic and often ephemeral objects of queer affect.

In her work on the relationships between affect and queer experience, however, queer-feminist theorist Sara Ahmed has offered a generous critique of the contagion model of affect to remind us that the circulation of affect is never a neutral process. ${ }^{10}$ In her discussion, Ahmed points out that

Thinking of affects as contagious does help us to challenge an 'inside out' model of affect by showing how affects pass between bodies, affecting bodily surfaces or even how bodies surface. However, I think the concept of affective contagion tends to underestimate the extent to which affects are contingent (involving the hap of a happening): to be affected by another does not mean that an affect simply passes or 'leaps' from one body to another. The affect becomes an object only given the contingency of how we are affected, or only as an effect of how objects are given. ("Happy Objects" 36)

In other words, Ahmed understands the contagion model as a sort of short cut that does not account for the deep material/social mediations involved in the transmission of affect

\footnotetext{
${ }^{10}$ To be clear, Ahmed is not critiquing Gries, and Gries demonstrates her awareness of the non-neutrality of circulation on nearly every page of her book, despite her uptake of the contagion metaphor for affect.
} 
and affective objects. This small corrective-directed, again, not at Gries but at affect studies generally — is important to studies of queer archives by reminding that social forces - so often leveraged in opposition to LGBTQ lives and histories - must not be occluded in the name of a "turn" toward materiality (as if there were an immaterial position from which to turn). Rather, we must also remain attentive to how social forces shape the transmission of affect across bodies.

Looking beyond the originary capacity for affectability and the participation in the emergence of rhetorical phenomena, affect can also be considered as that which remains after the intervention of affective encounters - a bodily archive. Megan Watkins, drawing on Spinoza, distinguishes between affectus, "the force of an affecting body," and affectio, "the impact it [affectus] leaves on the one affected" (269). This perspective, especially, speaks to the unpredictable nature of affective intensities, where entanglements with others (marked both as human and nonhuman) can produce an affectio that "may be fleeting but . . . may also leave a residue, a lasting impression that produces particular kinds of bodily capacities" (269). Affective connections, then, augment and transform capacities for feeling, but interpretations of affect should not assume such transformations as being necessarily generative or positive: "As much as we sometimes might want to believe that affect is highly invested in us and with somehow magically providing for a better tomorrow ... [, ] affect instead bears an intense and thoroughly immanent neutrality" (Seigworth and Gregg 10). In this chapter, I attempt to avoid a teleological conception of affect that points toward the augmentation of the "good" through increased affective connections. Furthermore, I do not consider "positive" affect to be synonymous with "good feelings, since "it is the very assumption 
that good feelings are open and bad feelings are closed that allows historical forms of injustice to disappear .... [A] a concern with histories that hurt is not then a backward orientation" (Ahmed, "Happy Objects" 50). Bad feelings, as Ahmed suggests, can function as a generative - though difficult and often traumatizing — archive of LGBTQ experience.

Reading these definitions and articulations of affect together, we might consider affect as the material, processual entanglements that provide the ground for not only rhetoric but feeling. These entanglements flow between, within, and amongst people, institutions, texts, and objects. Taking this perspective, the WNA/KGLEC can be understood as a materialization — and a mediation — of affect. Ultimately, I see conversations regarding both affect and new materialism to be complementary and addressing the same phenomena: the processual, material entanglements involved in the world's becoming and the inadequacy purely discursive inquiries into such becomings. Given that this chapter's primary material and much of the scholarship I engage deals explicitly with feelings, I take "affect" as an operative term to indicate not a shift from but a further extension of the materialist perspective I develop throughout this dissertation. If the archive can be understood as a "dynamic site of rhetorical power" (Morris, "Archival Turn" 115) and if "The meaning of matter is constituted by the consequences that emerge with time and space via its relations with other entities" (Gries 86), can we understand the WNA/KGLEC as a material entanglement of affective intensities? How does the materialization of affect inflect the archive's rhetorical production of meaning? 
These questions are important, as they speak to deep, interconnected rhetoric involved in the formation of an archive. Yet, attempting to answer them may be perilous: affect eludes. It is easy to fall back on commonsense conceptions of emotion when considering affect, but this is a misdirection. As Brian Massumi writes, "Emotion is qualified intensity, the conventional, consensual point of insertion into semantically formed progressions, into narrativizable action-reaction circuits, into function and meaning" (88). Emotion, in other words, is the ordering of affect. Given the difficulty of accessing the embodied, material, and pre-linguistic nature of affect, I look for it at a slant, exploring the letters sent in response to Williams's "Newspaper Project" as materializations - traces — of queer affect. Crucially, a materialization is always a mediation, a transformation. So, whereas it may be difficult to locate affect, we may find affect's traces in its materialization as a queer archival form. The letters themselves, as I argue in the next section, exist as "small archives" containing such material traces of queer affect. I then discuss further transformations-with deep affective and ethical implications—enacted by Williams's archival practices.

\section{Queer Correspondence}

As suggested above, not all of the correspondence that emerged from Williams's project is informative to understanding either affect or archival practice. Much of it was, simply, requests for information. Among these documents, however, are a number of moving letters that generally had to do with writers processing their own sexual identities through epistolary correspondence. One writer, for example, wrote to Williams: 
Yes, I would like to know the facts of homosexuality. I am one, in a way. Which I can't express now. But maybe when you answer this, it would let me know. Are you against it or for it. [sic] (The Newspaper Project).

The uncertainty that the author demonstrates reflects the leap of faith taken by writers who responded Williams's sometimes opaque advertisements — certain writers must have been unaware of Williams's intentions when they sent their initial letters. This specific letter, moreover, reflects a common interest in negotiating their own conflicting identification through writing, pointing to the excesses of sexual identification. The writer claims a non-normative identification — "I am one"-immediately qualifies_-"in a way"- and then immediately undercuts their own identification, "which I can't express now."

Another letter, from a self-identifying lesbian woman, expresses confusion not with her sexual identity but with her social subjectivity within a homophobic public sphere. She mentions hearing that Williams had collected "data on misinformation about gay men and women in KY" and writes that "I would appreciate receiving a copy of that data. I am new to this area [specific location removed] but it seems being gay is not accepted well here. Those who are must be in the 'closet'. I guess I have to admit I prefer to stay there myself." She then abruptly shifts, however, to discuss her desire for connections with other lesbians: "At the same time I need to find out from you where to find the networking system. Are there womens groups (more mature) in the local area + newsletters? How do you meet new people in this homophobic community? Am feeling this must be the worst place on earth for a lesbian!! Probably need to ask you for a list of therapists as well!!" (The Newspaper Project). Both this and the previous letter express 
desire for connection and identification: the first with Williams, since the author felt that the correspondence would help them to process their own sexual identity, and the second with a larger lesbian and gay community. Williams responded to the first with information about bisexuality, noting that "There is nothing wrong with gay or bisexual feelings: these are perfectly normal human tendencies." To the second author, Williams wrote that while he was unsure of lesbian and gay life in the author's town, "I did receive another letter from a gay man in [specific location removed], and I could write to ask him if he might want you to contact him in some way.” Additionally, he recommended GLUE's Hotline as a resource for support (see Chapter 2).

The analysis of these and other letters could certainly fall along the lines of the historiographic "recovery" of LGBTQ voices that emerged from Louisville and the rural areas that surround it. Such work would— to be certain—be an important intervention into queer-rhetorical historiography. But I want to consider here the ways that feeling becomes embedded in artifacts, and how searching for the transformative materialization of feeling can reveal a resonant affective presence within archival objects. This is by no means unproblematic. There are signals of differing class dynamics and, potentially, literacy within these and other letters sent in response to Williams's advertisements. Additionally, to my knowledge, race is rarely and only briefly mentioned among them, which potentially points to a problematic assumption of whiteness. Clearly, the subjectivities carved along the axes of class, literacy, and race have profound affective influence on individuals — especially people inhabiting marginalized positions in relation to them. Given the little evidence we have of the authors' lives beyond what they include in their own writing, however, I have attempted to avoid superimposing onto them 
identities regarding class, literacy, and race beyond what the letters themselves state or demonstrate (though I do discuss two letters' comments regarding financial matters, which clearly speaks to the affective intersectionality of class and sexuality).

Beyond limited access to the authors' embodied, contextualizing identifications and social positions, the affective entanglements produced by way of this correspondence and Williams's subsequent archival practices is further problematized by these writers' seeming lack of awareness that their letters would be preserved and circulated, leading to complex ethical questions that I engage toward the end of this chapter. At the same time, the writers regularly expressed a desire to write their experience - arguably a queerarchival form, which further complicates their inclusion in the archive. Turning now to an analysis of three specific, detailed letters, I point to the uncertain divisions between practices of inscription and archiving, and how these uncertainties speak to the complexities of queer archival formation to which the materialization and circulation of affect is central.

"Twice so Bad"

The following letter was mailed to Williams in 1987. By all indication, it was typewritten hastily, and there were several handwritten inscriptions and revisions applied before the letter was sent. I have attempted to transcribe it here as accurately as possible. Most line breaks—not all—were signaled by the author with a hyphen, indicated in my transcription. The letter reads:

Dear David,

I saw your letter in the News-Enterprise. I am - glad you wrote that.

Perhaps, you can help me in - some way. I am a homosexual, and have been for - 
many years. I live [specific location removed]. I - am white, 46 years old, and still live with my elderly parents. I am un-happy, miserable as anyone - could be. I am an only child. I am retired to a - certain extent. (SELF-IMPOSED). [NOTE: "selfimposed" is written in handwriting above a scratched out typewritten passage.] $I$ was in the Army - quite a while, After this my Mother and I run a-Motel for 12 years. She retired in 1978, and - I just simply quit. I was having high-bloodpressure, and just needed to get away from the public. I get by in a monyed way, by drawing the interest - off savings, and also, an Aunt's estate. But since the interest rate has dropped so much - I am like a lot of other people, I could use more income. I had thought, I would never have to th - ink twice about money, when I quit the motel in - 78. Anyway, I am not writing about money. I have not had any affairs what-so-ever with anyone sice 1975. Starting out, I did have an affair with an army friend, who lived in Hoopestan, Illinois. This was in 1964. But it was very short-lifed. I was raised in the country, and he was raised in an,very large town. He did not like the country - and I did not like the large town. We broke up - and went our separate ways, although, we sti - ll wrote each other, called, and visited, once in - a while. Through him, I met a friend of his who-was gay, and we had a short-lifed affair. Same - situation with him. He was raised in Columbus - Ohio, and did not like the country either. This was Nov., of 1975 that we broke up. I finally just give up on finding anyone. I had been - hurt twice so bad. [Note: underline handwritten in original.] [Specific location removed] is just a wide space in - the road. POP.-500-600. If there are any gays in - [Specific location removed], they are hiding it awfully well. The same - with [Specific location 
removed]. I need someone to write as a beginning [Note: "beginning" circled in handwriting] in my age brackett. And someone to write me. Just to tell troubles to, and vice versa. Perhaps, you could help me in this way. I am an squea -y clean person. I sure do not have Aids, by-no-me - ans, what-so-ever. I just simply need a clean, de - cent person to write to, and as I said, vice versa. This has been a difficult letter for me to type. I have made lots of typing errors, just not hardly knowing what to say. I hope you can help me. [underline in original]." (The Newspaper Project)

On first glance, the most striking aspect of this letter is, perhaps, its movement through a wide range of feeling. The author begins the letter "glad" that Williams had publicly expressed positive messages regarding homosexuality. Quickly, however, the author shifts to state that he is "un-happy, miserable as anyone - could be." A form of nostalgic lovesickness seems to take hold later in the author's discussion of his former lovers, which culminates in an expression of hopeless romance: "I fin - ally just give up on finding anyone. I had been - hurt twice so bad." Fear, too, permeates the letter, not just in its awareness of the dangers of inhabiting marginalized identities but also of the threat of AIDS. Finally, the letter returns to an epistolary hope, a desire for recognition andgiven that writing is invoked repeatedly—inscription.

Consider the author's repeated appeals to writing and to being written. The letter begins with an acknowledgment of Williams's writing ("I'm glad you wrote that"), attempts to redirect its object ("I am not writing about money"), and notes the importance of writing to a former relationship ("we sti - 11 wrote each other"). While the author attempts to quickly move past his discussion of money, its inclusion in the letter- 
seemingly unanticipated even to the author-suggests the knotted, intersectional, and affective entanglements that constitute identification. An additional participant in the authors' identification, it seems, is being recognized by the other through writing. The author needs "someone to write as a beginning. ... And someone to write me.... I just simply need a clean, de - cent person to write to, and as I said, vice versa." Finally, the epistolary closes with a reflection on the difficulty of writing: "This has been a difficult letter for me to type. I have made lots of typing errors, just not hardly knowing what to say. I hope you can help me." Clearly, the author's desire is to be written to by other, understanding people capable of recognizing and accepting him. Expressed within this hope, however, is a complementary desire to be written, i.e., to have his experiences inscribed - literally — by recording them as letters. What begins to emerge, from this perspective, is an image of the letter as archive, as the author's attempt and desire to record his experience. This is supported by the details he presents about his life, many of which are not explicitly related to his sexuality.

Understanding the letter as an archive makes the author's revisions and handwritten inscriptions on the page intriguing, as they reflect processuality of archiving experience. Specifically, the disconnect between the typewritten copy and the handwritten revisions reveals a materialization —a trace - of the dynamic interplay between queer affect and subtractive cognition. By queer affect, I here refer to the intensities and forces that seem to overtake the author as he attempts to write his first typewritten copy of his letter. This draft feels exploratory, rushed, and at times automatic, channeling and archiving the author's intensities and surges of feeling. By "subtractive cognition," I draw on Massumi's point that the attempt to enter affect into cognition 
enacts a subtractive cut, since "Will and consciousness . . . are limitative, derived functions which reduce a complexity too rich to be functionally expressed" (90). From my perspective, Massumi here points to the same phenomenon described by Barad's "agential cut": the reduction of complexity through the intervention of particular apparatuses (which include cognition and concepts more generally) as a way of ordering the world's complexity into an epistemologically functional register. Again, this is neither teleological nor linear but emerges differentially based on the differing entanglements of a variety of phenomena.

The gap between the writer's initial draft-itself a mediation of intensities to which we have no access - and the revisions, then, archives the processuality of affect's emergence and materialization. Of course, much of this editing simply responds to typos, though the author himself remarks that these mistakes manifested through the difficulty of articulating his feelings. But his underline of "twice so bad" and his circling of “beginning” work differently, materially and rhetorically orienting readers toward particular feelings. Furthermore, inscribing and physically marking bad feelings_- "twice so bad"-is specifically the progressive movement, the identificatory "beginning," that the writer desires: "I need someone to write to," he explains, "and someone to write me." Given the lack of information on the writer beyond this letter, we cannot know whether the registering of "bad feelings" served the therapeutic function for the letter's author that both Cvetkovich and Ahmed claim is possible (114; 50). This letter, however, materializes the mediation of affects that are ultimately unknowable in an objectivist sense but no less resonant. This materialization is archival both metaphorically —as the 
author's desire to archive himself — and literally, given Williams's decision to preserve (and thereby mediate) it.

"Plus, trust them."

Williams received another series of letters from a midwestern man outside of Kentucky. In what seems to be his first letter, the man identified himself as "hearing impaired, soon deaf, and 48 yrs. old.” He was interested in Williams's information “about the area, including the gay area" (The Newspaper Project). While this letter was brief and formal in tone (likely, as already discussed in this and other chapters, because of the uncertainties involved in circulating queer identifications), his follow-up letter was detailed and laden with affective force. Like the previous letter-writer, affect reveals itself in the interplay across two separate layers. In this case, however, these layers were comprised not by text/revision but actually by two separate letters, stapled together and delivered. What seems to be the "main" letter reads:

Dear David,

I would like this just be a big help to you and cause no trouble. In the past it was one night stands and one sided. I gave 1000\% and gotten nothing in return, plus, it was hands off and eyes off of them, a few covered (including keep my body off of them). Also, a few was covered between the waist and the thighs. So I really never learned. Hopefully it won't happen in the future.

After you this whole thing you will close the door, give up on me, and etc... 
[Note: the letter writer includes a paragraph here too personally identifying to transcribe, but the author claims disabled embodiments beyond his hearing impairment and also states that he is HIV-negative.]

Everyone has scared me, so, I will be on my guard and back off. Maybe say 'no' or shoo that person away or just walk away or? I have to wait and see on it, then go from there (what direction will it go in). Plus, trust them.

When I do relocate I don't know where. Because I lived and worked in [location removed] I must live here to get government help, and then retired here. Why! The ammount I would get (can not live anywhere else on it). If doctors give proof I need to change my climate.

I like all four seasons - winter, fall, summer, and spring. Verbally doctors told me "Winters aren't good for you. You need mild ones.

Appended to this letter was another one, reading:

NOTE

This 6" 9 9" note to you is confidential.

From [specific dates removed] taking care of elderly persons (my foster parents). From [specific date removed] until now, taking care of elderly person (foster dad), and it looks like I will until my foster parent's death.

I live with my foster parents, now foster parent house all of my life. I had temporary living else where.

My foster parents/foster parent doesn't want anyone in this house, to take care of them, and etc. 
They (foster parents(s) and foster family made sure I never left this house and etc., until they (foster parents) are gone//dead. Maybe I might go to bankrupt court.

What can be made of the conflicted identifications in this letter, the fact that the author's sexuality is only one among many of such identifications, and the affective, rhetorical force of materializing (and mediating) these feelings through inscription?

Among the many feelings archived in these letters, perhaps the most obvious is shame. While queer theorists have recognized the damaging and traumatic nature of queer shame, many have simultaneously sought to reclaim it as a potential space for the ameliorative emergence of queer identifications and experiences. Shame has been discussed as "a disruptive moment, in a circuit of identity-constituting identificatory communication" (Sedgwick 36); a potential affective space to inhabit for survivors to process sexual trauma (Cvetkovich, Archive of Feelings 98; 113); and as a queer subjectivity that can aid the reconstruction of identity and the production of queer alliances (Munt 100). In a discussion that is particularly illuminating in relation to this specific letter under discussion, Ahmed frames queer unhappiness as emerging from an individual's "failure" to desire a normative object, read as a shameful loss by the individual's familial relations, which enacts a sort of feedback loop wherein "the unhappy queer is made unhappy by the world that reads queers as unhappy" ("Happy Objects" 43). As discussed above, however, she argues that queer individuals can inhabit their enforced loss of happiness as a way of keeping queer feelings from disappearing ("Happy Objects" 50). In a sense, then, these scholars claim that an identification with shame or even trauma can — in qualified, particular cases - provide ground for both 
individual and collective healing. Taking these perspectives into account, an archive of feelings of shame and trauma — such as this author's letter—can be understood as circulating traces of queer affective forces with the potential of forming ameliorative queer identifications.

Remembering affect's neutrality as well as the unpredictability of circulation (see Chapter 2), however, such affective circulations cannot be guaranteed nor considered as fundamentally positive. Additionally, to be clear, I make no claim to speak for the literature emerging from trauma studies processes of healing. The attempt to articulate the affective force of both shame and loss, however, certainly permeates the letter, and the author does seem to take the occasion of writing as a way of processing his own conflicted feelings of shame. He begins with a presumed fear of becoming an object of "trouble," giving the sense of becoming a "burden" to others—a mark of Ahmed's conception of queer unhappiness and, of course, Butler's discussion of "troubling" gender as a dangerous but potentially subversive practice. Quickly, he shifts to discuss the unfulfillment of his own sexual desire: "In the past it was one night stands and one sided. I gave $1000 \%$ and gotten nothing in return.” These experiences were further shamed by the repressive character of the letter-writer's partners: "it was hands off and eyes off of them, a few waist covered (including keep my body off of them)." He goes on to express that, due to these troubling and unfulfilling experiences, "I really never learned. Hopefully it won't happen in the future." The author did, however, develop a cautious yet conflicted orientation toward his sexual identification, writing: "Everyone has scared me, so, I will be on my guard and back off. Maybe say 'no' or shoo that 
person away or just walk away or? I have to wait and see on it, then go from there (what direction will it go in). Plus, trust them."

These comments - discussing learned, embodied orientations to the world and to others - reflect and demonstrate discussions of affect's pedagogical capacity. Readers should, however, attempt to bracket dominant conceptions of pedagogy emerging from rhetoric and composition, as the perspectives on pedagogy emerging from affect studies are more similar to the concept of rhetoricity as an originary capacity for affectability than to pedagogy as the practice of teaching. Certainly, there are overlaps. Sedgwick's discussion of pedagogy as an emergent relationality rather than as the transmission of content - an orientation that brings her to ask "Is it true that we can learn only when we are aware we are being taught?" (Sedgwick 153)—clearly corresponds to foundational concepts and conversations in our field about the complexity of learning. But here I would like to read the letter — and the letter-writer — as pedagogical in a sense related to Massumi's discussion of “infolding.” Massumi writes: “The body doesn't just absorb pulses or discrete simulations; it infolds contexts, it infolds volitions and cognitions that are nothing if not situated. Intensity is asocial, but not presocial—it includes social elements, but mixes them with elements belonging to other levels of functioning, and combines them according to a different logic" (90-91). If this letter can be read-again, remembering affect's neutrality — as mediating the writer's embodied, affective response to shame, we can see a pedagogical form that does not correspond to "progress" or ameliorative practice. Rather, the author here contours a learned orientation that is complex and even contradictory: "Everyone has scared me, so, I will be on my guard and back off. Maybe say 'no' or shoo that person away or just walk away or? I have to wait 
and see on it, then go from there (what direction will it go in). Plus, trust them." The infolding of shame reflects affect's pedagogical capacity, but what was "learned" is both unsettled and unfulfilling: "I never really learned" (emphasis mine). And, of course, this pedagogical emergence is circulated and transformed further by dint of its enrollment as “archival material," literalized in its incorporation into Williams's educational center.

Given Ahmed's discussion of the relationship between normative conceptions of the family and queer unhappiness, it is unsurprising — though no less meaningful — that the author's second letter regarding his familial obligation, and not the letter detailing his sexual identifications, is marked "confidential." Given that queer unhappiness, for Ahmed, emerges in response to a non-normative orientation to "objects [that] are attributed as the cause of happiness [and ... ] already circulate as social goods" ("Happy Objects" 41), we can read the letter writer as expressing his position as a disorienting orientation toward a normative object. Ahmed writes:

When we feel pleasure from such objects, we are aligned; we are facing the right way. We become alienated — out of line with an affective community — when we do not experience pleasure from proximity to objects that are already attributed as being good. The gap between the affective value of an object and how we experience an object can involve a range of affects, which are directed by the modes of explanation we offer to fill this gap. (Ahmed, "Happy Objects" 37) In a sense, it is possible to read the gap between the two letters-between "confidential" feelings related to familial relations and the seemingly more "open" feelings regarding the authors own sexual orientations and experiences — as materializing and mediating conflicting affective intensities. In a sense, the writer expresses a disorientation toward 
multiple normative affective objects: compulsory heterosexuality, repressed performances of homosexuality, the family, as well as to his own precarious class position and financial position in relationship to family. In this sense, again, the letter demonstrates a queeraffective response to the transversal dynamics of normativity and its instantiation within "sanctioned" objects of desire.

The traces of these queer affects are, furthermore, ineluctably entangled. Whereas the decision to inscribe these feelings across two letters seems to indicate a desire to keep these affects separate, their coterminous delivery—both to Williams and to readers in the archive - complexifies their apparent division. Stapled together and classified as archival material, the letters encourage readers to consider them as existing together at a single temporal moment rather than as a process of inscription that spanned across time. Somewhat paradoxically, this phenomenon reflects what Lisa Gitelman has termed the "continuous present" of the Internet, where the flattened temporality of information leads to a "present tense of hermeneutics" that renders the processuality of the world elusive (Always Already New 145). This parallel does not reduce the fundamental mediatic differences between print and digital archives, but rather shows the ways that materializations of knowledge, information, and affect always involve meaningful transformations that exceed intentionality and instead participate in unpredictable, rhetorical emergences. This flattening demonstrates the "power of the archive," to borrow Morris's term ("Archival Turn" 115), in shaping queer knowledge. Attending to traces of affect's movement across documents provides one way of asserting the processuality of archival formation.

"Whomever it may concern" 
A third letter, yet again, made use of multilayered inscription in ways that reveal traces of affective intensities. In this case, the letter was comprised by one "main" message written on a sheet of lined paper with two, separate addendums written in the margins. The main document details experiences of sexual assault as well as the author's own relationship to his sexuality, reading:

Whomever it may concern:

Please send me whatever printed material you have on homosexuality. I have had disturbing sexual encounters with the same sex-but it was more a [word illegible] rape because it was done out of fear that I would be hurt or killed. Sometimes I'll have perverse thoughts of approaching another male and preforming anal [sp] sex with from a behind because that is what was done to me, but then I'll get sickened by the thought and drive it away. At times I may not think about this at all and other times I can't put it out of my mind. I do like women and have had several girlfriends. I'm just thoroughly confused and ashamed by my thoughts. Please enclose the material in the SASE I have enclosed because my relatives investigate my mail allot. (The Newspaper Project) An arrow points from "enclose the material" to a marginal note emphasizing the author's request for discreetness: "If you do send a larger envelope please do not disclose anything about homosexuality on the outside of the envelope." Finally, a second marginal note is included a few lines below: "I feel like I'm a pervert. A prisoner trapped by my own penis."

Phenomena already discussed in previous letters — shame, trauma, and a disorientation toward normative objects of happiness - coalesce in this deeply personal 
letter. That this letter was sent to a stranger-Williams—-likely speaks to the level of pain experienced by the author and potentially a desire to write his experience. Intentionally or unintentionally, the document serves as an affective disclosure across multiple senses of the word. The author discloses in the sense of "coming out," as an identification of his relationship to his sexuality and gender. This disclosure, however, is unsettled and unclear. Additionally, he discloses his own trauma emerging from his sexual assault, and the ways that it has become entangled with his own sexual desires and relationship to his body. At a meta-level, the rhetoric that emerges from the letter and marginalia can, itself, be understood as a disclosure as defined by Hekman. As discussed in Chapter 1, Hekman uses disclosure to refer to the material and differential ways that the world is made intelligible. Specifically, disclosure entails that "we do not constitute that reality with our concepts, but rather portray it in varying ways" (92). In a complementary comment, Cvetkovich has noted that "Recent queer/gay and lesbian theory, fortified by a critique of the repressive hypothesis, has been alert to the intricacies of acts of disclosure, where shifts in context, audience, and speaker can dramatically alter the meaning and effect of coming out, as well as what constitutes speaking (or being silenced)" (Archive of Feelings 94). With this in mind, I do not here attempt to give a name to the traumatic, embodied, and affective experiences signaled by this letter writer. To do so would be deeply unethical given the scant information we have about him and that he does not at any point identify himself as exhibiting a particular "category" of sexuality. To name his experience, in other words, would be to participate in practices of classifying-in effect, normativizing - queer archival materials critiqued by the work of both Bessette (Retroactivism) and Rawson ("Rhetorical Power"). 
The processuality of the three inscriptions, however, does seem to indicate traces of the passage of affect. Taken together, these traces flow from traumatic encounters with others ("I have had disturbing sexual encounters with the same sex"); toward the writer's interiority ("At times I may not think about this at all and other times I can't put it out of my mind"); outward to considerations of circulation, disclosure, and familial relations; and eventually to the writer's body itself, as indicated in what seems to be his final inscription: "A prisoner trapped by my own penis." Returning to Watkins's discussion of affect, the interplay between inscriptions can reveal the movements between affectus, "the force of an affecting body," and affectio, "the impact it [affectus] leaves on the one affected" (289), a phenomenon clearly at play in this final letter-writer's disclosure of trauma. Again, locating affect itself is difficult and potentially impossible, not least so using typical text-based modes of analysis. But by considering this author's three inscriptions as a process, we can find traces of affect's movement-a small archive of feelings. As Cvetkovich writes:

The archive of feelings is both material and immaterial, at once incorporating objects that might not ordinarily be considered archival, and at the same time, resisting documentation because sex and feelings are too personal or ephemeral to leave records. For this reason and others, the archive of feelings lives not just in museums, libraries, and other institutions but in more personal and intimate spaces, and significantly, also within cultural genres. (Archive of Feelings 244) Though I would caution against the notion of "immaterial" archives in favor of an expanded view of how we understand materiality (see Chapter 1), these letters clearly 
demonstrate ways that traces of queer affect and feelings become archived — embedded— in artifacts.

\section{$\underline{\text { Archival Ethics }}$}

I have argued that considering the processuality of inscription can reveal traces of affect in archival documents. This perspective frames certain letters sent in response to Williams's "Newspaper Project" as themselves small archives of affect's movement. If affect, returning to Seigworth and Gregg, refers to "a body's capacity to affect and be affected" (2), the incorporation of these letters into KGLEC/WNA augments the larger archive's own affective capacities. What, however, are the ethical ramifications of Williams archiving these letters? If, as Ahmed claims, our orientation toward objects emerges not from a vacuum but from the way objects are given, how can we consider the "given-ness" of this correspondence? As I've mentioned already, there seems to be no indication that these writers were aware their letters would be preserved, and an additional wrinkle is that not all of Williams's advertisements referred to the KGLEC as an archive, making it even less likely that the writers might know their letters were to be preserved. Again, if affect refers to capacities of affectability, then we must also consider the ways that Williams's archiving of these documents both augmented and transformed such capacities by way of his archival practice. I argue that such questions resist closure and instead are generative to the extent that they reveal the radical complexity of queer archival formation.

As discussed in Chapter 1, Kember and Zylinska have attempted to reframe media studies as a "'theory of life,' whereby mediation becomes a key trope for understanding and articulating our being in, and becoming with, the technological world, our 
emergence and ways of intra-acting with it, as well as the acts and processes of temporarily stabilizing the world into media, agents, relations, and networks" (xv, emphases in original). Reworking Barad's theory of agential realism, they theorize the "cut" as an intervention in the world's becoming. The "cut" refers to "any ... technical practice that involves transforming matter" and is enacted as "both a technique (an ontological entity encapsulating something that is, or something that is taking place) and an ethical imperative (as expressed by the command: 'Cut!')" (82). The cut, similar to Hekman's concept of disclosure, refers to practices that attempt to articulate and stabilize aspects of reality. While Kember and Zylinska are clear that such cuts "inevitably entail some degree of violence"-inasmuch as they are imbued with a desire to shape the world "according to the 'perpetrator's' wish or whim"- the authors draw on the work of Emmanuel Levinas to suggest that ethical cuts can be generative since they help to generate subjectivity through a form of "good violence." In this case, Kember and Zylinska explain, "violence is constitutive of subjectivity: indeed, the subject can emerge only in response to the intrusion of alterity" (89). I find the metaphor of violence to be sweeping and at times too charged to describe the phenomena of rendering aspects of the world intelligible. Yet, Kember and Zylinska's commentary casts interesting light on Williams's decision to archive the letters sent in response to advertisements, especially due to their highly personal and affective character.

A generative dissonance is sounded here by conflicting archival ethics. On one hand, as discussed in more detail elsewhere in this dissertation, there is a strong body of knowledge that has emerged across disciplines critiquing the role of power in the production of archives (Bessette; Blouin; Cvetkovich; Morris and Rawson; Nestle; 
Rawson, “Accessing Transgender"; Rawson, "Rhetorical Power"; Rubin). To this point, Rawson has recently noted that archival description can be so seamless that our access to the past has an illusion of proximity and coherence.... Yet even within queer collections_-just as within all archives - the normative logics of archival description, the seemingly 'noncontroversial, the nonpolitical, the self-evident,' warrant closer examination and continual queering. ("Rhetorical Power" 330, 331)

Turning Rawson's point on its head, there is a sense in which classifying the letterwriters' affective inscriptions as archival material — as that which is to be readreorients not their epistemological but also their affective capacity, and there is something troubling about viewing the letters' articulations of feeling while knowing that they may not have been meant to be read twice.

On the other hand, there are the realities of archival injustices that have often omitted LGBTQ voices from historical record. To not archive these letters could arguably participate in historical oppressions and reify Ahmed's claim that negating bad feelings leads to a loss of queer historical experience ("Happy Objects" 50). Again, as Muñoz argues, the radical intervention of queer archives is their ability to challenge normative practices of record keeping by providing "alternate modes of textuality and narrativity," a comment that points to the generative potential of Williams archiving these letters. Their affective intensity is powerful and speaks to the conflicted and at times confusing intersections of non-normative identification, embodied phenomena, and emotion that Ahmed argues permeates queer affect. The letters hold, in other words, the capacity to 
move readers in generative and progressive ways - though we should remember Seigworth and Gregg's warning not to assume that all such transmission is positive.

The persuasiveness of each of these two contradictory perspectives highlights a fundamental, generative question facing rhetorical inquiry, and it is one that structures my thinking throughout this dissertation. Without delving into disciplinary history, it seems accurate to say that among the strongest urges of our intellectual production has been to move toward ever more complex understandings of the distributedness of rhetoric and the subsequent difficulty of locating it within any bounded "unit" of analysis - the speaker, the culture, the audience, the context, the document, the consequence, the institution, the discourse, the ecology, the network, and so on. Indeed, my work throughout this dissertation is firmly rooted in the conviction that archival rhetoric is more complex than we think it is. (And-like all phenomena-too complex to ever fully understand.) Yet even as I recognize the porousness of identity and embodiment, I find it difficult to shake my own affective identifications to $m y$ writing. There seems to be a deadlock, located not only within scholarly productions but also within my thinking, between a recognition of the entangled, cross-cutting, and distributed nature of practices of meaning-making and the affective intimacy of humans' participation in those practices. Feelings matter, too.

While I am unable to cut my way through this Gordian knot, Muñoz provides an incision worth exploring. He writes that queer ephemera refers to "all of those things that remains after a performance, a kind of evidence of what has transpired but certainly not the thing itself" ("Ephemera" 10). In other words, the archival production of queer experience can never be traced back to its context of emergence. Rather queer ephemera 
provide traces of queer experience that have been systematically discounted from archival collections throughout history, but these traces can never be understood as the "thing itself." The letters discussed throughout this essay — and I would argue archival material more generally - must always be understood on two entangled levels: as a complex process of materialization and circulation that transforms the letter's rhetorical and affective capacities, and simultaneously as indicators of lives lived by real people with real feelings and emotions. Williams's decision to archive these letters-regardless of his own intentionality—contributes to the WNA's rhetorical capacities in part by inducing affective and ethical discomfort with how we approach and circulate history. These letters, moved to an archival context, challenge assumptions regarding affective connections to writing, access to historical materials, and the role of mediation in the production of knowledge. In so doing, they provide a queer critique of epistemological certitude, revealing the limitations and challenges of archives for the ethical production of knowledge.

\section{$\underline{\text { Conclusion }}$}

In this chapter, I have made several related arguments. First, I have used Williams's "Newspaper Project" to demonstrate the distributed nature of the WNA's formation, the larger interest of this dissertation. I moved deeper into this argument by showing how the materiality of the letters sent in response to Williams's advertisement reflect materializations of queer affective intensities. Finally, I asserted that ethical considerations regarding the circulation of these letters (and, in a sense, their writers) provides a queer challenge to practices of knowledge-making. Of course, these concerns are only heightened by the fact that I write about them here. Even the decision to omit 
identifying information is a potentially negative transformation - if it is my contention that a desire to write one's experience was among the affective intensities structuring these letters, is it a violation of that experience to not include its author? Being committed to the ethical amplification of LGBTQ voices (Morris, “Archival Queer") but also aware of the subjective and potentially violence of "outing" individuals without their approval — and here the label of violence most certainly applies—-the decision to omit identificatory information seemed to be most ethical. But, ultimately, there is no "objective" position from which to produce meaning. As Barad writes, "We are of the universe - there is no inside, no outside. There is only intra-acting from within and as part of the world in its becoming" (Meeting 396). If, as Ahmed claims, the transmission of bad affect can positively mark the realities of historical oppressions, then perhaps the discomfort produced by these archived letters carries its own rhetorical potential, rupturing normative desires for closure and reorienting readers toward the contingency and unpredictability of our entanglement in and with the world. 


\title{
CHAPTER IV
}

\section{QUEER ARCHIVES, RHETORICAL ACCRETION, AND ENTANGLEMENT: QUEER CURATORIAL RHETORIC AND THE FORMATION OF THE WILLIAMS- NICHOLS ARCHIVE}

\begin{abstract}
"I want to relate what is 'missed' when we 'miss' the table to the spectrality of history, what we miss may be behind the table in another sense: what is behind the table is what must have already taken place for the table to arrive" (Ahmed, Queer Phenomenology 37).
\end{abstract}

\section{$\underline{\text { Introduction }}$}

On August $1^{\text {st }}$, 1990, Williams sent a packet of photographic slides to a researcher interested in lesbian and gay archives, depicting the archive he had been collecting and curating since 1982. Included in this packet were descriptions of the photographs and of his archival activity, in which he jokingly referred to his collection as:

[T]he only archives in the country that is still in the closet! Actually, when I moved into my current residence four years ago, about the only place I had to put the archives was in a huge walk-in closet off the dining room. Since that time, the archives has expanded to my kitchen and parts of my bedroom, but the heart of the archives remains "in the closet." (Williams, Personal interview. 9 Feb. 2018) 
For one photo, Williams remarked that "This is the archives office: actually the eating area of my kitchen. My lover, Harold, sometimes gets annoyed at the papers piled up on the table, but I try to work around our eating schedule." For another, he stated, "These are the tools of the archivist: scissors, pen, stapler, $3 \times 5$ notecards, and cellophane tape. Much of my work involves cutting out magazine and newspaper articles for our extensive clippings file." What initially struck me about the photos—apart from Williams's mirror photograph of himself-was their thing-ness. In other words, the archive was visually described as a collection of objects. Reorienting the epigraph from Ahmed above, this chapter considers what might be related when we consider the archive beyond its seeming textuality and givenness and attend to how human and non-human phenomena are entangled in the emergent arrival of the WNA. I argue that attending to this emergence reveals the transformative potential of queer rhetoric and queer archives, and that the realization of this potential demonstrates a phenomenon I refer to as queer curatorial rhetoric.

Among the ur-theorists of "the archive" is (of course) Foucault, who claimed in The Archaeology of Knowledge that the Archive is not a collection of texts or materials but "first the law of what can be said, the system that governs the appearance of statements as unique events ... [and] also that which determines that all these things said do not accumulate in an amorphous mass, nor are they inscribed in an unbroken linearity, nor do they disappear at the mercy of chance external accidents" (126). For Foucault, the archive is the system that orders discourses and assembles them into particular taxonomies - an obvious exertion of power. Friedrich Kittler, a media theorist, provided a response to Foucault that looks both before and after Foucault's analysis to complicate 
the earlier theorist's discursive focus. In a characteristically provoking fashion, Kittler asserts:

Even writing itself, before it ends up in libraries, is a communication medium, the technology of which the archaeologist [Foucault] simply forgot. It is for this reason that all his analyses end immediately before that point in time at which other media penetrated the libraries stacks. Discourse analysis cannot be applied to sound archives or towers of film rolls. (5)

Kittler's response signals a move away from the poststructuralist accounts of the archive that Foucault's discourse analysis engaged in and helped give rise to, and toward a posthuman, materialist account that highlights the how of the archive: How do materials become assembled into an archive? How do these materials act? How does an archive emerge, and at what point in that emergence do we focus our analysis?

As discussed in Chapter 1, the disciplinary history of rhetoric and composition reveals the methodological importance of archives, particularly to historiographic research. Archives have been especially significant for understanding the history of the discipline, as well as producing rhetorical histories. However, a greater attention to the disciplinary practices of archivists and to understandings of archives that focus on their deep and robust materialities can contribute to and extend these conversations. I use the plural form of materiality because, as scholars within and outside the discipline have argued, an acceptance that the world is material leads to an awareness of multivariate and sometimes contending types of materiality_embodiment, economic positionality, technologies, physical matter, and even discourse itself — can and have been theorized as fundamentally material phenomena (Barad, Meeting; Bennett; Braidotti; Rickert). A 
recognition that all of life emerges from and as matter gives rise to Barad's claim—which she extends and reworks from physicist Niels Bohr-that "concepts are materially embodied in the apparatus" (Meeting 143). As Barad explains, "apparatuses are the material conditions of possibility and impossibility of mattering; they enact what matters and what is excluded from mattering" (148). Even concepts such as sexuality and gender are material, not in an essentialist or determined sense, but because they are differentially and materially articulated by multivariate apparatuses. Crucially, apparatuses themselves emerge through the boundary-making practices of other apparatuses, which allows for a theoretical claim underpinning this dissertation (and discussed in more Chapter 1): the WNA is both an apparatus entangling a variety of phenomena to assemble and materially produce LGBTQ lives, histories, and experiences and its own meaningful emergence, performed through the constitutive entanglements of other apparatuses. From this perspective, there is no choice but to embrace materiality, since multiple material phenomena - again: embodied, economic, technological, physical, and even discursiveare operative in the formation and practices of archives, inflecting and at times determining our historiographic productions. This points to a need to expand Lerner's generative claim for the fundamental sociality of archival research (195-96), calling us to attend to the material practices as well the rhetorical performances of matter in the formation of a queer archive, which can be enacted through augmenting our understanding of curatorial practices.

One welcome addition to this conversation has been Morris and Rose's chapter in Working in the Archives, which demonstrates the generative potential of forming alignments between rhetoricians and professional archivists. Morris and Rose note that 
the archivist's role is too often invisible to researchers and identify a need to make this archival labor more visible (70). More frequently, however, archivists are discussed—not just in informal talk in hallways and conferences but even in some published research (Houck) - with a degree of suspicion or even antagonism, which may give one the sense that the archival disciplines are somehow oppressive or oppositional to rhetorical historiography. This is faulty logic. While there may be times that the aims of researchers and archivists diverge, an ignorance of or antipathy toward archival and curatorial practices threatens to produce confused rhetorical histories. Scholars such as Nan Johnson have rightly told us that "Historical scholarship is heuristic in the sense that the active research itself creates and recreates conceptual directions as well as an emerging hierarchy of topical and procedural priorities." Johnson goes on to write that the historian's work "bears the unique mark of how the investigative method has proceeded and of the inevitable hierarchy of topics and conclusions that have emerged to guide conceptual development" (Octalog 17). This chapter extends Johnson's claim to understand the material performances of archivists, curators, and also materials themselves in the formation of the WNA.

I contend that an attention to materiality and material practices is especially salient for studying a queer archive. This attention can help to avoid facile understandings of archives that so often assert (1) that institutional archives are the seat of power, oppressive, and totalizing, or (2) that "recovery" through the archiving of documents gives unmediated access to rhetorical histories. My perspective, instead, is informed by new materialist critiques of representationalism. According to Barad, representationalism is "the belief in the ontological distinction between representations and that which they 
purport to represent" (Meeting 46). Highlighting representationalism's inability to account for the inseparability of matter and discourse (which Barad combines into the term "material-discursive"), Barad instead argues for shifting to a performative theory that "takes account of the fact that knowing does not come from standing at a distance and representing but rather from a direct material engagement with the world" (49). Taking this further, she argues that "Images or representations are not snapshots or depictions of what awaits us but rather condensations or traces of multiple practices of engagement" (53). As I've argued, archives, too, emerge by way of material performances. Taking up this stance, I argue that considering the materialities of the WNA's formation can help us to understand how an archive emerges through boundarymarking practices, how the production of an archive is necessarily a transformation (not a representation), and how we might understand the negotiations between Williams and the "professional" archival staff as challenging normative archival practices. Most importantly, this perspective reveals the formation of an archive as a complex, ongoing performance of queer rhetoric, rather than as a container of materials related to LGBTQ life.

In this chapter, then, I discuss the ways the history and movement of the WNA from William's home to the University of Louisville's Archives and Special Collections challenged both Williams's commitment to grassroots historiography (Bessette, Retroactivism) as well as the "official" practices of the university's trained archivists. Reading our discipline's concept of rhetorical accretion alongside Barad's conception of entanglement, I highlight the ways that both the archive's movement and these challenges are constitutively entangled with phenomena marked both as human and non-human, 
such as activists, archivists, tables, floors, and, broadly, matter itself - a form of transformational and rhetorical accretion. Throughout, I argue that considering this entanglement can help develop a robust understanding the WNA and its demonstration of what I refer to as queer curatorial rhetoric, a process that not only challenges normative archival practices (though certainly that) but that also destabilizes typical modes of thinking about subjectivity, a project of queer theory and new materialisms alike.

\section{On "Material Rhetoric"}

Our discipline has a long and critical engagement with materiality, and has produced a number of varying articulations of "material rhetoric," which Jack Selzer argues has emerged "as a consequence of postmodern and poststructural turns in rhetorical thought." He goes on to describe two primary paradigms of material rhetoric: the material manifestations and circulations of oral and literate attempts to persuade, and the ways that material conditions and artifacts are themselves fundamentally rhetorical (9). Barnett identifies the various materialisms produced by the field as indicating a "material turn," but notes that Harman's object-oriented philosophy (discussed in more detail Chapter 1) can push these directions further. Ian Bogost similarly draws on Harman's work, writing that "If ontology is the philosophical study of existence, then from Harman we can derive an object-oriented ontology . . . contending that nothing has special status, but that everything exists equally" (6). Rickert has, perhaps, delivered the most persuasive push toward an object-oriented rhetoric, contouring an "ambient rhetoric" defined as "an emergent result of environmentally situated and interactive engagements, redolent of a world that affects us, that persuades us prior to symbolicity" (34). In doing so, he explicitly shifts away from theories of materiality that retain a focus 
on language-e.g., analyses of language's material effects (Greene; McGee) or Marxist theories of the material circulation of texts (Chaput; Trimbur) — and instead attempts to account for the rhetoricity of matter and things themselves (21).

There have been a number of critiques of these object-oriented modes of thinking, not only from scholars uncomfortable with the non-anthropocentric underpinnings of object-oriented ontology, but also from writers who share new materialist commitments. In her introduction to Object-Oriented Feminism, for example, Katherine Behar notes that:

$\mathrm{OOO}$ seems to relish, in the idea that humans too are objects, a sense of liberation from the shackles of subjectivity.... OOF therefore positions itself as a friendly if pointed rejoinder, reminding this flourishing philosophical discussion first, that object-oriented approaches to the world are practiced in disciplines outside philosophy, and second, that all too many humans are well aware of being objects, without finding cause to celebrate in that reality. (5)

In other words, histories of marginalized people — such as women, LGBTQ individuals, and people of color-being considered objects creates friction against the largely male and often celebratory "turn toward objects." Additionally, Zoe Todd has noted the irony of much of new materialist thought "worshipping a european thinker for 'discovering' what many an Indigenous thinker around the world could have told you for millennia." Though limitations of time and scope have left me unable to consider Indigenous theories of emergence and interconnectedness in this dissertation, these critiques point to the danger of object-orientations that omit an attention to the materiality and meaning and human and social phenomena. 
Perhaps unsurprisingly, it has been feminist theorists that have articulated the deep materiality of the world while also not occluding an ethical attention to humansthough some feminist materialisms have argued that the category of "human" is, itself, an invention, often with marginalizing or confusing underpinnings (Haraway; Barad, Meeting). A touchstone piece in the area of feminist-material rhetoric has been Tolar Collins's "The Speaker Respoken: Material Rhetoric As Feminist Methodology." However, this article seems notably omitted from these recent discussions of materiality in our field. Collins theorizes "rhetorical accretion" as the (decidedly human) agential layering of texts that leads to mutual transformations on and with an original text (548). This term has been taken up by Clary-Lemon from an archival orientation to frame location, relationships, positionalities, images, and contexts as additional layers of rhetorical accretion to be read as texts that augment our understanding of the production and distribution of particular archival documents in space and time, affect our selection and triangulation of archival texts, and hint at a need for a changing vocabulary to address archival methods and methodologies together. (387)

Both Tolar Collin's and Clary-Lemon's work, then, already destabilizes the boundaries of both "text" and archive, including material factors that seem to exist outside each yet still become swept up in transformational entanglement, a phenomenon that Barad would refer to as intra-activity.

From the perspectives offered throughout this dissertation, it is possible to critique the anthropocentrism and the discursivity of Collins's theorizing as well as the potential for accretion to be understood as additive, in other words, one self-contained text layering 
upon another, rather than engaging in transformative entanglement. Indeed, Barad's theory of entanglement—which undergirds this dissertation — states that "phenomena are the ontological inseparability of intra-acting 'agencies.' That is, phenomena are ontological entanglements" (Meeting 333, emphasis in original). In other words, entanglement is the structuring principle of the world's becoming and reflects the deep inseparability and collectivity of existence in the absence of an intervening apparatus, making it impossible to disentangle human and nonhuman phenomena. However, given that Collins and Clary-Lemon's theories of rhetorical accretion already offer vocabularies to consider how rhetoric is always contingent upon material contexts, it seems more productive to retain and extend them, rather than subject them to critique. To do so, I read them alongside Gries's new materialist-informed conception of rhetorical transformation, which Gries defines as "the process in which things become rhetorical in divergent, unpredictable ways as they circulate, transform, and catalyze change" (27).

Transformations and becomings are even more important when considering the queer archive under discussion here. Gries notes that "Things that propagate the fewest and most consistent consequences have have the most stable meanings.... But often, things have a multiplicity of meanings that simply go unnoticed by scholars because case studies are typically bound by certain contextual elements" (51). Because, as Morris and Rawson note, queer archives challenge the often invisible forces of archival normativity (76), and — as Bessette has powerfully argued — both queerness and normativity are dynamic and shift across contexts ("Queer Rhetoric"), it becomes even more pressing to consider the ways that rhetorical accretion — which I understand as the transformative entanglement of material that develops its own persuasive potential—-transforms 
materials, researchers, curators, archivists, and many other "bodies" through intra-action. This transformative intra-action reveals the formation of a queer archive as deeply rhetorical, as queer curatorial rhetoric. Rather than casting this formation in a purely object-oriented mode, the queer-feminist materialist perspective I take up here helps to understand how humans and things are transformed and redefined through their entanglement. And these entanglements have consequences that matter.

\section{The Matter of the Williams-Nichols Archive}

As discussed in Chapter 2, the archive that would become the WNA was begun in the early-1980s as a project to contribute to Gays and Lesbians United for Equality, a social movement organization operative in Louisville from 1982 to the early 1990s. It continued to grow exponentially, not least so when Williams began advertising the archive and accepting contributions from the lesbian and gay community in Louisville. As described in meeting minutes in 1983: "Dave W. will be starting to attend the meetings on a more regular basis. He will bring his box, so that we can see what type of historical information he has collected thus far" (GLUE, "Minutes," 17 Nov. 1983). This comment is important, as it reflects the accretive, entangled nature of the archive's emergence. Indeed, curating an archival collection is, quite literally and physically, the process of transformatively entangling matter through accretion. This accretion of this matter emerges through the entangled forces of human and non-human phenomena; as Williams himself wrote, "These are the tools of the archivist: scissors, pen, stapler, $3 \times 5$ notecards, and cellophane tape" (Packet).

In an interview with Williams, I asked about the early days of the archive, and he responded that 
Williams: Yeah, it was a slow process. 1986 - what was he my uh fourth lover (laughs) left for California and I was kind of heartbroken and so I didn't have much to do. At about the same time another collector here in town, name of Collin Schwoyer, knew about the archives, and he had been collecting. He had "sticky fingers" like I do. He had lived in New York in the early '70s so and so he decided to give us this huge collection of early New York Gay and Lesbian newspapers. Which is a fabulous trove today.... So it was his contribution that kind of got me interested in expanding it a little more. And so from about 1987 all the way up to 2000 I just started collecting everything. Books, magazines. I would collect stuff from the Courier Journal about stuff that really didn't pertain to gays and lesbians necessarily, like I started a folder on Elton John and I started one on Madonna, you know. And sometimes the Courier Journal would have a little gay snippet of news from Idaho so I'd clip that out.

Wysocki: Yeah.

Williams: So gradually over the next decade and a half it became not just a Louisville thing or a Kentucky thing but a national archive in scope. And it just got really out of hand. (Williams, Personal interview. 9 Feb. 2018).

In this brief comment, Williams reveals a number of entangled phenomena that contributed to his collection and curation of the archive's materials: the affective force of romance; the material circulation of publications containing material relevant to lesbian and gay life; the material practice of "clipping out" articles from these publications, as well as the curatorial activities of archiving them; and the boundary marking practices of deciding what constitutes lesbian and gay material. Furthermore, as he explains, there 
were other collectors involved that were highly formative for the archive, providing further evidence for the entangled nature of the archive's emergence.

As discussed in the previous chapter, Williams's collection soon grew too large to "bring his box," and he was eventually forced into opening his home to visitors of the archive, which he also began to advertise more publicly: "The archives is a prime source of research for local gay groups wanting to know more about their own organizations and about gay life in the local community." The advertisement also noted that "Heterosexuals are welcome provided they have legitimate reasons for wanting to see the archives" and also that "Care is taken that no names, phone numbers or addresses of individuals in the community are revealed to persons who may do harm with such information" ("Kentucky Gay and Lesbian Archives"), reflecting an attunement to how the material embodiment and identity of potential visitors might inform their intentions, as well as how Williams's own material practices of record might intersect with those bodies in unpredictable ways.

Much of Williams's home became dedicated to housing the archive, which slowly but consistently grew to include a staggering amount of material across a range of formats and from a number of different regions, a material reality that would become its own persuasive force. When I asked about Williams's decision to move the archive, he explained:

I just couldn't handle it. For one thing there was no space in my basement left. I started collecting videotapes and audiotapes, which I didn't keep in the basement for moisture reasons. I kept them in my walk-in closet. And then the book collection—-the library—started exploding uh between ' 87 and 2001. The front room of my house was just nothing but bookcases and then my living room and 
then my bedroom you know (laughs). I started joking with people that the archives was not in my house: I lived at the archives. (Williams, Personal interview. 9 Feb. 2018).

Williams's anecdote calls attention not just to the materiality of rhetoric, but also to rhetoricity of matter, which enacted its own rhetorical force in the emergence of the archive. In other words, the literal weight of the archive's accretion was a persuasive element in Williams's decision to move the archive.

When I asked about a rumor I had heard that the archive had damaged the foundation of his house, Williams explained that that was an exaggeration but that an important factor in his decision to re-house the archive was its literal, actual weight. He explained: "Well the books, books are so heavy you know, and they were all in the front room. It's an old house built in 1895, so I think that lore comes from the fact that I was really worried that the floors were gonna start to sag or crack [laughs]. That was another issue and I thought, 'Well maybe we need to get it out of the house,' you know" (Williams, Personal interview. 9 Feb. 2018). Clearly, matter weighed heavily in Williams's decision to rehouse the archive, which points to a need for considering the blunt, physically persuasive effects of rhetorical accretion. Other material factors, of course, played an integral role, such as the economic consequences of damage to the home. Taking these material factors into account allows us to further extend Jenny Edbauer's argument that elements of the "rhetorical situation" are not static and discrete but "bleed" into one another. In this case, rhetorical entanglements between human and nonhuman elements, as well as the fundamental inseparability of matter and discourse, 
produced its own persuasive and, considering scholarship on queer archives, political force.

There is an understandably strong push in many conversations regarding queer archives toward sustaining grassroots, LGBTQ community-based practices and locations of archives. Joan Nestle, co-founder of the Lesbian Herstory Archives (the well-known archives housed in Brooklyn, NY), has argued against "institutionalizing" queer archives, writing:

We cannot trust "historical understandings" or "academic institutions." Both of these terms are failures. Historical understanding does not change because data exists to disprove myths or dethrone prejudices. If this were so, Black Americans would have been given reparations years ago. Academic institutions are mostly both educational and cultural failures, even for the students they seek to serve. A people must experience their own history in such a way as to change history.... We live on our homes, on the streets, in the bars, at our desks, at our jobs, with our children, in our groups, and we create our history every day. It is this story the archives wants to preserve and share. (Nestle)

In other words, Nestle considers academic institutions as incapable of properly contextualizing lesbian experience and frames archival practice as explicitly activist. Additionally, at least in the case of lesbian archives, Nestle argues that such archives must necessarily be emic, produced by and located within the communities from which they emerge. These comments, and the legacy of the Lesbian Herstory Achives, reflect a radical divergence from academic and professional attitudes toward archival labor, 
captured succinctly on the "What are Archives?" page of the Society of American Archivists (SAA):

In the course of everyday life, individuals, organizations, and governments create and keep information about their activities. These records may be personal and unplanned ... or they may be official and widely shared... . These records, and the places in which they are kept, are called archives, and archivists are the professionals who assess, collect, organize, preserve, and provide access to these records. (Society of American Archivists).

Clearly, Nestle and the LHA are opposed to this definition, seeing archives and archival labor not as the neutral preservation of records but rather, as described by Bessette, as retroactivism, which "manifests as lesbian collectives impugn, deconstruct, and scavenge existing historical accounts and libraries, and compose new histories and archives out of the detritus to shape identification and political leverage" (Retroactivism 11). While these conversations specifically discuss lesbian archives, I would argue that such perspectives and practices are reflective of archiving LGBTQ experience more broadly,

While Nestle and the LHA offered vocal and early articulations of the politics of locating queer archives, the question of location reverberates through queer archival scholarship. Gayle Rubin has called for "the continued need to build stable institutional forms that can insure the ongoing development, preservation, and transmission of such knowledge" (347), highlighting that a lack of access to institutional support can also contribute to the loss of queer knowledge. Cvetkovich, however, has argued that while she has been "amazed by the proliferation of queer archives," she remains committed to "questions about what kind of archive we want: a traditional archive with paper 
documents and records, or one that uses ephemera to challenge what we mean by the archive? Inclusion and assimilation into existing archives, or a separate (but equal) archive? Or do we want an entirely different version of an archive, one that perhaps lies outside a bounded spatial enclave" ("Queer Archival Futures")? In rhetoric and composition, Rawson and Morris have made similar critiques, arguing that the location of queer archives in institutional libraries dissuades the use of such archives by LGBTQ communities (85), and Rawson has argued, discussing transgender archives specifically, that "the language that an archive 'speaks' has wide-ranging consequences for archival practices." In response, he has described a continuum of archival values from institutional to professional to grassroots archives that correspond to a shifting focus on "efficient access" (institutional archives) to "discovery" (grassroots archives) (“Accessing Transgender” 136).

My intention is not to prescribe the locating of queer archives in academic or grassroots contexts, though these debates certainly reveal the complexities of such decisions. Rather, and returning to Williams's decision to re-house his archive, the key point is that matter was an entangled force in ultimately political decisions about the curation of Louisville's queer history, a realization that may seem surprising given Latour's claim that we have, largely, yet to include objects in our understandings of politics ("Realpolitik to Dingpolitik" 7). But to stop there, to say only that matter matters, would be to exit into an object-oriented mode of thinking. Instead, as Malea Powell has helped us to understand, "We need ... to move our conversations and our practices toward 'things,' to a wider understanding of how all made things are rhetorical, and of how cultures make, and are made by, the rhetoricity of things" (Agnew et al. 122). While 
the new materialist orientation I take up would add that all things — made by humans or otherwise - have the potential for rhetoricity, I take Powell's point to ultimately be that focus solely on humans or on misses the flows from which boundaries and meanings of each emerge. The point to me is not to orient toward objects, but rather to include materiality and matter as vital aspects in our readings and productions of queer-archival histories, understanding that these histories emerge not from isolated and bounded rhetorical subjects but through the entanglement of a wide array of phenomena, including accretive, rhetorical flows between bodies bounded as human and non-human. An archive emerges at the intersection of curation, material performances, "natural" phenomena like moisture, and even researcher's practices of reading, since published research on an archive, in my estimation, necessarily transforms the archive under consideration by circulating particular disclosures of its meaning. Ernst writes that the archive is "a relational but not coherent topology of documents that wait to be reconfigured, again and again" (194). As discussed in Chapter 3, this a recognition fraught with ethical heft.

Williams's archive, then, enacts an ongoing performance that can be understood in terms of Kennedy's conception of "distributed curatorial practices," where the "labor of curation is distributed across time and space, carried out recursively by scholars, publishers, and booksellers as they curate and distribute texts, reusing and expanding the same information base" (15). Crucially, Kennedy asserts that such practices cannot exist solely within the human province, noting "[t]he network of nonhuman actors who take part in the technological system of print production and circulation" (27). Kennedy's project focuses on the curation and authorship of encyclopedic knowledge, and she 
argues that a distributed account of curation simultaneously destabilizes the ideologies of the Author as "an identifiable, discrete genius" (25) and also reveals the complex roles of the curator, who "wrestles with and decides what constitutes knowledge and how readers might access it" (32). Synthesizing Kennedy's perspective with those of new materialist feminisms, then, offers a way to consider the archive's materiality that does not discount the role of human or nonhuman phenomena but attempts to see them in their dynamic processes of entanglement. ${ }^{11}$

The examples discussed thus far, however, have focused on rather literal, though no less important, understandings of "matter." Further, they are more or less obvious once one begins to consider the role of matter in the emergence of archival rhetoric. I now turn to a number of less obvious examples by considering the material, rhetorical negotiations between Williams and "official" archivists and curators of the University of Louisville's Archives and Special Collections. These material practices, as I will show, entangle with human and non-human phenomena.

\footnotetext{
${ }^{11}$ Readers may notice a shift from "entanglement" to "distribution" in this discussion of Kennedy's work. In the context of this dissertation I ultimately find this to be a rather minor theoretical point, but the key difference between the two is that entanglement, in the context of Barad's new materialism, implies a coming-together where phenomena emerge and are (re)defined through their intra-action. In this view, agency is the effect of entanglement. Distribution, on the other hand, is a term typically drawn from Latour and describes how any particular phenomenon cannot be described solely based on human activity but rather is a distributed effect of the pre-existing agencies of humans and non-humans. The difference may seem pedantic but becomes salient when one considers the dangers of "human" as an assumed and selfevident category in the distribution model, which new materialist feminisms rightly identify as a historically incorrect and problematic assumption. While engaging and important, these internal debates in new materialist thought largely fall outside the scope of this dissertation, and I welcome Kennedy's call to bring non-human phenomena more fully into our scholarly purview.
} 


\section{Queer Curatorial Rhetoric in Institutional Space}

During an interview, I asked Carrie Daniels, the Director of Archives and Special Collections at the University of Louisville, about her general roles and duties. One of the many activities she describes stands out to me: "I work to bring [archives and collections] in and to get some physical and intellectual control over them." Later, reading over this statement in my interview transcription, my mind leapt toward Foucault and to Derrida, reveling at the possibility of discovering some sort of hidden motive, some implication of power and control inherent to "the Archive." Then I saw another comment, coming exactly after: "so that means describing them in our catalog. . . [A]nd then materials are ... processed for use. So, they are, if they are in a state of disarray they have to be ordered," a much less sinister claim. To be clear, practices of classification can surely become problematic, especially in the case of LGBTQ archives. In a discussion of transgender archives, Rawson has powerfully warned that "archival description can be decidedly unqueer as it requires stabilization, categorization, and normalization across an axis of power" ("Rhetorical Power" 348). Considerations of the transformative power of archives are crucial and do call for a healthy skepticism toward practices of classification. I would extend Rawson's work to argue that my initial reaction reflected what Sedgwick refers to as a "paranoid reading" incapable of registering archival negotiations and transformations. Such a reading would stabilize both the WNA and Archives and Special Collections into a queer/normative binary, underemphasizing the material and resistant rhetoric emerging through their entanglement.

As Sedgwick explains, queer theory tends to (understandably) be susceptible to paranoid readings, both because of historical oppressions and a theoretical lineage 
connected to psychoanalytic thought. The problem is that paranoid readings often disavow reparative practices that question what particular modes of knowledge perform and that retain the potential for ameliorative practices of knowledge making: "How, in short, is knowledge performative, and how best does one move among its causes and effects" (124)? Rather than attempt to excavate hidden ideologies or "truths," I extend Sedgwick's performative stance and attempt to attune myself to reparative practices, including phenomena less recognizable as matter-at least in conventional uses of the word — but that still become physically and materially entangled in the archive's performance: negotiations between Williams as a grassroots archivist, the "trained" staff of Archives and Special Collections, and archival materials themselves. Taking ClaryLemon's point that "we may view both archival spaces and what we find in them as layers of rhetorical accretion to be read during an archival research process" (392), one can see these material entanglements as a form of rhetorical accretion that performs knowledge and rhetoric, rather than contains it.

Returning to Daniels's comment, it is true that ordering materials is not a neutral activity. As Bessette writes, "[s]ystems of classification in archives draw boundaries around materials, identifying records together in distinction from other classificatory categories," a reality that has wrought injustices and oppressions upon LGBTQ individuals and communities throughout history "both through omission of documents that would make queer lives and activity enunciable in Foucault's sense and through systems of classification that organized materials around categories of pathology, crime, and immorality (Retroactivism 69, 64). Similarly, Morris and Rose have written that "researchers examining materials in a collection will draw inferences about the 
intellectual relationships among the materials from their physical relationships to each other" (56), a comment that serves as a wonderfully practical example of Barad's point about the inseparability of matter and meaning. But the WNA cannot be understood solely in terms of a power differential where its institutionalization makes it a passive victim to the normative practices of archivists. Rather, the archive is better understood in terms of tensions and negotiations between human and nonhuman phenomena. These negotiations become salient when one begins to examine the practices of professional archivists.

In our interview, Daniels describes the general practices of archival staff and of herself. As materials are accessioned into Archives and Special Collections, they tend to be put in a temporary location before moving on to the processing stage, which is comprised by both arrangement and description. In the arrangement process, there are two abiding archival principles that tend to be followed as closely as possible. The first is a French term: respect des fonds. This term refers to the practice of keeping archives or collections grouped according to their provenance, which the SAA defines as "referring to the individual, family, or organization that created or received the items in a collection." The SAA goes on to write that "The principle of provenance or the respect des fonds dictates that records of different origins (provenance) be kept separate to preserve their context." Daniels gives a simpler, but no less meaningful definition: "respect des fonds ... means that, the material from one entity is not gonna be mixed with the material from another entity." Respect des fonds is a boundary-marking practice, one of many apparatuses that individuates "an archive" from the rest of the world. The second abiding principle is "respect for original order." As Daniels describes it, "if we get 
things ... in some kind of order we try to leave it in that order. . . [S]ometimes

organizational records come that way because multiple people have [been] using the files so they've had to create some kind of order so that it's intelligible" (Daniels, Personal interview. 2 Feb. 2018).

There is a way of reading both these archival principles and Daniels's comments that, while productive, might edge toward the types of "paranoid" readings discussed by Sedgwick. Daniels's appeal to intelligibility, for example, would likely remind readers of Butler's claim that the demand for social intelligibility is a tactic of control and marginalization directed toward unruly bodies and sexualities (Gender Trouble). It is also true that description is a fundamentally rhetorical practice but that it too often assumes a single epistemological orientation as a statement of fact. The archival disciplines have, however, recognized their non-neutral role in the production of knowledge, discussing and theorizing strategies for more equitable practices in their academic publications. In 1999, for example, Francis X. Blouin charted the ways that poststructuralism has led to a move from a traditionalist model of archival work — seeing records as a "sort of raw material" that "were created as a result of human interaction true to the transaction" and that are then "moved to inactive status and ultimately transferred to the archives" (103, 104) - to a perspective more informed by issues of power that takes archives "as an object of study, not simply as a place where study occurs" (103). Charting these shifting perspectives, Blouin ultimately enjoins archivists to consider the role of mediation in archival practice. This mediation leads to a disjuncture between "history" —"in some ways an official expression derived from institutions (archives) that have official social 
responsibilities" - and "social memory," a "new mode of looking at the past, go[ing] beyond the archives to a validation of situational perspectives on the past" (109).

Further, archivists Michelle Light and Tom Hyry go so far as to critique finding aids' role in the workings of power, since they typically present an archive as a supposedly rational, objective description of an archive/collection. They note: "Archives and archivists are not disinterested bystanders documenting human experience, but active agents in creating very specific views of historical reality" (219). The authors argue that the finding aid has remained a largely unquestioned genre within archival science, omitting the impact of processing, providing only one perspective on an archive, and contributing to an ideology of objective description. In response, Light and Hyry argue that "postmodern thought challenges archivists, as individuals and social actors unable to separate their own viewpoints and decisions from their contexts, to consider our mediating role in shaping the historical record" (217). Enacting its own form of material, rhetorical accretion, these practices have effects on researchers, who are presented a seemingly objective and/or rational representation of an archive (220), and the authors note that "archivists technical-rational processes tend to hide the true social and political implications of our work" (221). In an effort to make the mediations of archival labor more visible, the authors propose that archivists include colophons_-"statements regarding the creation of a work" to contextualize archival practices (223), and annotations to finding aids that "allow multiple voices to express different perspectives and readings of a collection after processing is complete" (226). Daniels agrees. At the end of our interview, she cites the need to make archivists effects more visible to researchers, since "We have touched it." (Daniels, Personal interview. 2 Feb. 2018). 
Of course, as with scholarship in any field, the turn toward thinking about the roles of archivists and documents such as the finding aid does not mean that they are automatically put to practice in day to day operations. In fact, Williams's curatorial practices can be understood as a form of productive resistance to the "official" practices of the archive. Not least among these resistant practices is the fact that Williams continues to grow the archive, dropping off more documents - typically on a monthly basis - and fielding donations from across Louisville's LGBTQ community, a practice that materially forecloses on the development of a comprehensive finding aid. In an interview, Williams notes that one of his most prolific collectors is a traveler, continuously bringing more materials for Williams to add to the archive: "she just collects, she travels everywhere. She goes to Europe, Thailand and she goes to Palm Springs a lot so she brings a lot of stuff back" (Williams, Personal interview. 9 Feb. 2018). Furthermore, as noted by Delinda Buie - the Rare Books Curator and the staff member who works most closely with the WNA - the archive is also somewhat challenging due to the amount and variety of material that Williams accessions, which include, for example, a silver bowl given as an award and a large umbrella carried during a Gay Pride picnic. While Buie has no qualms about keeping the umbrella—and I should note that Archives and Special Collections has been committed to sensitive and informed practices since their incorporation of Williams's archive — she does admit that she is not quite sure of its role within the larger Archives and Special Collections:

Buie: [I]t's just leaning up in a corner, in the storage area cause I don't know what else to do with it.

Wysocki: Is that something that's like, pull-able, if someone came in? 
Buie: Yeah.

Wysocki: Oh wow. That's interesting.

Buie: Yeah.

Wysocki: I may have to pull that at some point [laughs]

Buie: [laughs] I mean I can just carry it. (Buie, Personal interview. 27 Mar. 2018) Buie highlights at least two challenging forms of materiality in this comment. First, the umbrella quite literally does not fit into the existing structure of the archive, which did not imagine that particular format in the construction of its storage area. It also speaks to the embodied materiality of archival labor, and reminds that the archive emerges through the entanglement of human and non-human bodies.

Williams's voracious practices of collecting, furthermore, reflect a phenomenon of queer archival formation described by Muñoz. Muñoz theorizes the collection of queer ephemera as a fundamentally political act and notes the possibility of "discuss[ing] an object whose ontology, in its inability to "count" as a proper proof,' is profoundly queer" ("Ephemera" 6). He goes on to assert that such ephemera, in their inability to be integrated into normative apparatuses, serve as a modality of anti-rigor and anti-evidence that, far from filtering materiality out of cultural studies, reformulates and expands our understandings of materiality. Ephemera, as I am using it here, is linked to alternate modes of textuality and narrativity like memory and performance: it is all of those things that remains after a performance, a kind of evidence of what has transpired but certainly not the thing itself. (10) 
In other words, queer ephemera - in their very existence — challenge structures of knowledge-making that have prohibited alternative epistemologies. As Bessette argues: "Because official archives, libraries, and histories have corrupted, forgotten, or elided queer pasts, queer archives must be composed with contents and in forms that do not look like the official paper records we expect archives to contain" (Retroactivism 39). While I argue in Chapter 2 that attending to the queer production of these "official records" can reveal resistant rhetorical material practices, Muñoz and Bessette provide necessary critiques of the modes of knowledge produced by traditional archival apparatuses.

Again, I want to emphasize that Archives and Special Collections is committed in good faith to the preservation of the WNA and to sensitive and informed practices. But, of course, there remain points of disagreement that are informative for considering the entangled nature of the archive's emergence. An illuminating example is Williams's collection of videotapes. As Williams noted in a quote above, one of his common practices was to collect and record videotapes of television programs relevant to lesbian and gay life. According to Williams, there were at one point at least six-hundred such tapes in his collection which, as indicated in quotation from Williams above, necessitated special practices and locations when the archive was in his home. Once the archive was moved to the University library, however, they posed a new set of challenges, as indicated by Buie:

Wysocki: Have there been any disagreements between the archival staff and David about keeping particular things or, types of material that gets collected? Buie: I wouldn't say disagreements. We've had questions before. ... Really the biggest dispute has been — and even that's not really a dispute, David was really 
passionate about recording stuff, and, off television-

Wysocki: Oh, I see.

Buie: - and we couldn't accept that. We couldn't keep it, we couldn't provide access to it. It's a violation of copyright, not for David as an individual but for an institution.

Wysocki: Yeah.

Buie: And that's been really hard for him, because he has just boxes and boxes and boxes of stuff that he recorded, cherished, catalogued, cared about wanted people to have access to and we just can't do it. And, so.

Wysocki: So does he still have all those tapes, or?

Buie: I've still got some of them.

Wysocki: Yeah.

Buie: Um... There were, when, um, he also got a bunch of stuff from the Fairness Campaign. And we had the conversation then that we weren't gonna take them. So he destroyed them.

Wysocki: Yeah.

Buie: Or gave them to people I'm not sure what he did with them. Don't want to know [laughs]. . . . But, um, instead of us accepting them and then trying to deal with them after the fact, Wysocki: Yeah.

Buie: um, we're pretty up-front that, not even to bring them in. (Buie, Personal interview. 27 Mar. 2018) 
On first glance, this seems like a sort of inverse form of rhetorical accretion- a rhetorical disavowal, perhaps. As argued in Chapter 2, however, it is important to remember that a decision not to include materials is itself a material performance that transforms the type of research able to be enacted. Discussing the loss of these tapes, Williams seemed to understand Archives and Special Collections decision, noting that "they don't even have a working video tape machine anymore." He then, however, went on to state that "hopefully all these are out on CD and the Internet somewhere" and admitted that "it is a little heartbreaking” (Williams, Personal interview. 9 Feb. 2018). The key point, however, is that the choice to reject the videotapes was not an autonomous decision made the institution. Rather, it is better seen as emergent, rhetorical response to the entanglement of both Archives and Special Collections and the WNA with larger apparatuses within which they are situated.

\section{$\underline{\text { Archival Records }}$}

Thus far, I have argued two primary points. First, that the WNA emerged - and continues emerge, due to Williams's continued collection-because of material, rhetorical accretion entangling human and non-human phenomena. Second, I have tried to indicate how the incorporation of the Williams's archive into Archives and Special Collections might be understood not as a process of "norming" the archive through institutionalization, but rather more complexly as a potentially reparative practice of mutual transformation, where the queer-activist practices of Williams's prolific curation cast light on and relativize the material practices of "trained" archival staff. Perhaps the most salient example of this that has emerged from my research regards Archives and Special Collections own practices of record keeping. 
As researchers-like myself — enter Archives and Special Collections, they place their bags into a small cubby and speak to a member of the archival staff. The staff member scans some form of photo identification into their records as the researcher fills out a form, identifying their full name, home address, email address, and their university affiliation/status. Upon first glance, this may seem relatively benign, but the potential problems can be seen quite clearly when considering that the individuals filling out these forms are kept on file as having visited an LGBTQ archive, a material inscription with the unlikely but also uncertain potential for circulation (see Chapter 2). As already discussed, this was a problem not only for Archives and Special Collections but also for Williams when the archive existed in his home, leading to the claim in his advertisement that "Care is taken that no names, phone numbers or addresses of individuals in the community are revealed to persons who may do harm with such information" ("The Kentucky Gay and Lesbian Archives"). While this concern was immediately evident to Williams as a gay activist active in lesbian and gay social movement organizations, the issue was made salient to Archives and Special Collections because of its incorporation of the WNA.

When I asked both Daniels and Buie about any challenges they found to be specific and unique when working with the WNA, each of them independently raised the topic of keeping records of visitors. Daniels noted that "as part of our security process we have to record - we have to register everybody that comes in, and it's part of our obligation to these materials that we keep, so we periodically have this discussion. There is this tension between you know can we, you know, we've-we feel sometimes we put people on the spot" (Daniels, Personal interview. 2 Feb. 2018). Similarly, Buie identified 
"the problems with having stuff in closed stacks, where people had to come and show identification and register and request things," and also noted that "sometimes I will notice a young person coming in realizing that they're going to have to make a formal request for something and leaving, without saying why they've come or what they want. And I suspect that that really is the issue" (Buie, Personal interview. 27 Mar. 2018).

The issue is complicated further by the material effects of Williams's prolific and ongoing collection and donation of materials. Put simply, these flows of materials make it difficult for the archival staff to know what is contained in any particular folder, and nearly impossible to verify that it stays there. For this reason, Buie notes that she is "grateful for the arrangement of our research room"- a collection of large tables, all of which are capable of being seen by on-staff archivists - and that "if I had a folder of manuscripts I would check in the folder and make sure that I knew what was in there before I handed it to somebody. ... I'm not gonna do that with one of David's resource files, because there's just so much that not only could I not count the pieces, I would totally lose track of all the different types of material that was in there" (Buie, Personal interview. 27 Mar. 2018). If institutional archives privilege "efficient access" over "discovery" (Rawson, "Accessing Transgender" 136), we can see that the material accretion of the WNA leads to a disruption of the normative practices of efficient access and poses challenges to standard practices of the archival staff. At the same time, this disruption is itself entangled with those practices. Bessette correctly argues that queer archives implicate "the role of the archive in the history of politics, power, and nonnormative sexuality" and that "archives are not merely places where documents naturally assemble due to their inherently preservable worth; they are shaped by 
rhetorical decisions of selection and arrangement" (Retroactivism 63). The WNA, however, shows the ways that the accretion of queer materials and their entanglement with Archives and Special Collections enacts a form of queer curatorial rhetoric that resists normative practices of classification. These material entanglements, furthermore, expose invisible overlooked aspects of the standard practices of archivists. This point extends Morris and Rawson's claim that "Queer archives ... in their very existence, critique and challenge the normativizing collecting and circulating practices of other institutions" (76) by revealing that a queer archive, when entangled within those institutions, has the potential to transform those institutions in reparative ways.

\section{Conclusion}

In this chapter, I have attempted to make the following arguments. First, an attention to feminist-new materialisms, such as Barad's theory of entanglement, can be productive in allowing us to consider the mutually transforming entanglement of human and non-human phenomena, and that reading this insight into our understandings of rhetorical accretion can provide new insights into material rhetoric. More important, I have used this synthesized framework to show the ways that matter intervenes in the ongoing emergence of the WNA. Taking a view of materiality that includes not only matter but also the entangled material practices of archivists, collectors, and curators as they intra-act with things and objects, I have argued for a complexified, reparative understanding of the incorporation of queer archives into institutional structures that is attentive to the transformative potential of a queer archive's emergence within a typically normative context. I refer to the realization of this potential as queer curatorial rhetoric. 
Of course, this reparative optimism could be looked at from another angle as simply naïve, and I am willing to accept accountability for such interpretations of my analysis - not least so because of my own distance from the communities affected by the William-Nichols Archive as a cisgender, heterosexual male. Still—and perhaps this arises from my own positionality — I would be deeply uncomfortable with producing an account of the WNA incapable of pinpointing moments of transformative resistance. It is true that there remain important concerns, not least so regarding the politics of location and their effects on audience. As Morris and Rawson note, it is possible that "many of those who champion and theorize and assemble queer archives, histories, and memories dangerously presume audiences' receptivity, recognition, and response" (85). It is without a doubt the case that the entanglement of the WNA with Archives and Special Collections does not create ideal conditions of access for LGBTQ populations, and there is a pressing need to further develop the "inducement" to queer archives and "infrastructural rhetorics" that Morris and Rawson call for (85). To omit the transformations enacted upon Archives and Special Collections by the WNA's material and fundamentally rhetorical accretion, however, would be to participate in the erasure of queer rhetoric and — broadly—queer agency that has been a feature of scholarship across disciplines for far too long. 


\section{CONCLUSION}

In this dissertation, I have argued that an attention to and an insistence on the materiality of an archive can illuminate the rhetoricity of queer archival practice in ways underemphasized by discursive accounts. Contrary to debates about the ethics of a "turn toward objects," I have found little value in pitting new materialism and queer theory against each other in a competition for critical territory. Rather, I have attempted to demonstrate an approach to the transversal materiality of an archive in ways that neither appeal to abstracted discursive formations nor omit the social element of human experience (which, as any suitable materialism would emphasize, is itself emergent from and entangled with material phenomena). Ernst has provocatively written that materialist analyses (in his case, media archaeology) "expose[] the technicality of media not to reduce culture to technology but to reveal the technoepistemological momentum in culture itself" (73). Similarly, I have sought to contour material entanglements involved in the emergence of a queer archive, not to negate lived experience and embodiment but to show how the production of a queer archive materially intervenes in ways that might not be evident without a robust consideration of the intra-activity involved in its becoming.

This is a rhetorical claim. It is rhetorical because it calls attention to how meaning emerges through complicated and entangled material practices. It is rhetorical because it 
attends to the ways that communities, individuals, and objects enact rhetorical (dis)identifications, agential cuts that are neither reducible to nor fully determined by the material conditions of their articulation. Rhetoric suffuses production, circulation, classification, description, revision, retraction, negotiation—all of which I have attempted to demonstrate as central to the formation of the WNA. The formation of an archive can be understood as a meta-rhetoric, a disclosure of history that is neither objectively representational nor subjectively constructed since, as Hekman states, "the dichotomies between the real and the constructed is, like all dichotomies, a false one" (Hekman 110). An archive emerges at the intersection of the production and circulation of documents, the transmission and material traces of affects, and human and nonhuman material practices (among many other phenomena). Approaching the transversal materiality of archives proves a Sisyphean task.

I have attempted to demonstrate ways of approaching the complexity of the WNA's formation while at the same time acknowledging the impossibility of a complete representation of the archive's emergence. Each chapter details only a few steps in the archive's dance. Furthermore, a challenge in writing this dissertation has been, to put it playfully, writing this dissertation. As Gitelman has claimed of the production of media history (and we should remember that an archive is, among many other things, a media technology):

Inscriptive media in particular are so bound up in the operations of history that historicizing them is devilishly difficult. There's no getting all of the way "outside" of them to perform the work of historical description or analysis. Our sense of history — of facticity in relation to the past—is inextricable from our 
experience of inscription. (Always Already New: Media, History and the Data of Culture 21)

Taking such difficulties into consideration, my analysis of the WNA archive's material emergence is limited in at least three ways. First, the necessity of turning to archival documents to tell the history of the WNA is a methodological challenge, since the archive mediates its own history. I therefore attempted to triangulate archival data with oral history interviews, but due to constraints of time and scope, a second limitation emerged in my relatively small sample set of interviews. Further research on the WNA should reach out to a greater number of willing participants in Louisville's LGBTQ community —members of GLUE, for instance—-for a more emic perspective of the archive's history.

Finally, making my arguments through rather traditional text-based practices is arguably disharmonic with my stated goal of thinking beyond discourse in considerations of archival rhetoric. I am compelled to agree with Kember and Zylinska that our habitual practices of scholarly production are in need of creative remediation "situated across the conventional boundaries of theory and practice, art and activism, social sciences and humanities" (188). Such critical media practices resonate with Morris and Rawson's claim that "archival queers must rhetorically induce and construct queer mnemonic socialization in alternative contact zones and counterpublic sites and subcultural spaces" (86). It is my contention that academics and archival researchers need to develop such artistic, creative, and consequential practices in the humanities as a way of amplifying the circulation and consequentiality of our work. Still, my commitments to the material practice of writing - the foundation of humanism - leads me to believe that there is value 
in textual work. As a way of engaging such practice at a slant, I include a brief manifesto synthesizing the implications of The Emergent Matter of Archives and suggesting directions for future work.

1. A queer archive is in some cases better understood as a rhetorical event unfolding across time, rather than a location, a site, or a container of documents. As I argued most explicitly in Chapter 3, the fact that an archive typically presents itself to us at once-inasmuch the documents that comprise it seem to exist in a flattened temporality as we glance through the finding aid—belies the processuality and emergent nature of how an archive is formed. By reading material traces of temporality into the archive, we can consider moments of rhetorical transformation and resistance.

2. The individuation of an archive (i.e., the ability to refer to an archive in the singular form) is an entangled, transformative achievement that deserves deeper analysis than we have tended to grant it. Considering an archive as a unified subject (or-as it has occasionally been framed to me in conversations with researchers in our field - as a place to find readymade narratives for scholarly analysis and production) underemphasizes the role of archives' circulation, their investment of affective intensities, and human and nonhuman actors involved their formation and curation. As I argued in Chapter 4, considering the formation of the WNA as a queer curatorial rhetoric entangling human and nonhuman phenomena underscores the dynamic rhetoricity of archival practice.

3. We should (generously) expand our knowledge about the roles and practices of curators, archivists, and library professionals. If we are to become "the deftest of 
archivist-rhetors" (Morris, "Archival Queer” 149), we must also become better attuned to the practices of archival professionals, a point persuasively argued by Rawson ("Rhetorical Power"). As Rawson demonstrates in his analysis of classification in transgender archives (and as I've attempted to show in my work here), such work does not necessitate assimilating to the disciplinary and professional norms and assumptions of archivists, but it does require a generous awareness of archival practices that, in turn, may call for an attenuation of critical energy.

4. We should find new ways to mobilize our archival disclosures toward explicitly ameliorative and public ends. This is an aspirational claim, as my work throughout this dissertation has been traditional in its production of scholarly analysis rather than a clearly defined intervention in affairs outside of intellectual inquiry. My hope for future work (both my own and others') would be that we intensify a shift to a creative approach that mobilizes archival scholarship toward explicitly activist purposes. Jenny Rice and Jeff Rice discuss "pop-up archives"practices of community-based archiving that attempt to "create a digital space that memorializes and highlights the temporality of network connections, the fragile and momentary ways that agents affect one another" (247). While their digital lexicon does not map neatly onto the production of physical archives, we (and I) would do well to follow their lead, theorizing ways of leveraging archival knowledge in publicly efficacious ways.

These points are meant to indicate potential lines of work, not critiques of current practices of archival research. I do suggest, however, that as rhetoricians we are uniquely 
poised to take up these challenges in ways that are consequential and —in the best caseameliorative. Considering the materiality of the WNA reveals modes of archival resistance intersecting humans, material practices, objects, affects, and a host of other phenomena. As rhetoricians, we can assist in studying, amplifying, further developing, and circulating such entangled strategies in efficacious and ethical ways. 


\section{REFERENCES}

\section{$\underline{\text { Primary Sources }}$}

Aker, Richard E. Letter to Jack Kersey. 21 June 1983. TS. Sam Dorr Papers. Williams Nichols Archive, University of Louisville Archives and Records Center, Louisville, KY.

Buie, Delinda. Personal interview. 27 Mar. 2018.

Daniels, Carrie. Personal interview. 2 Feb. 2018.

Frisk, Pam. "To the Member Representatives of GLUE.” 24 March 1984. TS. Gays and Lesbians United for Equality: 1984. Williams Nichols Archive, University of Louisville Archives and Records Center, Louisville, KY.

G.L.U. Meeting minutes. 15 August 1982. TS. Gays and Lesbians United for Equality: 1982-1983. Williams Nichols Archive, University of Louisville Archives and Records Center, Louisville, KY.

G.L.U.E. Brochure. TS. Gays and Lesbians United for Equality: 1982-1983. Williams Nichols Archive, University of Louisville Archives and Records Center, Louisville, KY.

G.L.U.E. "Minutes of the Monthly Meeting of Gays and Lesbians United for Equality." 17 November 1983. TS. Gays and Lesbians United for Equality: 1982-1983. 
Williams Nichols Archive, University of Louisville Archives and Records Center, Louisville, KY.

G.L.U.E. "Minutes of the Monthly Meeting of Gays and Lesbians United for Equality." 9 August 1983. TS. Gays and Lesbians United for Equality: 1982-1983. Williams Nichols Archive, University of Louisville Archives and Records Center, Louisville, KY.

G.L.U.E. "Minutes of the Monthly Meeting of Gays and Lesbians United for Equality." 20 February 1983. TS. Gays and Lesbians United for Equality: 1982-1983. Williams Nichols Archive, University of Louisville Archives and Records Center, Louisville, KY.

G.L.U.E. "Minutes of the Monthly Meeting of Gays and Lesbians United for Equality." 3 October 1983. TS. Gays and Lesbians United for Equality: 1982-1983. Williams Nichols Archive, University of Louisville Archives and Records Center, Louisville, KY.

G.L.U.E. "Minutes of the Monthly Meeting of Gays and Lesbians United for Equality." 20 October 1983. TS. Gays and Lesbians United for Equality: 1982-1983. Williams Nichols Archive, University of Louisville Archives and Records Center, Louisville, KY.

G.L.U.E. "Minutes of the Monthly Meeting of Gays and Lesbians United for Equality." 15 December 1983. TS. Gays and Lesbians United for Equality: 1982-1983. Williams Nichols Archive, University of Louisville Archives and Records Center, Louisville, KY. 
G.L.U.E. "Minutes of the Monthly Meeting of Gays and Lesbians United for Equality." 19 January 1984. TS. Gays and Lesbians United for Equality: 1984. Williams Nichols Archive, University of Louisville Archives and Records Center, Louisville, KY.

G.L.U.E. "Minutes of the Monthly Meeting of Gays and Lesbians United for Equality." 17 April 1984. TS. Gays and Lesbians United for Equality: 1984. Williams Nichols Archive, University of Louisville Archives and Records Center, Louisville, KY.

Kentucky Gay and Lesbian Archives. "The Kentucky Gay and Lesbian Archives.” April 5, 1986. TS. Kentucky Gay and Lesbian Educational Center. Williams Nichols Archive, University of Louisville Archives and Records Center, Louisville, KY.

“The Kentucky Gay and Lesbian Educational Center." N.d. TS. The Newspaper Project. Williams Nichols Archive, University of Louisville Archives and Records Center, Louisville, KY.

Kersey, Jack, Charles Raith, Jim Oxyer, Ken Terrill, Pam Frisk, Elise Bruch, and Nancy Collins. "Dear Mr. Priddy.” 26 March 1984. TS. Gays and Lesbians United for Equality: 1984. Williams Nichols Archive, University of Louisville Archives and Records Center, Louisville, KY.

Newspaper clipping. N.d. TS. The Newspaper Project. Williams Nichols Archive, University of Louisville Archives and Records Center, Louisville, KY. The Newspaper Project (folder). Williams Nichols Archive, University of Louisville Archives and Records Center, Louisville, KY. 
Priddy, Deney and Michael Kretman. Unpublished interview by David Williams. April 1984. TS. Deney, Priddy. Williams Nichols Archive, University of Louisville Archives and Records Center, Louisville, KY.

Williams, David. Packet of photograph slides and descriptions sent to Deborah Shelby. August 1, 1990. TS. Kentucky Gay and Lesbian Educational Center. Williams Nichols Archive, University of Louisville Archives and Records Center, Louisville, KY.

Williams, David. Personal interview. 9 Feb. 2018.

Williams, David. Personal interview. 21 Mar. 2018.

Williams, David. "Brief History of GLUE with Personal Observations.” N.d. TS. Gays and Lesbians United for Equality: 1982-1983. Williams Nichols Archive, University of Louisville Archives and Records Center, Louisville, KY.

\section{$\underline{\text { Secondary Sources }}$}

Agnew, Lois, et al. “Octalog III: The Politics of Historiography in 2010.” Rhetoric Review, vol. 30, no. 2, 2011, pp. 109-34.

Ahmed, Sara. "Happy Objects." The Affect Theory Reader, Duke UP, 2010, pp. 29-51. ---. Queer Phenomenology: Orientations, Objects, Others. Duke UP, 2006.

Alcoff, Linda. "The Problem of Speaking for Others." Cultural Critique, no. 20, 1991, pp. 5-32.

Alexander, Jonathan, and Jacqueline Rhodes. "Queer Rhetoric and the Pleasures of the Archive." Enculturation: A Journal of Writing, Rhetoric, and Culture, 2012.

Barad, Karen. "Interview with Dolphijn, Rick and Iris van Der Tuin." New Materialism: 
Interviews \& Cartographies, Open Humanitiies P, 2012, pp. 48-70.

---. Meeting the Universe Halfway: Quantum Physics and the Entanglement of Matter and Meaning. Duke UP, 2007.

---. "Posthuman Performativity: Toward an Understanding of How Matter Comes to Matter.” Signs, vol. 28, no. 3, 2003, pp. 801-31.

Barnett, Scot. "Toward an Object-Oriented Rhetoric: A Review of Tool-Being: Heidegger and the Metaphysics of Objects and Guerrilla Metaphysics:

Phenomenology and the Carpentry of Things by Graham Harman.” Enculturation: A Journal of Writing, Rhetoric, and Culture, vol. 7, 2010.

Behar, Katherine. "An Introduction to OOF." Object-Oriented Feminism, U of Minnesota P, 2016, pp. 1-36.

Bennett, Jane. Vibrant Matter: A Political Ecology of Things. Duke UP, 2010.

Berlant, Lauren, and Michael Warner. "Sex in Public." Critical Inquiry, vol. 35, no. 2 , 1998, pp. 547-66.

Bessette, Jean. "An Archive of Anecdotes: Raising Lesbian Consciousness after the Daughters of Bilities." Rhetoric Society Quarterly, vol. 43, no. 1, 2013, pp. 22-45.

---. "Queer Rhetoric in Situ.” Rhetoric Review, vol. 35, no. 2, 2016, pp. 148-64.

---. Retroactivism In the Lesbian Archive: Composing Pasts and Futures. Southern Illinois UP, 2018.

Biesecker, Barbara A. "Of Historicity, Rhetoric: The Archive as Scene of Invention." Rhetoric \& Public Affairs, vol. 9, no. 1, 2008, pp. 124-31.

Biesecker, Barbara A., and John Louis Lucaites. "Introduction." Rhetoric, Materiality, and Politics, edited by Barbara Biesecker and John Louis Lucaites, Peter Lang, 
2009, pp. 1-16.

Blouin, Francis X. "Archivists, Mediation, and Constructs of Social Memory." Archival Issues, vol. 24, no. 2, 1999, pp. 101-12.

Bogost, Ian. Alien Phenomenology, or What It's Like to Be a Thing. U of Minnesota P, 2008

Bordelon, Suzanne. "Embodied Ethos and Rhetorical Accretion: Genevieve Stebbins and the Delsarte System of Expression." Rhetoric Society Quarterly, vol. 46, no. 2, 2016, pp. 105-30.

Boyd, Nan Alamilla, and Horacio Roque Ramírez. Bodies of Evidence: The Practice of Queer Oral History. Oxford UP, 2012.

Braidotti, Rosi. Metamorphoses: Towards a Materialist Theory of Becoming. Polity, 2002

Brereton, John C. "Rethinking Our Archive: A Beginning." College English, vol. 61, no. 5, 1999, pp. 574-76.

Butler, Judith. Gender Trouble. Routledge, 1990.

Chaput, Catherine. "Rhetorical Circulation in Late Capitalism: Neoliberalism and the Overdetermination of Affective Energy." Philosophy and Rhetoric, vol. 43, no. 1, 2010, pp. 1-25.

Clary-Lemon, Jennifer. "Archival Research Processes: A Case for Material Methods.” Rhetoric Review, vol. 33, no. 4, 2014, pp. 381-402.

Collins, Vicki Tolar. “The Speaker Respoken: Material Rhetoric As Feminist Methodology.” College English, vol. 61, no. 5, 1999, pp. 545-75.

Cvetkovich, Ann. An Archive of Feelings: Trauma, Sexuality, and Lesbian Public 
Cultures. Duke UP, 2003.

---. "Queer Archival Futures: Case Study Los Angeles.” E-Misférica, http://hemisphericinstitute.org/hemi/en/e-misferica-91/cvetkovich. Accessed 11 Sept. 2018.

DeLauretis, Teresa. "Queer Theory: Lesbian and Gay Sexualities—An Introduction." Differences, vol. 3, no. 2, 1991, pp. iii-xviii.

Derrida, Jacques. Archive Fever: A Freudian Impression. U of Chicago P, 1995.

Dolphijn, Rick, and Iris van der Tuin. New Materialism: Interviews \& Cartographies. Open Humanitiies P, 2012.

Duggan, Lisa. "Making It Perfectly Queer." Socialist Review, vol. 22, 1992, pp. 11-31.

---. The Twilight of Equality?: Neoliberalism, Cultural Politics, and the Attack on Democracy. Beacon P, 2003.

Edelman, Lee. No Future: Queer Theory and the Death Drive. Duke UP, 2004.

Ernst, Wolfgang, and Jussi Parikka. Digital Memory and the Archive. U of Minnesota P, 2013.

Ferreira-Buckley, Linda. "Rescuing the Archives from Foucault." College English, vol. 61, no. 5, 1999, pp. 577-83.

Finnegan, Cara A. "What Is This a Picture Of?: Some Thoughts on Images and Archives." Rhetoric \& Public Affairs, vol. 9, no. 1, 2008.

Fosl, Catherine, et al. Kentucky LGBTQ Historic Context Narrative. 2016, https://www.nps.gov/articles/upload/Statewide_LGBTQHeritageofKentucky-508compliant.pdf.

Fosl, Catherine, and Lara Kelland. “'Bring Your Whole Self to the Work’: Identity and 157 
Intersectional Politics in the Louisville LGBTQ Movement." The Oral History Review, vol. 43, no. 1, 2016, pp. 138-52.

Foucault, Michel. The Archaeology of Knowledge and the Discourse on Language. Vintage Books, 1972.

Gitelman, Lisa. Always Already New: Media, History and the Data of Culture. MIT P, 2006.

---. Paper Knowledge: Toward a Media History of Documents. Duke UP, 2014.

Glenn, Cheryl. Unspoken: A Rhetoric of Silence. Southern Illinois UP, 2004.

Glenn, Cheryl, and Jessica Enoch. "No Invigorating Historiographic Practices in Rhetoric and Composition Studies." Working in the Archives: Practiucal Research Methods for Rhetoric and Composition, edited by Alexis E. Ramsey et al., Southern Illinois UP, 2010, pp. 11-27.

Greene, Ronald Walter. "Rhetorical Materialism: The Rhetorical Subject and the General Intellect." Rhetoric, Materiality, and Politics, edited by Barbara A. Biesecker and John Louis Lucaites, Peter Lang, 2009, pp. 43-66.

Gries, Laurie. Still Life With Rhetoric: A New Materialist Approach for Visual Rhetorics. Utah State UP, 2015.

Haas, Angela M. "Wampum As Hypertext: An American Indian Intellectual Tradition of Multimedia Theory and Practice." Studies in American Indian Literatures, vol. 19, no. 4,2008 , pp. $77-100$.

Halberstam, Jack. In a Queer Time and Place: Transgender Bodies, Subcultural Lives. New York UP.

Haraway, Donna. Simians, Cyborgs, and Women: The Reinvention of Nature. Routledge, 158 
1991.

Harman, Graham. Tool-Being: Heidegger and the Metaphysics of Objects. Open Court, 2002.

Havens, Sara. "7 Questions With ... LGBTQ Archivist David Williams.” Insider Louisville, https://insiderlouisville.com/lifestyle_culture/7-questions-with-lgbtarchivist-david-williams/. Accessed 16 Oct. 2018.

Hekman, Susan. The Material of Knowledge: Feminist Disclosures. Indiana UP, 2010.

Houck, Davis W. “On or About June 1988.” Rhetoric \& Public Affairs, vol. 9, no. 1, 2008, pp. 132-37.

Kember, Sarah, and Joanna Zylinska. Life after New Media: Mediation as a Vital Process. MIT P, 2012.

Kennedy, Krista. Textual Curation: Authorship, Agency, and Technology in Wikipedia and Chambers's Cyclopoedia. U of South Carolina P, 2016.

Kittler, Friedrich. Gramophone, Film, Typewriter. Stanford UP, 1999.

L'Eplattenier, Barbara. “An Argument for Archival Research Methods: Thinking Beyond Methodology." College English, vol. 72, no. 1, 2009, pp. 67-79.

Latour, Bruno. "From Realpolitik to Dingpolitik: An Introduction to Making Things Public.” Making Things Public: Atmospheres of Democracy, edited by Bruno Latour and Peter Weibel, MIT P, 2004.

---. Reassembling the Social: An Introduction to Actor-Network Theory. Oxford UP, 2005.

---. "Visualisation and Cognition: Drawing Things Together." Knowledge and Society Studies in the Sociology of Culture Past and Present, edited by Henrika Kuklick, Jai 
P, 1986.

---. "Why Has Critique Run out of Steam? From Matters of Fact to Matters of Concern." Critical Inquiry, vol. 30, no. 2, 2004, pp. 225-48.

Lerner, Neal. "Archival Research as a Social Process." Working in the Archives: Practical Research Methods for Rhetoric and Composition, edited by Alexis E. Ramsey et al., Southern Illinois UP, 2010, pp. 195-205.

“Lesbian, Gay, Bisexual, Transgender (LGBT) Studies: Primary Sources.” William F. Ekstrom Library, https://library.louisville.edu/ekstrom/lgbt_studies/primary.

Light, Michelle, and Tom Hyry. "Colophons and Annotations: New Directions for the Finding Aid." The American Archivist, vol. 65, no. 2, 2002, pp. 216-30.

Lynch, Paul, and Nathaniel Rivers. "Introduction: Do You Believe in Rhetoric and Composition?" Thinking with Bruno Latour in Rhetoric and Composition, edited by Paul Lynch and Nathaniel Rivers, Southern Illinois UP, 2015, pp. 1-22.

Mailloux, Steven. "Reading Typos, Reading Archives.” College English, vol. 61, no. 5, 1999, pp. 584-90.

Mao, LuMing. "Writing the Other into Histories of Rhetorics: Theorizing the Art of Recontextualization." Theorizing Histories of Rhetoric, edited by Michelle Balliff, 2013, pp. 41-57.

Massumi, Brian. “The Autonomy of Affect.” Cultural Critique, no. 31, 1995, p. 83.

McCarthy, John D., and Mayer N. Zald. "Resource Mobilization and Social Movements: A Partial Theory." American Sociological Review, vol. 82, no. 6, 1977.

McGee, Michael Calvin. “A Materialist's Conception of Rhetoric.” Rhetoric, Materiality, and Politics, Peter Lang, 2009, pp. 17-42. 
Micciche, Laura. "Emotion, Ethics, and Rhetorical Action.” JAC, vol. 25, no. 1, 2005, pp. 161-84.

Miller, Thomas P., and Melody Bowdon. "A Rhetorical Stance on the Archives of Civic Action." College English, vol. 61, no. 5, 1999, pp. 591-98.

Morris, Charles E. “Archival Queer.” Rhetoric \& Public Affairs, vol. 9, no. 1, 2008, pp. 145-51.

---. "The Archival Turn in Rhetorical Studies: Or, the Archive's Rhetorical (Re)Turn." Rhetoric \& Public Affairs, vol. 9, no. 1, 2008, pp. 113-15.

Morris, Charles E., and K. J. Rawson. “Queer Archives, Archival Queers.” Theorizing Histories of Rhetoric, Southern Illinois UP, 2013, pp. 74-89.

Morris, Sammie and Shirley K. Rose. “Invisible Hands: Recognizing Archivists’ Work to Make Records Accessible." Working in the Archives: Practical Research Methods for Rhetoric and Composition, edited by Alexis E. Ramsey et al., Southern Illinois UP, 2010, pp. 51-78.

Muñoz, José Esteban. Cruising Utopia: The Then and There of Queer Futurity. New York UP, 2009.

---. Disidentifications: Queers of Color and the Performance of Politics. U of Minnesota P, 1999.

---. "Ephemera as Evidence: Introductory Notes to Queer Acts." Women and Performance: A Journal of Feminist Theory, vol. 8, no. 2, 1996, pp. 5-16.

Munt, Sally. Queer Attachments: The Cultural Politics of Shame. Ashgate, 2008.

Nestle, Joan. "Radical Archiving: A Lesbian-Feminist Perspective." Outhistory, http://outhistory.org/exhibits/show/an-early-conversation-about-ga/voice-2-joan- 
nestle. Accessed 12 June 2018.

Octalog. "The Politics of Historiography." Rhetoric Review, vol. 7, no. 1, 1988, pp. 5-49. Parks, Steve. “'I Hear Its Chirping Coming From My Throat': Activism, Archives, and the Long Road Ahead." Literacy in Composition Studies, vol. 5, no. 1, 2017, pp. 8591.

Pflugfelder, Ehren Helmut. "Rhetoric's New Materialism.” Rhetoric Society Quarterly, vol. 45, no. 5, 2015, pp. 441-61.

Phelan, Peggy. Unmarked: The Politics of Performance. Routledge, 1993.

Poster, Carol. "Oxidation Is a Feminist Issue: Acidity, Canonicity, and Popular Victorian Female Authors." College English, vol. 58, no. 3, 1996, pp. 23-42.

Powell, Malea. "Stories Take Place: A Performance in One Act." College Composition and Communication, vol. 64, no. 2, 2012, pp. 383-406.

Ramsey, Alexis E., et al. "Introduction." Working in the Archives: Practical Research Methods for Rhetoric and Composition, edited by Alexis E. Ramsey et al., Southern Illinois UP, 2010, pp. 1-8.

Rawson, K. J. “Accessing Transgender // Desiring Queer(Er?) Archival Logics.” Archivaria, vol. 68, 2009, pp. 123-40.

---. "The Rhetorical Power of Archival Description: Classifying Images of Gender Transgression." Rhetoric Society Quarterly, vol. 48, no. 4, 2018, pp. 327-51.

Rice, Jenny, and Jeff Rice. "Pop-Up Archives." Rhetoric and the Digital Humanities, edited by Jim Ridolfo and William Hart-Davidson, 2015, pp. 245-54.

Rickert, Thomas. Ambient Rhetoric: The Attunements of Rhetorical Being. U of Pittsburgh P, 2013. 
Rivers, Nathaniel. “Tracing the Missing Masses: Vibrancy, Symmetry, and Public Rhetoric Pedagogy." Enculturation: A Journal of Writing, Rhetoric, and Culture, 2014.

Rohy, Valery. "In the Queer Archive: Fun Home." GLQ: A Journal of Lesbian and Gay Studies, vol. 16, no. 3, 2010, pp. 341-61.

Royster, Jacqueline Jones, and Gesa Kirsch. Feminist Rhetorical Practices : New Horizons for Rhetoric, Composition, and Literacy Studies. NV-1 onl, Southern Illinois University Press, 2012, http://0site.ebrary.com.webpac.lvlspa.org/lib/moravianlibrary/Doc?id=10551767.

Rubin, Gayle. “Geologies of Queer Studies: It's Déjà Vu All Over Again.” Deviations: A Gayle Rubin Reader, Duke UP, 2011, pp. 347-56.

Ryan, Jacob. “Man Behind University of Louisville's LGBTQ Archive Picked For State Award.” WFPL, 2015, https://wfpl.org/man-behind-university-louisvilles-lgbtqarchive-picked-state-award/.

Sedgwick, Eve Kosofsky. Touching Feeling: Affect, Pedagogy, Performativity. Duke UP, 2003.

Seigworth, Gregory J., and Melissa Gregg. "An Inventory of Shimmers.” The Affect Theory Reader, Duke UP, 2010, pp. 1-28.

Selzer, Jack. "Habeas Corpus: An Introduction.” Rhetorical Bodies, edited by Jack Selzer and Sharon Crowley, U of Wisconsin P, 1999.

Sharer, Wendy B. “Disintegrating Bodies of Knowledge: Historical Material and Revisionary Histories of Rhetoric.” Rhetorical Bodies, edited by Jack Selzer and Sharon Crowley, U of Wisconsin P, 1999, pp. 120-42. 
Simonson, Peter. "Reinventing Invention, Again." Rhetoric Society Quarterly, vol. 44, no. 4, 2014, pp. 299-322.

Snow, David A., and Robert D. Benford. "Master Frames and Cycles of Protest." Frontiers in Social Movement Theory, edited by Aldon D. Morris and Carol McClurg Mueller, Yale UP, 1992, pp. 133-55.

Society of American Archivists. "What Are Archives?" Society of American Archivists, https://www2.archivists.org/about-archives. Accessed 10 Aug. 2018.

Spinuzzi, Clay. "Symmetry as a Methodological Move." Thinking with Bruno Latour in Rhetoric and Composition, edited by Paul Lynch and Nathaniel Rivers, Southern Illinois UP, 2015, pp. 23-39.

Stuckey, Mary E. "Presidential Secrecy: Keeping Archives Open.” Rhetoric \& Public Affairs, vol. 9, no. 1, 2008, pp. 138-44.

Trimbur, John. "Composition and the Circulation of Writing." College Composition and Communication, vol. 52, no. 2, 2000, pp. 188-219.

VanHaitsma, Pamela. "Gossip as Rhetorical Methodology for Queer and Feminist Historiography." Rhetoric Review, vol. 35, no. 2, 2016, pp. 135-47.

---. "Queering the Language of the Heart: Romantic Letters, Genre Instruction, and Rhetorical Practice." Rhetoric Society Quarterly, vol. 44, no. 1, 2014, pp. 6-24. Warner, Michael. Fear of a Queer Planet. U of Minnesota P, 1993.

---. Publics and Counterpublics. Zone Books, 2002.

Watkins, Megan. "Desiring Recognition, Accumulating Affect." The Affect Theory Reader, Duke UP, 2010, pp. 269-88.

Wells, Susan. "Claiming the Archive for Rhetoric and Composition." Rhetoric and 
Composition as Intellectual Work, edited by Gary A. Olson, Southern Illinois UP, 2002, pp. 55-64.

Williams, Kathie D. “Louisville's Lesbian Feminist Union: A Study in Community Building." Carryin' On in the Lesbian and Gay South, edited by John Howard, New York UP, 1997. 


\title{
CURRICULUM VITAE
}

\author{
Rick Wysocki
}

\section{$\underline{\text { Education }}$}

- Ph.D. in Rhetoric and Composition, University of Louisville (expected Spring 2019)

- Master of Arts in English, University of Louisville (2015)

- Bachelor of Arts in English, Chapman University (2013)

\section{$\underline{\text { Dissertation }}$}

Title: The Emergent Matter of Archives: A Rhetorical Investigation of the (Queer) Formation of the Williams-Nichols Archive

Committee: Dr. Karen Kopelson (Chair), Dr. Mary P. Sheridan, Dr. Fran McDonald, Dr. Jacqueline Rhodes

\section{$\underline{\text { Research }}$}

Peer-Reviewed Publications (Single Author)

- "The World Outside the (Web)Text." Making Future Matters, edited by Rick Wysocki and Mary P. Sheridan, Computers and Composition Digital Press/Utah State University Press, 2018.

- "'There is already something wrong': Toward a Rhetorical Framework for Aging." Present Tense: A Journal of Rhetoric in Society, vol. 6, no. 2, 2016.

Peer-Reviewed Publications (Collaborative)

- "Introduction." Making Future Matters, edited by Rick Wysocki and Mary P. Sheridan, Computers and Composition Digital Press/Utah State University Press, 2018. (Coauthored with Mary P. Sheridan)

- “On Multimodal Composing." Kairos: A Journal of Rhetoric, Technology and Pedagogy, vol. 21, no. 2, 2016. (Coauthored with Sara P. Alvarez, Michael Baumann, Michelle Day, Khirsten L. Echols, Layne M. P. Gordon, Ashanka 
Kumari, Laura Matravers, Jessica Newman, Amy McCleese Nichols, Caitlin E. Ray, Jon Udelson, and Dànielle Nicole DeVoss)

- Wysocki, Rick, Jon Udelson, Caitlin E. Ray, Jessica Newman, Laura Sceniak Matravers, Ashanka Kumari, Layne M.P. Gordon, Khirsten L. Echols, Michelle Day, Michael Baumann, Sara P. Alvarez, and Dànielle Nicole DeVoss. "On Multimodality: A Multivocal Manifesto." Bridging the Gap: Multimodality in Theory and Practice. Edited by Santosh Khadka and Jennifer Lee. Utah State UP, Forthcoming.

Peer-Reviewed Publications (In process)

- "Gays and Lesbians United for Equality: Disidentification, Circulation, and the Archive as a Rhetorical Emergence." Submitted to Rhetoric Review. (27 manuscript pages)

- "Reading Our Disciplinary Future(s): Toward a Mobilities Framework for Agency." Mobility Work in Composition, edited by Bruce Horner, Megan Faver Hartline, Ashanka Kumari, and Laura Matravers. (In process with Utah State University Press)

Conference Presentations

- "Queer Curatorial Rhetoric: An LGBTQ Archive in the Making." Rhetoric Society of America Conference (2018)

- "'Make is the Clean Word': Counter-stories from a Hackerspace." Conference on College Composition and Communication (2017)

- "Shirking the Ballot Box: Refusing to Vote as a Rhetorical Act." Rhetoric Society of America Conference (2016)

- "Making Connections: The Makerspace as a Site of Multiliteracies." Computers and Writing (2016)

- "Makerspaces and Graduate Education." Thomas R. Watson Conference (2016)

- "Border, Language, Space: Theorizing Assignments for Negotiating Agency." Thomas R. Watson Conference (2014)

- "Modernity/Coloniality and the Spanish Civil War." The Louisville Conference on Literature and Culture (2014)

- "Toward an Action Research Pedagogy." The Language, Literacy, and Culture Conference (2014)

\section{$\underline{\text { Teaching }}$}

\section{Courses Taught}

- English 306: Business Writing (4 Sections)

- English 303: Scientific and Technical Writing (1 Section)

- English 101: Introduction to College Composition (2 Sections) 
- English 102: Intermediate College Composition (1 Section)

- English 312: American Literature from 1865 to Present (1 Section)

Invited Lectures:

- "Theory Matters," in Dr. Mary P. Sheridan's graduate seminar "Theories that Matter" (2018)

○ An invited lecture on "New Materialism"

$\underline{\text { Service }}$

\section{Editorial and Research Positions}

- Associate Editor at Kairos: A Journal of Rhetoric, Technology, and Pedagogy (2016-Present)

- Work with HTML, CSS, and JavaScript files to assess and support authors' submissions

- Improve and maintain accessibility across webtext submissions

- Copyedit and check citational practices

- Collaborate with Kairos staff as webtexts move through the various stages of editing

- Co-editor (with Mary P. Sheridan) of Making Future Matters, published by Computers and Composition Digital Press / Utah State University Press (2018) http://ccdigitalpress.org/makingfuturematters

$\circ$ Worked with both rising and senior scholars to help them materialize digital arguments

- Corresponded with Computers and Composition Digital Press and Utah State University Press to ensure suitability for digital publication

- Developed a front-end design for the collection using HTML, CSS, JavaScript, and jQuery

- Improved and maintained accessibility across chapters

- Research Assistant to Dr. Mary P. Sheridan (2016-17)

○ Organized and led workshops on digital pedagogy and scholarship

- Oversaw a digital production-oriented computer lab and assisted students and faculty in digital pedagogy and composition

- Collected various research materials for Dr. Mary P. Sheridan

- Website/Design Editor for The Miracle Monocle (Issue 8, 2016)

$\circ$ Prepared poetry and short prose for web publication using HTML/CSS and Plone

- Editorial Assistant at the Henry James Review (2014-15)

- Corresponded with authors

- Read submissions and assessed their suitability for publication

- Carried out multiple stages of print-based copyediting for accepted pieces using standard copyediting marks 
- Checked and ensured the accuracy of final proofs from John Hopkins University Press

Departmental Service

- Writing Center Consultant for the Dissertation Writing Retreat (May 2018 / May 2017)

○ Consulted with doctoral students across disciplines during an intensive, week-long writing retreat

- Chair of University of Louisville's Rhetoric Society of America Student Chapter

- Ph.D. - Faculty Representative for the University of Louisville English Department (2017-2018)

- Peer Mentor for Incoming Ph.D. Student (2017-2018)

- English Department Representative to the Graduate Network of Arts and Sciences (2016-2017)

- English Department Digital Media Coordinator (2016-17)

- Peer Mentor for Incoming MA Student (2016-2017 / 2014-2015)

- Twitter Coordinator for the Thomas R. Watson Conference (2016)

- Assistant Coordinator for New Media symposium on "Paleofuturism" (2014)

- Writing Center Consultant (2013-2014)

Book Reviews and Disciplinary Blog Posts

- "Entangled Frames: New Materialist Feminism and Queer Archives." Digital Rhetoric Collaborative, 27 Dec. 2017, www.digitalrhetoriccollaborative.org/2017/12/27/entangled-frames-newmaterialist-feminism-and-queer-archives/

- Review of 2016 Computers and Writing Panel: "Beyond a Single Language/Single Modality: Crossing Multimodal/Translingual Pedagogies" Digital Rhetoric Collaborative, 28 June 2016, www.digitalrhetoriccollaborative.org/2016/06/28/a4-beyond-a-singlelanguagesingle-modality-crossing-multimodaltranslingual-pedagogies/

- "Review of Rhetoric and the Digital Humanities by Jim Ridolfo and William Hart-Davidson." enculturation: A Journal of Rhetoric, Writing, and Technology, vol. 23, 2016. www.enculturation.net/rhetoric-and-the-digital-humanities

\section{Learning Communities and Workshops}

- Organizer of WPA-Go Webinar on Professional Writing (2018)

- Panelist for workshop on "Business, Science, and Technical Writing Pedagogy" (2018)

- Panelist for workshop on "Building Successful Dissertation Committees" (2017)

- Organizer of a workshop on "Justifying Digital Pedagogy" (2017)

- Organizer of a workshop on "Doing Digital Research" (2017) 
- Faculty Learning Community on Active Learning Pedagogies and Spaces (20162017)

- Organizer of a workshop on Infographics (2016)

- Organizer of a workshop on Podcasting (2016)

$\underline{\text { Awards }}$

Fellowships

- University Fellowship: Two-year course release for research awarded to most qualified doctoral students. University of Louisville (2016-2017, 2018-2019)

- HASTAC Scholars Program: A fellowship for scholars working at the intersection of technology, research, and teaching. Humanities, Arts, Science, and Technology Alliance and Collaboratory (2017-2019)

Teaching

- Faculty Favorite: Student Nomination for Excellence in Teaching. University of Louisville Delphi Center for Teaching and Learning (2015)

Professional Memberships and Skills

Professional Memberships

- Member of the Rhetoric Society of America

- Member of the National Council of Teachers of English

Markup, Programming Languages, and Web Development Frameworks

- $\mathrm{HTML} / \mathrm{CSS} / \mathrm{SCSS} /$ Bootstrap

- Jekyll

- Liquid

- Markdown

- JavaScript/jQuery

- Ruby

- Ruby on Rails

- Git

Design

- Adobe InDesign

- Adobe Illustrator 
- Adobe Photoshop

Audio Production

- Ableton Live

- Pro Tools

- Audacity 